Florida International University FIU Digital Commons

$7-1-2016$

\title{
Influence of Experimental Sheet Flow on Aquatic Foods Webs of the Central Everglades
}

Sarah C. Bornhoeft

Florida International University, sbornhoe@fiu.edu

DOI: $10.25148 /$ etd.FIDC000760

Follow this and additional works at: https://digitalcommons.fiu.edu/etd

Part of the Biology Commons

\section{Recommended Citation}

Bornhoeft, Sarah C., "Influence of Experimental Sheet Flow on Aquatic Foods Webs of the Central Everglades" (2016). FIU Electronic Theses and Dissertations. 2562.

https://digitalcommons.fiu.edu/etd/2562

This work is brought to you for free and open access by the University Graduate School at FIU Digital Commons. It has been accepted for inclusion in FIU Electronic Theses and Dissertations by an authorized administrator of FIU Digital Commons. For more information, please contact dcc@fiu.edu. 


\title{
FLORIDA INTERNATIONAL UNIVERSITY
}

Miami, Florida

\section{INFLUENCE OF EXPERIMENTAL SHEET FLOW ON AQUATIC FOOD WEBS OF THE CENTRAL EVERGLADES}

\author{
A thesis submitted in partial fulfillment of \\ the requirements for the degree of \\ MASTER OF SCIENCE \\ in \\ BIOLOGY \\ by
}

Sarah C. Bornhoeft 
To: Dean Michael R. Heithaus

College of Arts, Sciences and Education

This thesis, written by Sarah C. Bornhoeft, and entitled Influence of Experimental Sheet Flow on Aquatic Food Webs of the Central Everglades, having been approved in respect to style and intellectual content, is referred to you for judgment.

We have read this thesis and recommend that it be approved.

Evelyn Gaiser

John Kominoski

Joel C. Trexler, Major Professor

Date of Defense: July 1, 2016

The thesis of Sarah C. Bornhoeft is approved.

Dean Michael R. Heithaus

College of Arts, Sciences and Education

Andrés G. Gil

Vice President for Research and Economic Development and Dean of the University Graduate School

Florida International University, 2016 


\section{ACKNOWLEDGMENTS}

Thank you to my adviser Joel Trexler, committee members Evelyn Gaiser and John Kominoski and collaborator Barry Rosen. I would also like to thank all the dedicated graduate students and field technicians who assisted with this project, especially Mike Bush and Jessica Sanchez.

This project was funded by the USGS for the DECOMP Physical Model project (Cooperative Agreement G10AC00409) and the Florida Coastal Everglades LTER cite funded by the National Science Foundation (Grant No. DEB-1237517). 


\section{ABSTRACT OF THE THESIS \\ INFLUENCE OF EXPERIMENTAL SHEET FLOW ON AQUATIC FOOD \\ WEBS OF THE CENTRAL EVERGLADES \\ by}

Sarah C. Bornhoeft

Florida International University, 2016

Miami, Florida

Professor Joel C. Trexler, Major Professor

Establishing historical water velocities is a goal of Everglades restoration because of their role maintaining landscape topographic relief. However, flows may also change the trophic state of marshes by phosphorus loading. I used fatty acid (FA) and stoichiometric data to quantify how increased sheet flow altered the relative heterotrophic and autotrophic contributions to aquatic consumers in a field experiment that introduced flowing water to an Everglades marsh in November, 2014. Algal taxonomic composition was different between pre-flow and flow sampling, marked by increases in the nutrient exploiting Mougeotia species (green algae) during flow sampling. Dietary tracer FAs in consumers reflected changes in algal resources, including an increase in green algaederived and a decrease in bacteria-derived FAs. These food web responses indicate that establishing historic water velocity in degraded wetlands can shift the origins of organic matter from a more detrital to more algal supported web. 


\section{TABLE OF CONTENTS}

CHAPTER

PAGE

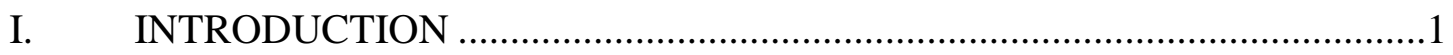

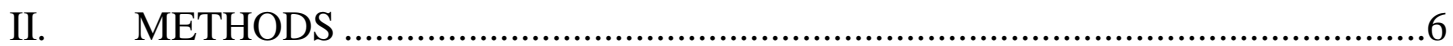

Laboratory Experiment ........................................................................

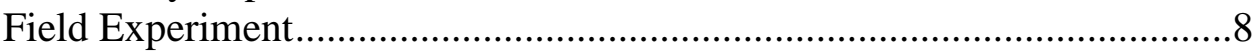

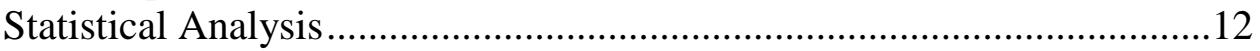

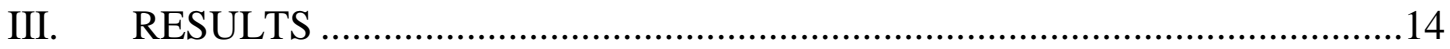

Laboratory Experiment ……………………………….....................14

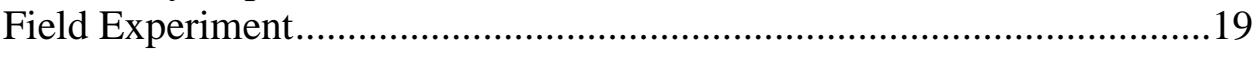

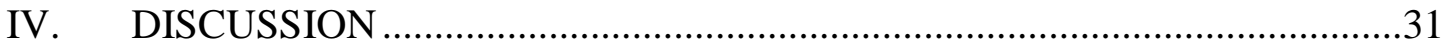

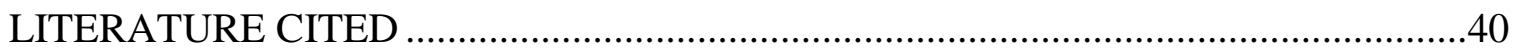

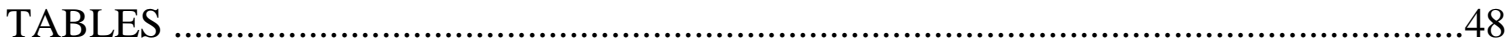

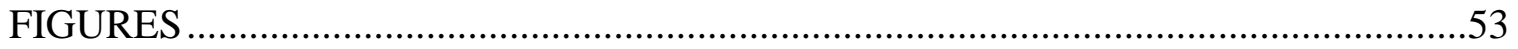

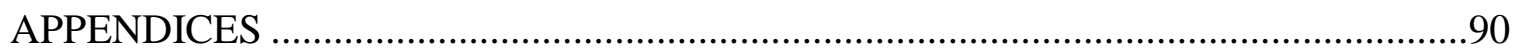




\section{LIST OF TABLES}

TABLE

PAGE

1. Nutrient content and FA total response of all food sources in the laboratory and

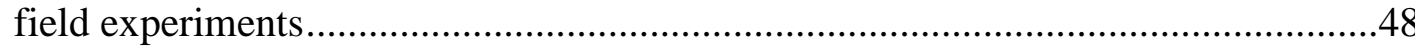

2. Field conditions during October and November field experiments.......................49

3. Sources of fatty acids reported in literature referenced from Belicka et al. 2012 ....50

4. Within month similarity and between month dissimilarity of algal species relative

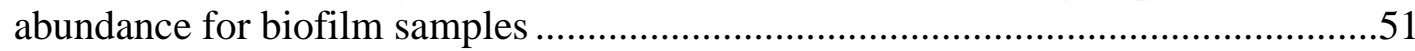

5. Within month similarity and between month dissimilarity of algal species relative

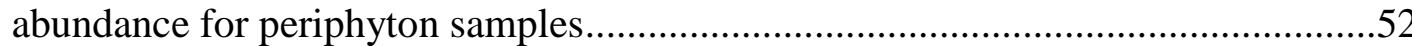




\section{LIST OF FIGURES}

FIGURE

PAGE

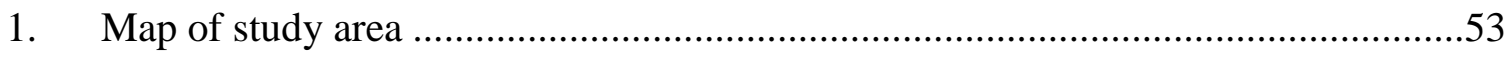

2. Diagram of a single block with four treatment cages in the field experiment and its orientation within the path of flow ............................................................54

3. Total nutrient stoichiometry from laboratory experiment diets ............................55

4. Two dimensional non-metric multidimensional scaling ordination plot based on square root transformed FA relative abundances from experimental diets ..............56

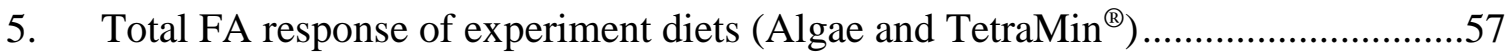

6. Growth rate of consumers (G. holbrooki; P. latipinna) at 3 weeks from laboratory experiments on full-Algae and full-TetraMin ${ }^{\circledR}$ experimental diets ........58

7. Total FA response of consumers (G. holbrooki; P. latipinna; P. paludosus) from laboratory experiments including those on each diet (full-Algae; full-TetraMin $₫$; Algae to TetraMin $®$; TetraMin ${ }^{\circledR}$ to Algae) and sampling period (3 weeks and 6 weeks).

8. Consumer stoichiometric nutrient ratios from laboratory experiment

9. Two dimensional non-metric multidimensional scaling ordination plot based on square root transformed $P$. latipinna FA relative abundances from the laboratory experiment

10. Two dimensional non-metric multidimensional scaling ordination plot based on square root transformed, $G$. holbrooki FA relative abundances from the laboratory experiment.

11. Two dimensional non-metric multidimensional scaling ordination plot based on square root transformed, $P$. paludosus FA relative abundance from the laboratory experiment

12. Biofilm stoichiometry from October and November field experiments......

13. Periphyton stoichiometry from October and November field experiments including initial and final samples

14. Percent organic content for basal resource (biofilm; periphyton) samples from October and November samples 
15. Biomass of basal resource (biofilm; periphyton) samples from October and November samples.

16. Two dimensional non-metric multidimensional scaling ordination plot based on biofilm algae species relative abundances from October and November field experiment, standardized by total and square root transformed

17. Two dimensional non-metric multidimensional scaling ordination plot based on periphyton algal species relative abundances from October and November field experiment, standardized by total and square root transformed, including initial and final samples

18. Total FA response of biofilm during October and November field experiments .....70

19. Total FA response for periphyton during October and November field experiments, including initial and final samples

20. Two dimensional non-metric multidimensional scaling ordination plot based on square root transformed biofilm FA relative abundances from October and November field experiment

21. Two dimensional non-metric multidimensional scaling ordination plot based on periphyton square root transformed FA relative abundances from October and November field experiments including initial and final samples

22. Relative abundance of dietary tracer FA groups (algae; bacteria; vascular plant) in biofilm samples from October and November samples

23. Relative abundance of dietary tracer FA groups (algae; bacteria; vascular plant) in periphyton samples from October and November samples, including initial and final samples

24. Relative abundance of FAs by saturation type (SAFA; MUFA; PUFA) from biofilm samples.

25. Relative abundance of FAs by saturation type (SAFA; MUFA; PUFA) from periphyton final and initial samples

26. Growth rate of consumers (G. holbrooki; P. latipinna) from field experiments (October and November)

27. Total FA response of consumers (G. holbrooki; P. latipinna; P. paludosus) during October and November field experiments including initial and final specimens 
28. Consumer stoichiometry (G. holbrooki; P. latipinna; P. paludosus) from October and November field experiments including initial and final specimens.....80

29. Two dimensional non-metric multidimensional scaling ordination plot based on square root transformed $P$. latipinna FA relative abundances from October and November field experiment, including final and initial specimens

30. Relative abundance of dietary tracer FA groups (algae; bacteria; vascular plant) in P. latipinna from October and November

31. Relative abundance of FAs by saturation type (SAFA; MUFA; PUFA) from $P$. latipinna final and initial samples

32. Two dimensional non-metric multidimensional scaling ordination plot based on square root transformed $G$. holbrooki FA relative abundances from October and November field experiment, including initial and final specimens

33. Relative abundance of dietary tracer FA groups (algae; bacteria; vascular plant) in G. holbrooki from October and November....

34. Relative abundance of FAs by saturation type in G. holbrooki final and initial samples

35. Two dimensional non-metric multidimensional scaling ordination plot based on square root transformed $P$. paludosus FA relative abundances from October and November field experiment, including initial and final specimens

36. Relative abundance of dietary tracer FA groups (algae; bacteria; vascular plant) in P. paludosus from October and November field experiments .88

37. Relative abundance of FAs by saturation type (SAFA; MUFA; PUFA) in $P$. paludosus final and initial samples 


\section{ABBREVIATIONS AND ACRONYMS}

$\begin{array}{ll}\text { AFDM } & \text { Ash-Free Dry Mass } \\ \text { ANOSIM } & \text { Analysis of Similarity } \\ \text { ANOVA } & \text { Analysis of Variance } \\ \text { DPM } & \text { Carbon } \\ \text { FA } & \text { Decompartmentalization and Sheet flow Enhancement } \\ \text { FAME } & \text { Fatty Acid } \\ \text { GC } & \text { Fas Chromatography } \\ \text { MUFA } & \text { Monounsaturated Acid } \\ \text { N } & \text { Nitrogen } \\ \text { P } & \text { Phosphorus } \\ \text { PUFA } & \text { Polyunsaturated Acid } \\ \text { SAFA } & \text { Saturated Fatty Acid } \\ \text { SIMPER } & \text { Similarity Percentages }\end{array}$




\section{INTRODUCTION}

Anthropogenic modifications of the Florida Everglades have transformed it from an expansive, interconnected, subtropical wetland to a compartmentalized, functionallyaltered ecosystem (Sklar et al. 2010). The addition of water supply and flood control structures has changed the pattern, volume, and quality of water flow throughout much of the wetland. One of the primary goals for Everglades restoration proposed through the Comprehensive Everglades Restoration Plan is to restore the historical quality, timing, and flow of water to its remaining natural areas by the removal of flow barriers and hydraulically reconnect historically linked portions of the Everglades (USACE, 2014). Restoring historic sheet flows will increase the connectivity of habitats and redistribute organic matter and nutrients across the landscape with the potential to affect food web energy dynamics.

Abiotic changes induced by hydraulic restoration may alter the balance of autotrophic and heterotrophic energy entering the Everglades food web. One proposed consequence of increased sheet flow is eutrophication caused by an increase in nutrient concentration or rate of delivery. As a historically oligotrophic wetland, the Everglades structural and functional elements are susceptible to eutrophication from agricultural and urban phosphorus (P) discharges (McCormick et al. 1996; McCormick et al. 2002; Gaiser et al. 2004; Noe et al. 2001). It has been suggested that eutrophication shifts the primary source of organic matter in Everglades food webs from a detritus-dominated to an algaldominated pathway (Trexler et al. 2015). Detritus is a key source of primary energy for wetlands, via the microbial loop, where nutrients returned to the food web through its 
breakdown influences community structure and dynamics allowing for more complex and resilient food webs than by autotrophs alone (Hairston and Hairston 1993; Moore et al. 2003). The consequences of shifting energy source inputs to the food web has been relatively unexplored and the interconnectedness of the heterotrophic and autotrophic energy pathways makes studying these contributions challenging (Moore et al. 2003).

Periphyton is the dominant form of primary production in the Everglades which contains components of both autotrophic and heterotrophic production. Periphyton is an association of autotrophs, heterotrophs, chemotrophs, and inorganic and detrital particles, in an extracellular polymeric matrix and occurs in diverse forms including on plants as epiphyton (or biofilm), benthic as epipelon and floating mats as metaphyton (Hagerthey et al. 2011). Periphyton is a sink for nutrients and quickly absorbs any excess from increases in concentration or flow, making it easily susceptible to nutrient enrichment (McCormick and Gaiser 2011). Changes in periphyton are generally predictable with enrichment and include increases in organic content, decreases in biomass, and changes in species composition (Gaiser et al. 2006). The proposed mechanism for increasing organic content starts with nutrient primed bacterial production producing increased $\mathrm{CO}_{2}$, which decreases $\mathrm{pH}$ and dissolves the calcite portion of periphyton. The initial priming of the bacteria biomass leads an eventual loss in the amount of detrital and cyanobacteria biomass.

Phosphorus additions spur changes in the algal community composition of periphyton mats from a physically and chemically defended matrix of calcareous cyanobacteria, to more palatable filamentous chlorophytes and diatoms (McCormick et al. 2002; Gaiser et al. 2005). Periphyton mats are dominated by calcium carbonate 
produced by filamentous cyanobacteria, predominantly Schizothrix calcicola and Scytonema hofmanni, which create an associational resistance with edible diatoms and green algae (Browder et al. 1994; Trexler et al. 2015). Cyanobacteria are generally low in fatty acids (FAs), including poly-unsaturated fatty acids (PUFAs; FAs with more than one double bond), have high C:P ratios and some produce cyanotoxins as secondary metabolites, further inhibiting their quality and consumption (Bellinger and Hagerthey 2010; DeMott and Müller-Navarra 1997). Algae and bacteria more competitive for P can quickly become dominant over endemic species causing the disintegration of mats and dominance of chlorophyte communities, especially Mougeotia spp. (Gaiser et al. 2005; Gaiser et al. 2011; Trexler et al. 2015). Diatoms have high PUFA content even when P limited whereas green algae nutritional content varies between species and nutrient status (Ahlgren et al. 1990; Muller-Navarra 1995; Gulati and DeMott 1997).

Nutrient enrichment not only alters the community structure of periphyton, but can alter the biochemical content of individual algae species. Algal biochemical responses to different abiotic conditions (light, nutrients, and temperature) vary within and between taxa making it difficult to predict their quality as a diet (Sterner and Elser 2002). Studies have shown that high-light and low-nutrient environments, like the oligotrophic Everglades, may produce algae that are deficient in nutrients and essential FAs, including PUFAs (Hill et al. 2011). Certain PUFAs that cannot be synthesized de novo by consumers may limit their growth and cellular function when in limited supply making their uptake from primary producers essential (Twining et al. 2015, Brett \& Muller-Navarra 1997). Poly-unsaturated fatty acids produced by algae are mainly contained in photosynthetic cytoplasmic membranes and triacylglycerol storage lipids. 
Thus, abiotic conditions that increase production of photosynthesis membranes (lowlight, high-nutrients) are expected to increase the amount of essential FAs in algae, while conditions that increase carbon fixation (high-light, low-nutrients) are expected to decrease essential FAs in algae, although there is considerable variation across taxa (Guschina \& Harwood, 2009; Hill et al. 2011; Cashman et al. 2013). Belicka et al. (2012) showed that FAs in basal resources from the Everglades with higher P content had a larger proportion of algal-derived PUFAs than those with lower P content. The increase in algae-derived FAs indicated that nutrient enrichment has the potential to increase basal resources edibility and nutritional content (Gaiser et al. 2005).

Although periphyton is an abundant basal resource, its quality as a food may be the cause of the disparity between observed high-primary and low-secondary production in the oligotrophic Everglades. Several studies have shown that the biomass, diversity, and whole body P content of invertebrates and small fish is greater in P enriched areas then unenriched areas (Turner 1999; Rader and Richardson 1994; Hagerthey 2014). Other studies have suggested that even when inorganic nutrients and food quantity are high, secondary production can be decreased if certain PUFAs are lacking (Müller-Navarra et al. 2000, Persson et al. 2007). Eutrophication may release consumers from both phosphorus and essential FA limitations since the amount of PUFAs has been shown to be positively correlated across a phosphorus gradient, although this has not been evaluated in Everglades basal resources or consumers (Hill et al. 2011; Twining et al. 2015). Further, consumers may respond to eutrophication driven diet changes differently depending on their trophic level. Herbivores generally consume food sources with high variability in quality (algae C:P range 100-1000), inherently affecting their growth and 
reproduction, whereas carnivore consumers consume a more constant quality diet (zooplankton C:P range 70-200; Boersma et al. 2008). Despite a relatively constant quality diet, consumers may be limited by reduced prey biomass and research supporting less strict nutrient homeostasis of primary consumers suggests that secondary consumers may be more nutrient limited than originally thought. (Plath and Boersma 2001; DeMott and Pape 2005).

I hypothesized that flow restoration to the Everglades will increase the availability of $\mathrm{P}$ and will increase the relative proportion of autotrophic-derived energy inputs into higher trophic levels. Support for this hypothesis will be evident through increase in the edibility and nutritional quality of basal resources indicated by increased algal production, nutrient, essential FAs, and organic content. I hypothesized that these changes will yield cascading effects through the food web to primary and secondary consumers (Iwaniec 2008; Trexler et al. 2015). Dietary shifts should yield an increase in consumer growth rate, algal-derived FAs and stoichiometric quality (Belicka et al. 2012). Although enrichment induced changes to Everglades basal resources have been well documented, nutritional repercussions of this autotrophic and heterotrophic energy alteration on consumers remains unexplored (Gaiser et al. 2005).

In this study, I used molecular distribution of FAs as a tool to trace dietary sources of energy from basal resources into common Everglades consumers. Fatty acids that are uniquely produced by bacteria, algae, and vascular plants have been demonstrated to be incorporated unmodified into the tissues of consumers and can be used to determine the relative abundance of these tracers from producers into a food-web (Budge et al. 2006; Dalsgaard et al. 2003; Iverson et al. 2004; Jardine et al. 2015; 
Williams et al. 2009). I designed a laboratory experiment to evaluate the stoichiometric and FA change to varying diet quality of three common consumers from the Everglades. Using results from that study, I designed a field experiment to test the effects of elevated water flow velocity on nutrient loading to basal resources and its impact on consumer growth and nutrient assimilation.

\section{METHODS}

\section{Laboratory Experiment}

The turnover rate of FAs and whole-body stoichiometry of three common Everglades consumers was documented under differing diet qualities. Specimens were housed at a density of 4 per 18.9-liter tank; water temperature was maintained at $25 \pm$ $1.0^{\circ} \mathrm{C}$ with $12: 12$ hour light/dark cycles of. Tanks were kept free of algal growth and water was changed weekly. Specimens of the herbivorous Sailfin Molly (Poecilia latipinna), omnivorous Eastern Mosquitofish (Gambusia holbrooki), and omnivorous riverine grass shrimp (Palaemonetes paludosus) were collected from marsh areas in the Florida Everglades at the smallest juvenile size possible (P. latipinna mean standard length $=15.0 \mathrm{~mm} ;$ G. holbrooki mean standard length= $12.7 \mathrm{~mm} ;$ P. paludosus mean total length $=16.1 \mathrm{~mm}$ ). These were sorted to yield uniform collections within species to ensure similar growth and minimize reproduction as the study progressed. Length and wet weight were recorded weekly for each specimen and treatments were replicated within the aquarium room in a blocked design to control for effects of position within the room. Length was measured from individual digital photographs of each specimen (Cannon Powershot ELPH). Images were downloaded to a computer and the standard 
length was measured using a calibrated image analysis with ImageJ software (Rasband 2015). Growth rate in length in mm per day was calculated as an average per tank at the 3-week time period. Growth rate was similarly documented after 6 weeks, but is not reported here because sexual maturation of some specimens led to reduction in growth rate and obscured interpretation of population patterns.

Diets were commercially produced TetraMin ${ }^{\circledR}$ Tropical Crisps and San Francisco Bay Brand ${ }^{\circledR}$ Seaweed Salad ${ }^{\mathrm{TM}}$ Green 100\% natural dried macroalgae (Porphyra yezoensis). Past studies have demonstrated that these diets yield easily distinguishable body isotopic composition (Green 2007). The experimental specimens were fed two diet regimes of 3 weeks of algae followed by 3 weeks of TetraMin ${ }^{\circledR}$ or 3 weeks of TetraMin ${ }^{\circledR}$ followed by 3 weeks of algae. Control specimens were fed diets consisted of only algae or TetraMin ${ }^{\circledR}$ for the full 6 weeks. Specimens were fed a measured ration of food once daily following Trexler (1997).

Following standard methods for humane use of animals in research (Jenkins et al. 2014), subsets of the specimens were sacrificed at the time of field collection (initial), at the midway point (3 weeks), and at the conclusion (6 weeks) of the experiment. Sampling maintained approximately equal density in each tank and treatments since density has been shown to affect poeciliid growth in experimental conditions (Busak and Gall 1983, Dahlgren 1979). At the conclusion of the experiment, all animals were held for a period of 24 hours before euthanization to permit gut clearance and then frozen at $-80^{\circ} \mathrm{C}$ degrees until further processing. The whole-body samples were lyophilized at $-50^{\circ} \mathrm{C}$ for approximately 24 hours and homogenized (Belicka et al. 2012) before being analyzed for 
FA composition and nutrient analysis. This work is covered by FIU IACUC permit 13046-AM01.

\section{Field Experiment}

This experiment was conducted in an area experiencing controlled water releases from the Decompartmentalization and Sheet flow Enhancement Physical Model (DPM) (Sklar et al. 2010). This physical model was designed to explore the hydrologic and ecological consequences of levee removal and canal backfilling. Ten 60 -inch culverts were installed in the L-67A levee to allow water from Water Conservation Area-3A to flow across the previously isolated marsh and over three 1,000 foot backfill treatments in the L-67C canal and levee into Water Conservation Area-3B (Fig. 1). The culverts were opened from November to January in 2013-2014, 2014-2015, and 2015-2016.

The field experiment was repeated twice, each trial was 21 days, first in October, 2014, prior to the sheet flow experiment and again in November, 2014, during the sheet flow experiment, permitting us to capture data for low-flow and high-flow periods. During each time period, we placed $201-\mathrm{m}^{3}$ cages in an area approximately $580 \mathrm{~m}$ downstream from the water-release point. The cages were open at the top and constructed with 2-mm mesh on the sides and bottom to form a bag. Half (10) of the cages were shielded from water flow and will be referred to as the control cages. The other ten cages were fitted with flow accelerating wings, design to funnel increased volumes of water and will be referred to as the open cages. Half of the control (5) and open cages (5) were stocked with a pre-determined number of animals to track the consumption of primary production by consumers. The consumer-free cages were used to 
track the growth and changes of algal and periphyton biomass and composition in each of the open and closed-flow treatments, free from consumer impacts. Thus, during both experiments there were four treatments, each replicated with 5 cages (Fig. 2; OpenStocked, Open-Empty, Control-Stocked, and Control-Empty). These cages were randomly arranged within 5 blocks, each replicated once per block, and arranged perpendicular to the flow of water. The level of replication was chosen following a power analysis to estimate the minimum sample sizes needed to detect biologically meaningful treatment effects, if present (Appendix 1).

Three weeks prior to the beginning of the field study, target species were collected in the same manner as for the laboratory experiment. The specimens were housed in aquarium facilities and fed a diet of algae flakes until the beginning of the field experiment to allow time for the FAs of all specimens to reach a standard baseline that was different from field-collected animals, improving our ability to detect change in the experimental treatments, if present. As a result of low survival of P. paludosus on the algae diet in the laboratory, grass shrimp were collected from the field at the start of each trial and placed directly into cages; they did not undergo the baseline-diet treatment. The standard length of each fish and carapace length of each shrimp was recorded prior to placement in the field cages. A subset of each species was sacrificed and preserved for an initial analysis. Each cage was stocked with the experimental consumers at densities equal to average marsh densities during the time of the study. Five Sailfin Mollies, 9 Eastern Mosquitofish, and 23 riverine grass shrimp created a food web fragment reflective of the ambient aquatic community. 
Following protocols from similar experiments conducted in the Everglades (Chick et al. 2008), I created a substrate for biofilm to grow by adding plastic strips to each cage at a density of 150 stems $\mathrm{m}^{-2}$, consistent with ambient vascular plant stem densities in the area at the time of the study. The short time span of the experiment allowed pioneer species of algae and bacteria to colonize, but did not allow dominance by cyanobacteria and development of periphyton calcareous matrix (Chick et al. 2008). A volume of 2,000 $\mathrm{ml}$ of floating periphyton mat, devoid of macro-consumers (e.g., adult aquatic insects, crustaceans, and fish), was taken from the surrounding marsh and added to each cage to match the mean biomass in the marsh. An aliquot of the periphyton was taken from each cage at the inception of the experiment to determine nutrient content, ash-free dry mass (AFDM), FA relative abundance, and algal composition. Flow velocity measurements were taken at the initiation of the experiment and then weekly using a SonTek FlowTracker Handheld Acoustic Doppler Velocimeter. Measurements were taken at 3 points in front of the open cages, within the control cages, and upstream of the study site as a control location. Temperature was monitored within open and closed enclosures using Onset $\mathrm{HOBO}$ pendant temperature loggers to determine whether flow enhancers/blockers effected water temperature. Photoperiod and air temperature data was used from the National Weather Service's Chekika, FL station.

After 3 weeks, the fish and shrimp were removed from the cages by lifting enclosure bags and allowing the water to drain out (Geddes and Trexler 2003; Dorn et al. 2006; Chick et al. 2008). Animals were picked out of periphyton, euthanized in MS-222, and immediately placed on ice. Standard length of each was measured and they were stored at $-80^{\circ} \mathrm{C}$ until being freeze dried and homogenized for Fatty Acid Methyl Esters 
(FAME) and nutrient analysis. Stomachs and their contents were removed from fish prior to preparation for FAME analysis to eliminate bacterial FAs present in the digestive tract tissue from being analyzed in combination with dietary sources of bacteria (Budge et al. 2006); it was not possible to remove the digestive tract of grass shrimp. Individual specimens were pooled to meet minimum dry weight requirements for both nutrient analysis and FAME analysis. At the end of each experimental trial, thirty strips of the artificial vegetation and a subsample of periphyton were collected from each cage and frozen for later processing (Geddes and Trexler 2003; Dorn et al. 2006; Chick et al. 2008). In the laboratory, biofilm was scraped from each blade of artificial vegetation, the area scraped was recorded, and samples were homogenized. Periphyton samples were thawed and plant material was removed under a dissecting microscope. Biofilm and periphyton were aliquoted for AFDM determination, FAME and nutrient analysis, and algal composition. Subsamples for algal taxonomic composition were preserved with 1 $\mathrm{ml}$ of Lugol's solution per $100 \mathrm{ml}$ of material. These samples were enumerated by Dr. Barry Rosen (U. S. Geological Survey) with a compound scope as number of biological units (cells for unicellular taxa, 10-um segments for filamentous taxa, and colonies for colonial taxa) per species (Eaton et al. 1995). Biovolume estimates (area, length, and width) were recorded for individuals of each taxon and were used to calculate relative abundance of biovolume by algal species for each sample. Periphyton and biofilm material was freeze dried and ground for FAME and nutrient analysis and were analyzed similarly as the for laboratory experiment. AFDM was determined by drying samples to a constant weight at $60^{\circ} \mathrm{C}$ ( 2days), recording the dry weight, and then combusting the material in a muffle furnace at $500^{\circ} \mathrm{C}$ for 1 hour, after which they were weighed again to 
determine ash weight. AFDM was calculated as the difference between the dry and mineral mass and organic carbon content as the proportion of AFDM to dry weight. Biomass estimates from biofilm were extrapolated to the entire $1-\mathrm{m}^{2}$ plot by multiplying the per stem estimates by the number of stems per plot.

The FAME analysis was completed by Microbial ID Inc. using gas chromatography (GC) on an Agilent 6890 GC-FID column and the MIDI Sherlock® Microbial Identification System. Total FA content was not analyzed for these samples. Instead, we analyzed the total peak area generated by GC-FAME analysis as a proxy for total lipid content to compare among samples in this study. Carbon, nitrogen, and phosphorus $(\mathrm{C}, \mathrm{N}, \mathrm{P})$ analyses was completed by the Freshwater Biogeochemistry Laboratory, Southeast Environmental Research Center at Florida International University. This work is covered by FIU IACUC permit 14-081.

\section{Statistical Analysis}

Log transformed consumer growth rate, stoichiometric, and total FA response data from the laboratory study were analyzed using two-way ANOVA models in R ( R Core Team, 2013) to determine whether growth rate (mm per day), nutrient content (molar ratios: $\mathrm{C}: \mathrm{N}, \mathrm{C}: \mathrm{P}, \mathrm{N}: \mathrm{P}$ ), and total FA response (total FA response per mg dry weight) were significantly different among diet treatments (TetraMin ${ }^{\circledR}$ Only, Algae Only, TetraMin ${ }^{\circledR}$ to Algae, Algae to TetraMin $\left.{ }^{\circledR}\right)$ and length of time subjected to a diet $(3,6$ weeks). Non-metric multidimensional scaling was performed on Bray-Curtis dissimilarity of square-root transformed FA relative abundance data using PRIMER 7.0 software (Clarke and Gorley, 2015) and SIMPER (similarity percentage breakdown) 
functions were used to determine groupings of FAs. Low sample sizes of consumers in the laboratory experiment did not allow for ANOSIM permutation test.

Growth, stoichiometric data, organic content and total FA response data from field-experiment basal resources and consumers were log transformed prior to analysis using a blocked ANOVA models in R to determine whether growth rate (mm per day), nutrient content (molar ratios: $\mathrm{C}: \mathrm{N}, \mathrm{C}: \mathrm{P}, \mathrm{N}: \mathrm{P}$ ), and total response (total FA response per mg dry weight) were significantly different among main effects of cage flow treatments (Enhanced-Flow, No-Flow), consumer treatments (Consumers-Present, ConsumersAbsent), and time (sampling periods: October, November), including the two-way interaction of flow and consumer. The block was represented by the southeast-northwest spatial location of the treatment cages in the slough (perpendicular to water flow). In the analysis of total $\mathrm{P}, 5$ values from biofilms and 2 from periphyton were excluded due to abnormally high vales. In order to retain power in the statistical analysis, an analysis of covariance was completed with position in the slough as the covariate, instead of discarding each block containing an outlier. The main effects were treated as fixed effects and the block was treated as a random effect. When within-month treatments were nonsignificant, they were removed from the model and between-month effects were analyzed. Multiple comparisons were made using Tukey's pairwise comparison's t-test procedure.

Non-metric multidimensional scaling was performed on Bray-Curtis dissimilarity of square-root transformed FA data from field experiment basal resources and consumers using PRIMER 7.0 software (Clarke and Gorley, 2015). The ANOSIM (analysis of similarities; reported as significant p-value when less than 0.05 and the number of 
possible permutations was over 300) and SIMPER (similarity percentage breakdown) functions were used to determine groupings of FAs between flow and consumer treatments and sampling periods. Low sample sizes of initial periphyton and consumer samples from the field experiment did not permit ANOSIM permutation test on these data.

Fatty Acids previously determined as dietary tracers were identified in the basal resource and consumer samples and the relative abundance for each group (algae, bacteria, vascular plants) was determined (Table 1). FAs were also identified by degree of saturation (saturated, SAFA; mono-unsaturated, MUFA; poly-unsaturated, PUFA) and relative abundance of each type was determined. The relative abundance of dietary tracers and saturation types were analyzed by blocked ANOVA with the same model used for stoichiometric, growth and total response data.

\section{RESULTS}

\section{Laboratory Experiment}

Experimental diets differed in their stoichiometric and FA content. TetraMin ${ }^{\circledR}$ had $7.8 \%, 17.3 \%$ and $35.1 \%$ more total nitrogen, carbon, and phosphorus than the algal diet (Nitrogen: $F_{1,4}=34.0, p<0.001$; Carbon: $F_{1,4}=807.2, P<0.001$; Phosphorus: $F_{1,4}=14.9$, $\mathrm{p}<0.01$; Fig. 3), yet they had comparable C:P ratios (algae mean $=151.3, \mathrm{sd}=3.6$; TetraMin $^{\circledR}$ mean=132.7, sd=16.8). The relative abundance of FAs for TetraMin ${ }^{\circledR}$ and algae had an average dissimilarity of $52.1 \%$ (R-stat $=1$; Fig. 4) with over 50 percent of the difference attributed to only 5 FAs (20:5 w3c, 18:2 w6c, 18:1 w9c, 17:0 10-methyl, and 16:1 w3c). According to the product manufactures, TetraMin ${ }^{\circledR}$ has 3 times more FA 
content than Seaweed Salad ${ }^{\mathrm{TM}}$ Green (guaranteed minimums of $12 \%$ and $4 \%$ of fat, respectively). Total FA response was 2.6 times greater in the $\mathrm{TetraMin}^{\circledR}$ diet than in the algae diet $\left(\mathrm{t}_{2.1}=-11.7, \mathrm{p}\right.$-value $<0.01 ;$ Fig. 5), demonstrating our method of estimating FA content is conservative.

The C:P ratio of wild P. paludosus (Tukey's p-adj < 0.001 ) and $P$. latipinna (Tukey's p-adj < 0.001 ) were on average 1.7 times higher than the $\mathrm{C}: \mathrm{P}$ ratio of the $G$. holbrooki. Both experimental diets $\mathrm{C}: \mathrm{P}$ ratios 1.2 times higher than all three wild species (G. holbrooki mean $=39.5, \mathrm{sd}=3.6 ;$ P. latipinna mean $=70.3, \mathrm{sd}=5.2$, . paludosus mean $=70.0$, sd $=5.1 ;$ Tukey's test $\mathrm{p}-\operatorname{adj}<0.001)$.

\section{Poecilia latipinna}

Poecilia latipinna on the TetraMin ${ }^{\circledR}$ diet grew marginally faster and sequestered more FAs than those on the algae diet. The P. latipinna fed the TetraMin ${ }^{\circledR} \operatorname{diet}$ had growth rates 1.5 times faster than those on the algae diet (Fig. $6 ; F_{1,10}=4.8, p=0.054$;

algae growth rate $=0.13 \mathrm{~mm} \mathrm{day}^{-1}, \mathrm{sd}=0.04 ;$ TetraMin $^{\circledR}$ growth rate $=0.19 \mathrm{~mm}^{\text {day }}{ }^{-1}, \mathrm{sd}$ $=0.06)$. At week $3, P$. latipinna on the all-TetraMin ${ }^{\circledR}$ diet had 3.9 times more total FA response than those on the all-algae diet (Tukey’s p-adj <0.05; Fig. 7). At 6 weeks, $P$. latipinna on the all-algae and algae-TetraMin ${ }^{\circledR}$ diet had 2.0 times and 4.3 times more total FA response than they did at 3 week (all-algae: Tukey's p-adj $<0.05$; algaeTetraMin ${ }^{\circ}$ : Tukey's p-adj < 0.001). Total FA response did not change for those on the all-TetraMin ${ }^{\circledR}$ and TetraMin ${ }^{\circledR}$-algae diets over the same time. At the conclusion of the study, $P$. latipinna on the all-TetraMin ${ }^{\circledR}$ had 2.4 and 1.9 time more total FA response than all-algae and TetraMin ${ }^{\circledR}$-algae diets (Tukey’s p-adj <0.05). The P. latipinna on the 
algae-TetraMin ${ }^{\circledR}$ also had 2.6 and 2.0 time more total FA response than all-algae and TetraMin $^{\circledR}$-algae diets at the conclusion of the study (Tukey’s p-adj $<0.05$ ).

Stoichiometric ratios increased more quickly for P. latipinna on the TetraMin ${ }^{\circledR}$ diets than for those on the algal diet (Fig. 8). At 3 weeks, P. latipinna on all-TetraMin ${ }^{\circledR}$ and TetraMin ${ }^{\circledR}$-algae had $24.7 \%, 45.2 \%$, and $16.4 \%$ greater C:N, C:P, and N:P ratios than those on the all-algae and algae-TetraMin ${ }^{(\mathrm{R})} \operatorname{diets}\left(\mathrm{C}: \mathrm{N}: \mathrm{F}_{3,8}=15.4, \mathrm{p}<0.01 ; \mathrm{C}: \mathrm{P}: \mathrm{F}_{3,8}=\right.$ 25.1, $\left.\mathrm{p}<0.001 ; \mathrm{N}: \mathrm{P}: \mathrm{F}_{3,8}=16.26, \mathrm{p}<0.001\right)$. At 6 weeks, P. latipinna on the all-algae diet, had 20.0\%, 37.6\%, and 14.2\% greater C:N, C:P, and N:P ratios than at 3 weeks $\left(\mathrm{C}: \mathrm{N}: \mathrm{F}_{1,4}=14.6, \mathrm{p}<0.05 ; \mathrm{C}: \mathrm{P}: \mathrm{F}_{1,4}=13.52, \mathrm{p}<0.05 ; \mathrm{N}: \mathrm{P}: \mathrm{F}_{1,4}=10.00, \mathrm{p}<0.05\right)$. At 6 weeks, P. latipinna on the all-TetraMin ${ }^{\circledR}$ had $15.0 \%$ greater C:N than at 3 weeks, but had no changes in $\mathrm{C}: \mathrm{P}$ and $\mathrm{C}: \mathrm{N}$ ratios $\left(\mathrm{C}: \mathrm{N}: \mathrm{F}_{1,4}=8.27, \mathrm{p}<0.05\right)$. At 6 weeks, P. latipinna on the algae-TetraMin ${ }^{\circledR}$ diet had 36.5\%, 68.8\%, 27.7\% greater C:N, C:P, and N:P ratios than at 3 weeks $\left(\mathrm{C}: \mathrm{N}: \mathrm{F}_{1,4}=12.61, \mathrm{p}<0.05 ; \mathrm{C}: \mathrm{P}: \mathrm{F}_{1,4}=19.63, \mathrm{p}<0.05 ; \mathrm{N}: \mathrm{P}: \mathrm{F}_{1,4}=26.22, \mathrm{p}<\right.$ 0.01). After 6 weeks on the TetraMin ${ }^{\circledR}$-algae diet, C:N ratios decreased by $13.4 \%$ (C:N: $\left.\mathrm{F}_{1,4}=8.2, \mathrm{p}<0.05\right)$, with no differences to C:P and N:P ratios. After 6 weeks, $P$. latipinna on the full-TetraMin ${ }^{\circledR}$ diet had $32.8 \%$ larger C:N than those on the TetraMin ${ }^{\circledR}-$ algae diet $\left(\mathrm{F}_{3,8}=6.23, \mathrm{p}<0.05\right)$.

Wild caught $P$. latipinna had different FA relative abundances from those on all four diet treatments at both 3 and 6 weeks with average dissimilarities of $24.4 \%(\mathrm{R}$-stat $=$ 1; Figure 9). After 3 weeks, P. latipinna FA relative abundances revealed two groupings indicative of all-algae and all-TetraMin ${ }^{\circledR}$ diets with dissimilarities of $30.2 \%(\mathrm{R}$-stat $=1)$. After 6 weeks, the all-TetraMin ${ }^{\circledR}$ and all-algae diets still had different FA relative abundances with $27.8 \%$ dissimilarity $(\mathrm{R}$-stat $=1)$. At 6 weeks, the all-TetraMin ${ }^{\circledR}$ diet was 
not distinguishable from the algae-TetraMin ${ }^{\circledR}$ diet, with a dissimilarity of only $6.3 \%$ (Rstat $=-0.04)$, contrary to the all-algae diet, which was still partially distinguishable from the TetraMin $^{\circledR}$-algae diet $($ dissimilarity $=18.2 \%$, R-stat $=0.56)$.

\section{Gambusia holbrooki}

Gambusia holbrooki on the TetraMin ${ }^{\circledR}$ diet grew marginally faster and sequestered FAs faster than those on the algae diet. The G. holbrooki fed the TetraMin ${ }^{\circledR}$ diet had growth rates 1.4 times faster than those on the algae diet $\left(\mathrm{F}_{1,10}=3.8, \mathrm{p}=0.08\right.$; algae growth rate $=0.12 \mathrm{~mm} \mathrm{day}^{-1}, \mathrm{sd}=0.03 ;$ TetraMin $^{\circledR}$ growth rate $=0.16 \mathrm{~mm}$ day $^{-1}, \mathrm{sd}$ =0.04; Fig. 6). At 3 weeks, G. holbrooki on the all-TetraMin ${ }^{\circledR} \operatorname{diet}$ had 2.5 times more total FA response than those on the all-algae diet (Tukey's p-adj <0.05, Fig. 7). At 6 weeks, G. holbrooki on the algae-TetraMin ${ }^{\circledR}$ diet had 2.5 time more total FA response than those at 3 weeks (Tukey's p-adj < 0.05). The total FA response did not change from 3 to 6 week for $G$. holbrooki on the all-algae, all-TetraMin ${ }^{\circledR}$, and TetraMin ${ }^{\circledR}$-algae diet during the experiment and at the conclusion of the study, all 4 diets had similar amounts of total FA response.

The G. holbrooki showed the largest change in stoichiometry when switched from the algae diet to the TetraMin ${ }^{\circledR}$ diet (Fig. 8). At 3 weeks, G. holbrooki had similar C:N, C:P and N:P ratios on all four diets. At 6 weeks, G. holbrooki on the all-algae, allTetraMin ${ }^{\circledR}$ and TetraMin ${ }^{\circledR}$-algae had similar C:N, C:P and N:P ratios to those at the 3 week time period. At 6 weeks, G. holbrooki on the algae-TetraMin ${ }^{\circledR}$ diet had C:P and N:P ratios 2.7 and 2.1 times greater than those at 3 weeks $\left(\mathrm{C}: \mathrm{P}: \mathrm{F}_{1,3}=146.4, \mathrm{p}<0.01 ; \mathrm{N}: \mathrm{P}\right.$ : $\left.\mathrm{F}_{1,3}=38.4, \mathrm{p}<0.01\right)$. At 6 weeks, $G$. holbrooki on the all-TetraMin ${ }^{\circledR} \operatorname{diet}$ had 1.5 and 1.4 
times higher $\mathrm{C}: \mathrm{N}$ than those on the all-algae and TetraMin ${ }^{\circledR}$-algae diet (Tukey’s p-adj < $0.05)$.

Wild caught $G$. holbrooki had different FA relative abundances from those on all four diet treatments at both 3 and 6 weeks with average dissimilarities of $25.6 \%$ (R-stat $=$ 1; Figures 10). After 3 weeks, G. holbrooki FA relative abundances revealed two groupings indicative of all-algae and all-TetraMin ${ }^{\circledR}$ diets with dissimilarities of $31.8 \%$ $(\mathrm{R}$-stat $=0.92)$. After 6 weeks, the all-TetraMin ${ }^{\circledR}$ and all-algae diets still had different FA relative abundances with $27.1 \%$ dissimilarity (R-stat=1). At 6 weeks the all-TetraMin ${ }^{\circledR}$ diet was not distinguishable from the algae-TetraMin ${ }^{\circledR}$ diet, with a dissimilarity of only $7.4 \%(\mathrm{R}-\mathrm{stat}=0.30)$, contrary to the all-algae diet, which was still partially distinguishable from the TetraMin ${ }^{\circledR}$-algae diet (dissimilarity $\left.=13.4 \%, \mathrm{R}=0.85\right)$.

\section{Palaemonetes paludosus}

Palaemonetes paludosus growth rate data were excluded because of a substantial loss of specimens in the laboratory. There were no significant differences in total FA response or stoichiometry during the laboratory experiment because of low samples size. (Fig. 8).

Wild-caught $P$. paludosus had the most different FA relative abundance from those fed TetraMin ${ }^{\circledR}$ with an average dissimilarity of $15.0 \%$ after 3 weeks $($ R-stat $=1)$ and $22.2 \%$ after 6 weeks $(\mathrm{R}$-stat $=0.92$; Fig. 11$)$. Wild-caught $P$. paludosus FA relative abundances were most similar to those fed algae with an average dissimilarity of only $7.6 \%$ after 3 weeks $(\mathrm{R}$-stat $=0.92)$. After 3 weeks, FA abundances of $P$. paludosus revealed two groupings indicative of all-algae and all-TetraMin ${ }^{\circledR}$ diets with dissimilarities 
of $15.5 \%(\mathrm{R}$-stat $=1)$. At 6 weeks, those on the algae-TetraMin ${ }^{\circledR}$ diet were only $9.1 \%$ different than full- TetraMin $^{\circledR}$, whereas those on the TetraMin ${ }^{\circledR}$-algae diet were $11.12 \%$ dissimilar than those on the all-algae diet.

\section{Field Experiment}

The field conditions that were present during October and November varied in temperature, photoperiod, and water flow (Table 2). The water temperature decreased by an average of $3.8^{\circ} \mathrm{C}$ from the October field experiment to the November field experiment and the air temperature decreased by an average of $3.7^{\circ} \mathrm{C}$. The photoperiod decreased by an average of 44 minutes from the October field experiment to the November field experiment. In October, water column velocities were $<1 \mathrm{~cm} \mathrm{~s}^{-1}$ and water column total $\mathrm{P}$ was approximately $3 \mu \mathrm{g} \mathrm{L}^{-1}$, indicating oligotrophic conditions (Saunders and Rosen unpublished). In the November, sustained water column velocities of $>3 \mathrm{~cm} \mathrm{~s}^{-1}$ were achieved approximately 400-m from water delivery culverts and water TP remained low (approximately $5 \mu \mathrm{g} \mathrm{L}^{1}$ ). However, neither the flow velocity nor the TP estimates were statistically distinguishable.

Stoichiometric composition of biofilms differed between months during the field experiment, but periphyton showed minimal changes. The nutrient content of biofilm had $29 \%$ and $32 \%$ lower $\mathrm{C}: \mathrm{P}\left(\mathrm{F}_{1,31}=11.98, \mathrm{p}<0.001\right)$ and $\mathrm{N}: \mathrm{P}\left(\mathrm{F}_{1,31}=15.40, \mathrm{p}<0.001\right)$ ratios in November than in October and did not change within month by the presence of consumers or flow treatment (Fig. 12). The C:N ratio increased 3\% in November $\left(\mathrm{F}_{1,31}=\right.$ $10.54, \mathrm{p}<0.01)$. Initial periphyton samples had no differences in nutrient content at the start of the October and November field experiments (Fig. 13). Within-month changes to 
periphyton nutrient content were observed during both months with $14.6 \%$ and $19.4 \%$ decreases in C:N (October: Tukey’s p-adj < 0.05; November: Tukey's p-adj <0.001). Periphyton C:P and N:P did not change during the experiment. Within-month consumer and flow treatments did not have significant effects on stoichiometry, algal species relative abundance, FA relative abundance or total FA response.

The organic content of biofilms varied more in response to location in the slough than to treatments. Block was significant in the analysis of biofilms for both October and November. Consumer and flow treatments affected the organic content in October, but only accounted for a less than $2.5 \%$ difference in content (Tukey's p-adj $<0.05$; October average organic content $=47 \%$ ). The organic content in October with consumers present was different than November with consumers present, but only contributed to an overall change in content by less than $1.4 \%$ (Tukey's p-adj < 0.05 ). The organic content of October and November initial periphyton samples were similar and the presence of consumers increased the organic content in October by 3.5\%. November final periphyton organic content was greater by $2 \%$ than October final periphyton $\left(\mathrm{F}_{1,28}=9.7 ; \mathrm{p}<0.01\right.$; Fig. 14).

Consumers affected the biomass of biofilms, but the impact differed between months. Consumer presence increased the biomass $31 \%$ (increased $0.06 \mathrm{~g} \mathrm{~m}^{-2}$; Tukey's p-adj < 0.01) in October and decreased it by $17 \%$ (decreased $0.03 \mathrm{~g} \mathrm{~m}^{-2}$; Tukey's p-adj < $0.05)$ in November. Overall, biofilm biomass was 1.2 times greater in October than November $\left(0.03 \mathrm{~g} \mathrm{~m}^{-2}\right.$; Tukey's $\mathrm{p}$-adj < 0.05$)$. There were no observed differences in periphyton biomass between October and November initial samples, and none within the October study because of the presence of flow or consumer treatments, or between final 
samples. In November, biofilms in the presence of consumers had 1.2 times more biomass than those without consumers (increase $10.79 \mathrm{~g} \mathrm{~m}^{-2}$; Tukey's p-adj $<0.05$; Fig. 15).

The algal species relative abundance varied from October to November sampling periods, with biofilms showing the greatest difference in abundances. Biofilm algal species relative abundances had an average dissimilarity of $62.5 \%$ from October to November $(\mathrm{R}$-stat $=0.99, \mathrm{p}=0.001 ;$ Fig. 16$)$. Over $50 \%$ of the dissimilarity was attributed to 5 species of algae (Mougeotia species; Lyngbya species; Encyonema evergladianum; Brachysira aponina; Cymbella species) The algal species with the highest ranked relative abundance was Mougeotia species (filamentous, green algae; $21.0 \%$ contribution to dissimilarity), which had 5 times greater relative abundance in November, seconded by Lyngbya species (filamentous cyanobacteria; $10.3 \%$ contribution to dissimilarity), which had 6 times less relative abundance in November (3.6\% decrease in November). Within month changes to algal species relative abundances in periphyton accounted for an average dissimilarity of $27.8 \%(\mathrm{R}$-stat $=0.32, \mathrm{p}=0.001)$ in October and $29.0 \%$ in November $(\mathrm{R}$-stat $=0.5, \mathrm{p}=0.001$; Fig. 17). Between month changes to algal species relative abundance in periphyton, had an average dissimilarity of $27.6 \%$ (R-stat $=0.62$, $\mathrm{p}=0.001$ ) between initial samples and an average dissimilarity of $43.0 \%$ between final samples $(\mathrm{R}$-stat $=0.96, \mathrm{p}=0.001)$. Over $50 \%$ of the dissimilarity between final periphyton samples was attributed to 6 species of algae (Mougeotia species; Lyngbya species; Cymbella species; Schizothrix species; Encyonema evergladianum; Mastogloia smithii). The algal species with the highest ranked relative abundance was Mougeotia species (23.6\% contribution to dissimilarity) which had 6.7 times greater relative abundance in 
November, followed by Lyngbya species (filamentous cyanobacteria; $8.66 \%$ contribution to dissimilarity), which had 1.9 times less relative abundance in November The biovolume of Mougeotia species was notably different between months during the field experiment and had an 11.8 times increase in size in November.

The total FA response of basal resources that grew during the November flow event were greater than those grown in October. The total FA response of biofilm was $50 \%$ greater in November than in October $\left(\mathrm{t}_{35.6}=7.86, \mathrm{p}<0.001\right.$; Fig. 18). Total FA response of periphyton was not different in initial samples, but increased by $31.6 \%$ in November final samples ( $\mathrm{t}_{4.1}=5.36, \mathrm{p}=0.005$; Fig. 19$)$.

The FAME analysis revealed a diverse assemblage of individual FAs, 86 from basal resources and 78 from consumers. Individual FAs had an average relative abundance of $1.2 \%$ and a median abundance of $0.2 \%$. The FAs with the highest relative abundances were ubiquitous in all samples with 16:0 (Palmitic acid) being the most abundant (average relative abundance of 24.7\%). The second most common FA was 16:1w7 (Palmitoleic acid; average abundance of 17\%) in basal resource samples and was 18:1w9 (Oleic acid; average abundance of 13\%) in consumer samples.

Biofilms and periphyton had different FA relative abundances from October and November field experiments. The between-month dissimilarity in biofilm FA relative abundances was $18.3 \%$ (R-stat $=0.983, p=0.001 ;$ Fig. 20) with the top ranked FA relative abundances being 18:3w3 (algal tracer; 10.4\% dissimilarity contribution) and 18:1w7 (bacteria tracers; 9.9\% dissimilarity contribution). The algal FA 18:3w3 had 4-times greater relative abundance and the bacterial FA 18:1w7 had 4.6 times less relative abundance in November biofilm. Initial periphyton samples from October were 17.0\% 
different $(\mathrm{R}$-stat $=0.806, \mathrm{p}=0.002)$ from October final samples and initial November samples were $16.7 \%$ different $(\mathrm{R}$-stat $=0.736, \mathrm{p}=0.001)$ from November final samples (Fig. 21). Changes to FA relative abundances between months were accounted for by an average dissimilarity of $14.0 \%$ between initial periphyton samples $(\mathrm{R}$-stat=1) and $16.3 \%$ between final periphyton samples $(\mathrm{R}$-stat $=0.704, \mathrm{p}=0.001)$. In final periphyton samples, the highest ranked relative abundance FA, 18:1w7, (bacterial tracer; $6.5 \%$ contribution to dissimilarity) was 1.3 times less in November and the third highest ranked FA, 18:3w3 (contributing 5.6\% dissimilarity; algal tracer), was 1.1 times greater in November (FA ranked second in relative abundance has no biological relevance to this study).

The relative abundance of dietary tracer FAs groups (algae, bacteria and vascular plant sources) in basal resources varied between months. Biofilm had 1.9 times more algal tracer FAs $\left(\mathrm{F}_{1,37}=109.9, \mathrm{p}<0.001\right)$ and 3.7 times less bacterial tracer FAs $\left(\mathrm{F}_{1,37}=\right.$ 96.3, p < 0.001) in November (Fig. 22). October and November initial periphyton samples had similar contributions to all 3 tracer FA groups (Fig. 23). The relative abundance of algal tracer FAs in periphyton increased by 1.9 times during October (Tukey's p-adj $=0.047$ ) and were 2.3 times greater in November final samples than in October initial samples (Tukey's $p$-adj $=0.0013$ ), but bacterial and vascular plant tracer FA relative abundances did not change substantially.

The relative abundances of SAFA, MUFA, and PUFAs in biofilm and periphyton varied during sampling months. The relative abundance of SAFAs and MUFAs in biofilms were 1.1 times less in November than in October (SAFA: $\mathrm{F}_{1,37}=79.56, \mathrm{p}<$ 0.001, decreased 3.5\%; MUFA: $\mathrm{F}_{1,37}=32.02, \mathrm{p}<0.001$ decreased 4.2\%; Fig. 24). The relative abundance of PUFAs in biofilms was 1.4 times greater in November than 
October $\left(\mathrm{F}_{1,37}=103.28, \mathrm{p}<0.001\right.$, increased $\left.7.7 \%\right)$. The relative abundance of SAFAs in periphyton were greater in October initial samples than all other sampling periods by an average of 3.2\% (October final: Tukey's $\mathrm{p}<0.05$; November initial: Tukey's $\mathrm{p}<0.005$, November final: Tukey's $\mathrm{p}<0.01$; Fig. 25). The relative abundance of MUFAs in November and October final samples were on average 1.2 times less than initial periphyton from November (November: Tukey's $\mathrm{p}=0.008$, decreased 6.5\%; October: Tukey's $\mathrm{p}=0.01$, decreased 6.3\%). The relative abundance of PUFAs in October initial samples were 1.4 and 1.5 times larger than both October and November final samples (October: Tukey’s p-adj=0.03, increased 6.6\%; November: Tukey’s p-adj=0.01, increased $1.5 \%)$.

\section{Poecilia latipinna}

The initial average length of $P$. latipinna from October and November cohorts were indistinguishable. Poecilia latipinna grew slower by an average of $0.11 \mathrm{~mm} \mathrm{day}^{-1}$ in the November trial than in October (October growth rate $=0.16 \mathrm{~mm} \mathrm{day}^{-1}$, November growth rate $=0.05 \mathrm{~mm}_{\text {day }^{-1}}$, Tukey's p-adj <0.001; Fig. 26). The initial P. latipinna from October and November experiments had similar amounts of total FA response (Fig. 27). The total FA response of P. latipinna at the end of October was 4.5 times greater than initial samples and in November was 2.4 times greater than initial samples (Tukey's p-adj<0.001). Final October samples had 2.3 times more total FA response than November final samples (Tukey’s p-adj<0.001).

Poecilia latipinna used for both October and November field experiments had similar stoichiometric content initially because they consumed a common laboratory diet 
$(\mathrm{C}: \mathrm{N}$ mean $=4.6, \mathrm{sd}=0.1 ; \mathrm{C}: \mathrm{P}$ mean $=38.7, \mathrm{sd}=4.0 ; \mathrm{N}: \mathrm{P}$ mean $=8.4, \mathrm{sd}=0.09 ;$ Fig. 28). In October, final $P$. latipinna samples had $1.25,1.9$ and 1.5 times higher $\mathrm{C}: \mathrm{N}, \mathrm{C}: \mathrm{P}$, and $\mathrm{N}: \mathrm{P}$ ratios than initial samples $\left(\mathrm{C}: \mathrm{N}: \mathrm{F}_{1,11}=56.88, \mathrm{p}<0.001 ; \mathrm{C}: \mathrm{P}: \mathrm{F}_{1,11}=127.4, \mathrm{p}<\right.$ 0.001; N:P: $\left.\mathrm{F}_{1,11}=87.18, \mathrm{p}<0.001\right)$. In November, final $P$. latipinna samples has 1.1 and 1.25 times higher $\mathrm{C}: \mathrm{N}$ and $\mathrm{C}: \mathrm{P}$ than initial samples $\left(\mathrm{C}: \mathrm{N}: \mathrm{F}_{1,11}=10.48, \mathrm{p}<0.01 ; \mathrm{C}: \mathrm{P}\right.$ : $\left.\mathrm{F}_{1,11}=8.93, \mathrm{p}<0.05\right)$. Final P. latipinna $\mathrm{C}: \mathrm{N}, \mathrm{C}: \mathrm{P}$, and $\mathrm{N}: \mathrm{P}$ ratios from October were 1.2, 1.6, and 1.3 times higher than those from final November samples $\left(\mathrm{C}: \mathrm{N}: \mathrm{F}_{1,18}=\right.$ 98.53, p < 0.001; C:P: $\left.F_{1,18}=105, \mathrm{p}<0.001 ; \mathrm{N}: \mathrm{P}: \mathrm{F}_{1,18}=48.01, \mathrm{p}<0.001\right)$.

The relative abundances of $P$. latipinna FAs changed more during the October experiment than during the November experiment. Initial $P$. latipinna samples used in October and November had FA relative abundances that were only $10.8 \%$ dissimilar because they consumed a common laboratory diet $(\mathrm{R}-\mathrm{stat}=0.444$; Fig. 29$)$. The relative abundances of FAs from October final P. latipinna samples were $34.1 \%$ dissimilar from October initial samples $(\mathrm{R}$-stat $=1, \mathrm{p}=0.003)$ and November final samples were $16.1 \%$ dissimilar from initial November samples $(\mathrm{R}$-stat $=0.63, \mathrm{p}=0.003)$. The FA relative abundances from final October and November samples were $20.0 \%$ different $(\mathrm{R}$-stat $=$ $0.92, \mathrm{p}<0.001)$. The number 1,3 and 4 ranked relative abundance FAs were $16: 1 \mathrm{w} 7$ (high in diatoms), 22:6w3 (algal-derived), and 22:5w3 (algal-derived). The relative abundance of 16:1w7 was 1.2 times greater in October and the FAs 22:6w3 and 22:5w3 were 1.4 times greater in November.

The relative abundance of dietary tracer FAs for algae, bacteria and vascular plant sources varied in contribution between and within months. At the start of both October and November field experiments, $P$. latipinna had similar relative abundances of all 3 FA 
tracer groups. The relative abundance of algal tracer FAs in P. latipinna decreased by 54\% during October (Tukey’s p-adj < 0.001; Fig. 30), but did not change during November. The relative abundance of algal tracer FAs were 1.7 and 1.6 times higher in both November initial and final samples than in October final samples (Tukey's p-adj < 0.01). The relative abundance of bacterial tracer FAs in P. latipinna increased by $52 \%$ in October (Tukey's p-adj < 0.001 ) but did not change in November. The relative abundance of bacterial tracer FAs in final October $P$. latipinna samples were 1.2 and 1.4 times greater than in November initial and final samples (Tukey’s p-adj < 0.001$)$ and November final samples had 1.2 times greater relative abundance than October initial samples (Tukey's p-adj < 0.05). The relative abundance of vascular plant tracer FAs contributed to less than $1 \%$ of total FAs in the final samples.

Relative abundances of SAFA, MUFA, and PUFAs varied within and between months for P. latipinna. Relative abundances of SAFAs in October and November initial P. latipinna samples were not different, but both decreased during each month (Fig. 31; $8.5 \%$ in October, $F_{1,11}=18.9 ; p<0.01 ; 10.8 \%$ in November, $\left.F_{1,11}=14.5 ; p<0.01\right)$. Relative abundances of MUFAs were 1.1 times greater in November initial P. latipinna samples than initial October samples $\left(\mathrm{F}_{1,4}=63.5 ; \mathrm{p}<0.01\right)$ and increased during each month by $57 \%$ in October $\left(\mathrm{F}_{1,11}=261.3 ; \mathrm{p}<0.001\right)$ and only $19.3 \%$ in November $\left(\mathrm{F}_{1,11}=\right.$ 14.4; $\mathrm{p}<0.01)$. At the conclusion of both experiments, relative abundances of MUFAs in October final samples of $P$. latipinna were $1.5 \times$ more than in November final samples $\left(\mathrm{F}_{1,18}=34.31 ; \mathrm{p}<0.001\right)$. The relative abundances of PUFAs in $P$. latipinna was $1.3 \times$ larger in October initial samples than in November initial samples $\left(\mathrm{F}_{1,4}=14.5 ; \mathrm{p}<0.05\right)$ and decreased by $46 \% \%$ in October $\left(\mathrm{F}_{1,11}=83.8 ; \mathrm{p}<0.001\right)$. Relative abundances of 
PUFAs did not change in November and were $1.5 \times$ greater than in October final samples $\left(\mathrm{F}_{1,4}=14.4 ; \mathrm{p}<0.01\right)$

\section{Gambusia holbrooki}

Gambusia holbrooki were on average $2 \mathrm{~mm}$ smaller in the November cohort than the October cohort $\left(\mathrm{t}_{16.7}=-6.02, \mathrm{p}<0.001\right)$. Gambusia holbrooki had similar growth rates for both October and November (October growth rate $=0.12 \mathrm{~mm} \mathrm{day}^{-1}$, November growth rate $=0.10 \mathrm{~mm} \mathrm{day}^{-1}$; Fig. 26). The initial G. holbrooki from the October and November experiments had similar amounts of total FA response to start and showed no changes in total FA response after the conclusion of both months (Fig. 27).

Minimal changes were observed in the stoichiometric content of G. holbrooki during the field experiments. Gambusia holbrooki used for both October and November field experiments had similar nutrient content initially because they consumed a common laboratory diet $(\mathrm{C}: \mathrm{N}$ mean $=5.3, \mathrm{sd}=0.4 ; \mathrm{C}: \mathrm{P}$ mean $=45.3, \mathrm{sd}=5.2 ; \mathrm{N}: \mathrm{P}$ mean $=8.5, \mathrm{sd}$ $=0.6$; Fig. 28). The N:P ratio of G. holbrooki was 1.1 times larger in October final samples than initial samples $\left(\mathrm{F}_{1,11}=7.29, \mathrm{p}<0.05\right)$, but was not different than November samples. The C:N ratio of final October G. holbrooki samples was 1.1 times greater than November final samples $\left(\mathrm{F}_{1,18}=6.53, \mathrm{p}<0.05\right)$.

Initial G. holbrooki samples used in October and November were only $18.4 \%$ dissimilar because they consumed a common laboratory diet $(\mathrm{R}$-stat $=0.56$; Fig. 32). FA relative abundances from October final $G$. holbrooki samples were $21.4 \%$ dissimilar from October initial samples $(\mathrm{R}-\mathrm{stat}=0.99, \mathrm{p}<0.003)$ and November final samples were $27.0 \%$ dissimilar from initial November samples $(\mathrm{R}-\mathrm{stat}=1, \mathrm{p}<0.003)$. The FA relative abundances from final October and November samples were $12.7 \%$ different $(\mathrm{R}$-stat $=$ 
$0.52 \mathrm{p}<0.001)$. The number 1,7 and 9 ranked FA relative abundances were algalderived 22:6w3, 18:4w3, and 20:4w6 which were 1.4, 1.7, and 1.2 times greater in November.

The relative abundance of dietary tracer FAs for algae, bacteria and vascular plant sources in G. holbrooki changes within and between months. At the start of both October and November field experiments, G. holbrooki had similar relative abundances of all 3 FA tracer groups. Although the relative abundances of algal tracer FAs in G. holbrooki did not significantly change during each month, final November samples had 1.5 times more than October final samples (Tukey's p-adj < 0.001; Fig. 33). The relative abundance of bacteria tracer FAs increased within month by $108 \%$ in October (Tukey's p-adj < 0.001 ) and $81 \%$ in November (Tukey's p-adj < 0.001 ), but between months relative abundances were not different. The relative abundances of vascular-plant tracer FA were not altered in $G$. holbrooki within and between sampling months.

The relative abundance of SAFAs in G. holbrooki were 1.3 times greater in initial November samples than in initial October samples $\left(\mathrm{F}_{1,4}=32.0, \mathrm{p}<0.01\right)$ and increased within month by $20.6 \%$ in October $\left(\mathrm{F}_{1,11}=23.4\right.$, $\left.\mathrm{p}<0.001\right)$ and decreased by $10.0 \%$ in November $\left(\mathrm{F}_{1,11}=17.9, \mathrm{p}<0.01\right.$; Fig. 34$)$. The relative abundance of SAFA were less in November final samples than October final samples by $4.8 \%\left(\mathrm{~F}_{1,18}=5.8, \mathrm{p}<0.05\right)$. The relative abundance of MUFAs in initial samples were similar and did not change within either month. The relative abundance of PUFAs in G. holbrooki were initially 1.6 times higher in October than November $\left(\mathrm{F}_{1,4}=22.2, \mathrm{p}<0.01\right)$. Within month, PUFA relative abundances decreased by $28 \%$ in October $\left(\mathrm{F}_{1,11}=30.7, \mathrm{p}<0.001\right)$ and increased by $7 \%$ in 
November $\left(F_{1,11}=26.1, p<0.001\right)$, ending with November final samples having 1.3 times greater relative abundance than October final samples $\left(\mathrm{F}_{1,18}=30.1, \mathrm{p}<0.001\right)$. Palaemonetes paludosus

Growth rate was not analyzed statistically for $P$. paludosus because negative cohort growth rates were observed, possibly resulting from high mortality rates from the experimental cages. The total FA response for $P$. paludosus initial specimens were similar in both the October and November field experiment and showed no changes at the conclusion (Fig. 27).

Field collected $P$. paludosus had 1.1 times higher body C:P ratios at the start of the October trial than at the start of the November trial $\left(\mathrm{F}_{1,4}=10.77, \mathrm{p}<0.05\right.$, October $\mathrm{C}: \mathrm{P}$ mean $=92.8 \mathrm{sd}=2.3 ;$ November C $: \mathrm{P}$ mean $=83.6 \mathrm{sd}=4.6 ;$ Fig. 28). Palaemonetes paludosus was observed to have no changes in stoichiometry during the October experiment. During November, C:N, C:P, and N:P ratios were 1.1, 1.2, and 1.1 times greater after 3 weeks $\left(\mathrm{C}: \mathrm{N}: \mathrm{F}_{1,11}=20.34, \mathrm{p}<0.001 ; \mathrm{C}: \mathrm{P}: \mathrm{F}_{1,11}=30.15, \mathrm{p}<0.001 ; \mathrm{F}_{1,11}=\right.$ 12.59, $\mathrm{p}<0.01)$. No distinguishable changes were observed for $P$. paludosus between final October and final November stoichiometric ratios.

Differences in the relative abundances of FAs between initial October and November samples of $P$. paludosus reflect ambient field conditions when captured. The relative abundance of initial sample FAs had an average dissimilarity of $16.0 \%$ (R-stat $=$ $1 \mathrm{p}<0.1$; Fig. 35). Final October and November FA relative abundances were $8.3 \%$ (Rstat $=0.65)$ and $19.7 \%(\mathrm{R}$-stat $=1)$ different than their initial samples. Final FA relative abundances were only $8.3 \%$ different between the two months $(\mathrm{R}$-stat $=0.39)$. 
The relative abundances of algal tracer FAs in $P$. paludosus were 1.6, 1.8 and 1.6 times greater in November initial samples than in all other samples (Tukey's p-adj < 0.001; Fig. 36). The relative abundances of algal tracer FAs decreased $37 \%$ in November and was not distinguishable from the amount in October initial and final samples. The relative abundances of bacterial tracer FAs increased within month by $14 \%$ in October and by $19 \%$ in November. The relative abundances of bacterial tracer FAs was 1.1 times greater in final November samples than final October samples (Tukey's p-adj < 0.001). Vascular-plant tracer FA relative abundances in P. paludosus was 2.3, 3.6, and 2.6 times greater in November initial samples than October initial, October final and November final samples (Tukey’s p-adj < 0.001).

The relative abundances of SAFAs in initial P. paludosus samples were 1.1 times greater in November initial than October initial samples $\left(\mathrm{F}_{1,4}=27.5, \mathrm{p}<0.01\right)$ and decreased in November by a $10.6 \%\left(\mathrm{~F}_{1,11}=46.3\right.$, $\mathrm{p}<0.001$; Fig. 37). October final samples of $P$. paludosus had a greater relative abundance of SAFA than November final samples $\left(\mathrm{F}_{1,17}=16.24, \mathrm{p}<0.0001\right)$. The relative abundances of MUFAs in $P$. paludosus were 1.3 times lower in initial November samples than in initial October samples $\left(\mathrm{F}_{1,4}=\right.$ $156.5, \mathrm{p}<0.001)$ and increased by $33.2 \%$ within November $\left(\mathrm{F}_{1,11}=53.17, \mathrm{p}<0.001\right)$. The relative abundances of PUFAs in $P$. paludosus were 1.1 times greater in initial November samples than initial October samples $\left(\mathrm{F}_{1,4}=28.1, \mathrm{p}<0.01\right)$ and decreased by $9 \%$ in October $\left(\mathrm{F}_{1,11}=6.4, \mathrm{p}<0.05\right)$ and by $12 \%$ in November $\left(\mathrm{F}_{1,11}=15.27, \mathrm{p}<0.01\right)$. November final samples had a relative abundance of PUFAs 1.1 times greater than October final samples $\left(\mathrm{F}_{1,17}=11.9, \mathrm{p}<0.01\right)$. 


\section{DISCUSSION}

The balance of autotrophic and heterotrophic energy entering this experimental food web was different for October and November field experiments. Changes in the characteristics and quality of basal resources were reflected to varying degrees in the tissues of the three common consumers in the relatively short three-week duration of the study. Although this study cannot directly implicate increased flow velocity, and thus $\mathrm{P}$ loading, as the driver behind changes seen, many of these effects are known to be caused by increases in P. Fatty acids tracers and stoichiometry proved to be sensitive tools for detecting changes in the relative proportion of autotrophic and heterotrophic energy and nutrients entering the food web. The laboratory study provided a proof-of-concept behind this interpretation of the effects of diet on consumer body composition.

The rate of sequestration of FAs directly affects the ability to detect dietary changes in consumer tissue. The laboratory study demonstrated that a diet allowing for increased growth and sequestration of FAs will result in FA profiles more completely and quickly reflective of that diet. Further, a decreasing quality diet is less detectable in FA profiles because of previously sequestered FAs. Other studies have shown a greater similarity between dietary FAs and fish FA profiles is produced in fast-growing young fish, in a relatively short time, whereas less similarity is achieved in large fish because initial FA profiles have a strong influence on final FA profiles (Robin et al. 2002;

Skonberg et al. 1994; Tidwell and Roninette 1990). This trend was also observed in cod that were first fed a low-fat squid diet squid for 6 weeks, followed by high-fat mackerel diet for 8 weeks (Kirsch et al. 1998). In only 3 weeks, cod FA profiles reflected squid profiles but when switched to the high fat diet, total body increased and the FA 
composition of cod changed even further to reflect the mackerel diet. The FA profiles, of consumers used in this study, rapidly reflected their diets allowing for responsive tracing of dietary changes.

Basal resources from the November (flow) sampling period showed responses consistent with nutrient enrichment leading to an increase in autotrophic production compared to October (pre-flow). Similar to past studies, biofilms were more sensitive to changes in environmental conditions than the established periphyton community sampled (Chick et al. 2008). Biofilms had lower C:P and N:P ratios reflecting a 1.5 times greater TP content in November. A decrease in SAFA and MUFA relative abundance was paired with an increase in PUFAs relative abundance in November. Other studies have shown that the periphyton C:P ratios are reduced with P enrichment and PUFA are increased with lower irradiance levels (Hill et al. 2011). Thus the observed decreased in C:P and $\mathrm{N}: \mathrm{P}$ ratios and increase in PUFAs could be caused by the synergistic effects of increase $\mathrm{P}$ absorption and shorter photoperiod. Increased relative abundance of filamentous green algae and decreased cyanobacteria was observed in taxonomic counts and in the FA dietary tracer analysis of biofilm and periphyton from November. Seasonal changes during this time normally include a shift from cyanobacteria dominance in the wet season to diatoms in the dry season, with very little green algae (McCormick et al. 1998). McCormick et al. found green algae comprised an average of $37 \%$ of biofilms at eutrophic locations and only $3 \%$ at oligotrophic locations during the wet season, but were not found in any samples during the dry season and never accounted for more than $3 \%$ of the algal community. In contrast, November samples of periphyton and biofilm from the field experiment had green algae comprising $32 \%$ and $52 \%$ of the algal community. 
Increases in filamentous green algae species, including Mougeotia species present in this study, have been linked to P enrichment in field and mesocosum studies and the species is considered characteristic of eutrophic environments (McCormick \& O'Dell, 1996, McCormick 1998, Hagerthey et al. 2011). The P concentration in water entering the study area was carefully monitored and little or no detectable changes were observed in water column TP from baseline (pre-flow) condition. Therefore, differences observed in basal resources could be documentation of a nutrient loading event, which increased autotrophic production.

The observed P- enrichment and increase in autotrophic productivity in basal resources was correlated with body condition changes in the herbivore $P$. latipinna, but the relationship was weak or absent in the omnivorous G. holbrooki and P. paludosus. At the conclusion of the November field experiment, P. latipinna had lower nutrient ratios, less total FA response and a greater relative abundance of PUFAs than in October, yet grew slower. G. holbrooki also had lower C:N and greater relative abundance of PUFAs in November but no differences in growth rate or total FA response were observed. These body condition effects suggest a higher quality diet in November led to a higher "quality" consumer, however consumers either grew slower or the same compared to those from October. Hagerthey et al. (2014) observed that consumers from oligotrophic regions had C:P and N:P ratios 2.8 and 2.1 times greater than consumers in eutrophic areas of the Everglades, suggesting that low quality basal resources have imparted P- limitation on primary consumers, reducing growth rate and subsequently reducing their density and biomass in oligotrophic regions (Hagerthey et al. 2014). This discussion brings up three apparent inconsistences in my results: 1) basal resources with lower C:P and higher 
PUFA content did not increase consumer growth rate in November; 2) high consumer C:P was associated with faster growth and more FAs in both my field and lab experiments; and 3) although consumers were subjected to identical treatments, responses were not the same for each species. I will discuss these in the next three paragraphs.

Consumers in the field study ingestion the "lower quality" food (high C:P) in October ended up growing faster and sequestering more FAs than those eating the "better" quality biofilms. The mechanism behind this could be attributed to basal resource taxonomy and $\mathrm{C}: \mathrm{P}$ changes in relation to dietary demands and temperature differences. Increases in filamentous green algae were not only detected in our taxonomic assessment and FA analysis, but were also visibly evident in the November sampling. It has been shown that physical structure of periphyton mats impedes effective grazing on its edible components and restricts consumers to grazing on the exterior of the mats only (Geddes and Trexler 2003; Trexler et al. 2015). Filamentous green algae were blooming on the exterior of the mats, on the cage walls (personal observation), and in biofilms in November. This filamentous green portion diluted other portions of the grazer diet, such as the more nutritious algae types like diatoms. If October $P$. latipinna were eating more diatoms than $P$. latipinna from November, it would also explain their increased FA content and subsequent higher $\mathrm{C}$ content. Further, the $\mathrm{C}: \mathrm{P}$ ratio of biofilms in November were only 19\% lower than the C:P in October as compared to commercial algae and TetraMin ${ }^{\circledR}$ diet which were $87 \%$ lower than the C:P of biofilms. Although an increase in $\mathrm{P}$ was observed in November, total $\mathrm{P}$ from all basal resources during the field experiment were similar to levels seen in oligotrophic parts of WCA-3A and were lower than eutrophic regions (Hagerthey et al. 2011). This demonstrates that the amount of $\mathrm{P}$ 
entering the food web fragment was enough to alter the algal community, but may not enough to release P-limitation and influence the growth rate of consumers in November. Higher temperature in October may also explain the increased growth rate of P. latipinna in the pre-flow experiment. Warmer temperature has been shown to increase female $P$. latipinna growth rate from 0.15 to $0.45 \mathrm{~mm}$ day-1, equaling a $0.042 \mathrm{~mm}^{-1} \mathrm{day}^{-1}$ increase with every $1^{\circ} \mathrm{C}$ increase (Trexler et al. 1990). This would translate the average $3.8^{\circ} \mathrm{C}$ higher temperature in October to a $0.16 \mathrm{~mm} \mathrm{day}^{-1}$ higher growth rate than November, which is similar to the observed difference of $0.11 \mathrm{~mm} \mathrm{day}^{-1}$.

The second discrepancy observed was that consumers with the highest C:P ratios had the fastest growth and sequestered more FAs in both the field and laboratory experiments. Variation in stoichiometry and fatty acid contents within a species can arise from differences in life history characteristics (sex, stage, and size), habitat and food (Hendrixson et al. 2007). The laboratory experiment was designed to control for those differences in order to describe consumer stoichiometric and fatty acid responses to diet quality. I hypothesized, that the high quality diet TetraMin ${ }^{\circledR}$ would lead to an increase in $\mathrm{P}$ content and decrease in $\mathrm{C}$ content (decrease in $\mathrm{C}: \mathrm{P}$ ) as seen in other freshwater fish species (Hendrixson et al. 2007). Contrary to this, after 3 weeks of this study, P. latipinna and G. holbrooki fed algae were of "better" stoichiometric quality with more total nitrogen and phosphorus and less carbon than those fed TetraMin ${ }^{\circledR}$. Although TetraMin ${ }^{\circledR}$ was the higher quality diet, it resulted in higher $\mathrm{C}: \mathrm{N}, \mathrm{C}: \mathrm{P}$ and $\mathrm{N}: \mathrm{P}$ ratios. Further, $P$. latipinna grew quickest in the October field experiment, yet there C:P ratios were higher than any other fish in my study $(\mathrm{C} . \mathrm{P}=73.8 \pm 6.8)$. The increase in carbon content may be accounted for by an increased amount of carbon-rich fatty acids. At week 3, both $G$. 
holbrooki and P. latipinna on the full-TetraMin ${ }^{\circledR}$ diet had over double the total FA response than those on the all-algae diet. Correspondingly, P. latipinna in the October field study had 4.5 times more FA total response than those at the start of the field experiment and 2.3 times more than those in November. Although, high growth rate and high $\mathrm{P}$ are thought to be connected because macromolecules essential for protein synthesis are $\mathrm{P}$ rich and contribute to a significant amount of an organism's total $\mathrm{P}$, these results imply that "lower" stoichiometric quality (high C: nutrient) consumers may have been growing faster and sequestered more FAs, diluting their $\mathrm{N}$ and $\mathrm{P}$ content (Vrede et al. 2004). Moreover, other studies have shown high C:N ratios being attributed to high lipids or high carbohydrate content (Gnaiger and Bitterlich 1984). Bulk organic carbon in the form of lipids are essential molecules for energy storage as well as for cell structure and function (Castell et al. 1972, Sterner and Elser 2002). Storage lipids are important for over-wintering in freshwater fish, where reduced primary productivity and decreased feeding increases demands on stored energy (Lemons and Crawshaw 1985; Moerland and Sidell 1981; Prentice 1989).

The third discrepancy observed was inconsistencies in each species' response to field conditions. As discussed above, at the conclusion of the field experiments, $G$. holbrooki, like $P$. latipinna, had lower nutrient ratios in November, but did not grow faster or increase in total FA response. Also, P. latipinna in the laboratory study had quicker growth rates while feeding on higher quality TetraMin ${ }^{\circledR}$ diet while $G$. holbrooki marginally increased. These difference may be because of sexual maturity and/or feeding guild differences. At the start of the both the laboratory and field experiments, $G$. holbrooki were approximately 30 days old and at the 3 week sampling point 
approximately 50 days old (ages calculated from length and age regression relationships; Haake and Dean 1983). The age at sexual maturity and first reproduction for females and males is reduced by increased temperature and ration quality and as their size increases, they progressively increase the proportion of energy allocated to reproduction and decrease the proportion to growth (Vondracek 1988). Considering G. holbrooki males can show gonopodium growth at 39 to 53 days under $25^{\circ} \mathrm{C}$ conditions and females have first reproduction at around 76 days (Vondracek 1988), no changes in growth rate during either study may have been because growth had already peaked for these individuals. In contrast, $P$. latipinna mature at approximately 115 days for males and 100 days for females, thus may have still been allocation a larger proportion of energy to growth than G. holbrooki (Trexler et al. 1990). The different feeding guilds of consumers used in this study may also have caused additional variation in consumer responses. The omnivorous G. holbrooki and P. paludosus showed less variation between months during the field experiment than the herbivorous P. latipinna did. Variation in the quality of primary production may have directly affected $P$. latipinna, whereas the omnivorous consumers may have been buffered from direct changes by the more homeostatic infauna they consume (Brett 1993). Furthermore, P. paludosus has a unique feeding method of penetrating periphyton mats to feed more selectively (Geddes and Trexler 2003). $P$. paludosus showed relatively no change in dietary tracer FAs or stoichiometry through the field experiment suggesting their ability to selectively graze on periphyton may have played a role. G. holbrooki and P. latipinna were shown to graze more effectively when the physical structure of periphyton mats was disrupted in contrast to $P$. paludosus that was less affected (Geddes and Trexler 2003; Trexler et al. 2015). Variation in consumer 
responses to eutrophication-driven alterations in diet may be reflective of the diverse biology and life history traits of Everglades consumers.

The present study aimed to test the hypothesized consequence of sheet flow restoration on aquatic food webs in the Everglades. I hypothesized that increased velocity, leading to nutrient loading from an increased rate of supply of phosphorus even as its concentration remains constant, would cause a shift in the relative contribution of energy from a heterotrophic pathway to an autotrophic one. Although water column TP did not increase during the flow event, observed changes to basal resources were consistent with known eutrophication changes seen in the Everglades. Therefore, increased sheet flow velocity and accompanying nutrient loading remains a plausible driver for observed changes. Further, the increase in $\mathrm{P}$ during this study was confounded with seasonal decreases in primary production and consumer growth rate. Thus, this could have limited more dramatic food web changes that might occur if increased flows were supplemented during the late-dry to early-wet season when rewetting occurs and nutrients desorbed from periphyton mats into the water column (Gottlieb et al. 2005; Thomas et al. 2006).

An increase in autotrophic-derived energy was evident in consumers, especially the herbivorous P. latipinna, but did not increase growth rates as hypothesized. Additionally, consumers grew the quickest and increased in $\mathrm{C}$ content under high quality diet scenarios, contrary to work linking increased whole body P to decreased $\mathrm{C}$ and increased growth rate (Hendrixson et al. 2007; Vrede et al. 2004). This research demonstrates the complexity of using stoichiometric data to infer the body condition of consumers. The suggestion that the high C:P content of oligotrophic consumers means 
they have slower growth rate and are a "poor" quality as compared to consumers from eutrophic areas may be an incomplete interpretation (Hagerthey et al. 2014). Although increases in autotrophic production may mean increases in palatable algae and $\mathrm{P}$, our study suggests this may not increase diet quality or consumer growth. Nutrient loading and eutrophication has caused dramatic changes to portions of the Everglades, including complete disassociation of periphyton mats and the invasion of monotypic stands of invasive Typha species (Dorn et al. 1997; Gaiser et al. 2005). This study, shows the subtle repercussion of possible low-level nutrient loading over a short time interval. More research is needed to fully understand how persistent nutrient loading alters the nutritional quality of basal resources and how individual species respond to these changes. 


\section{LITERATURE CITED}

Ahlgren, G., L. Lundstedt, M. Brett, and C. Forsberg. 1990. Lipid composition and food quality of some freshwater phytoplankton for some cladoceran zooplankters. Journal of Planktonic Research. 12:809-818.

Belicka, L.L., E.R. Sokol, J.M. Hoch, R. Jaffé, and J.C. Trexler. 2012. A molecular and stable isotopic approach to investigate algal and detrital energy pathways in a freshwater marsh. Wetlands 32(3): 531-542.

Brett, M.T. 1993. Comment on "Possibility of N or P limitation for planktonic cladocerans: an experimental test" (Urabe and Watanabe) and "Nutrient element limitation of zooplankton production" (Hessen). - Limnology and Oceanography 38:1333-1337.

Brett, J. R. and T.D.D. Groves. 1979. Physiological energetics, pp. 279-352. In: W.S. Hoar, D.J. Randell \& J.R. Brett (ed.) Fish Physiology, Academic Press, New York.

Brett, M.T. and D.C. Muller-Navarra. 1997. The role of highly unsaturated fatty acids in aquatic food webs. Freshwater Biology. 38:483-499.

Bellinger, B.J. and S.E. Hagerthey. 2010. Presence and diversity of algal toxins in subtropical peatland periphyton: the Florida Everglades, USA. Journal of Phycology. 46:674-678.

Boersma, M., N. Aberle, F.M. Hantzsche, K.L Schoo, K.H. Wiltshire, and A.M. Malzahn. 2008. Nutrient limitation travels up the food chain. International Review of Hydrobiologia 93:479-488.

Browder, J.A., P.J. Gleason, and D.R. Swift. 1994. Periphyton in the Everglades: spatial variation, environmental correlates, and ecological implications. In: Davis, S.M., J.C. Ogden, eds. Everglades: the ecosystem and its restoration. Delray Beach (FL): St. Lucie Press. 379-418.

Budge, S. M., S. J. Iverson, and H. N. Koopman. 2006. Studying trophic ecology in marine ecosystems using fatty acids: a primer on analysis and interpretation. Marine Mammal Science 22:759-801. 
Busak, C.A, and G.A.E. Gall. 1983. An initial description of the quantitative genetics of growth and reproduction in the mosquitofish, Gambusia affinis. Aquaculture 32:123-140.

Cashman, M.J., J.D. Wehr and K. Truhn. 2013. Elevated light and nutrients alter the nutritional quality of stream periphyton. Freshwater Biology 58:1447-1457.

Castell, J.D., R.O. Sinnhuber, D.J. Lee and J.H. Wales. 1972. Essential fatty acids in the diet of rainbow trout (Salmo gairdneri): growth, feed conversion and some gross deficiency symptoms. Journal of Nutrition 107:77-85.

Champely, S. 2009. Package 'pwr': Basic functions for power analysis. R package version 1.1.1. http://CRAN.R-project.org/package=pwr.

Chick, J.H., P. Geddes, and J.C. Trexler. 2008. Periphyton mat structure mediates trophic interactions in a subtropical march. The Society of Wetland Scientists 28(2):378389.

Clarke, KR, Gorley, RN. 2015. PRIMER v7: User Manual/Tutorial. PRIMER-E, Plymouth, 296pp.

Dahlgren, B.T. 1979. The effects of population density on fecundity and fertility in the guppy, Poecilia reticilata (Peters). Journal of Fish Biology 15:71-91.

Dalsgaard, J., M. St. John, G. Kattner, D.C Müller-Navarra and W. Hagen. 2003. Fatty acid trophic markers in the pelagic marine environment. Advances in Marine Biology 46:225-340.

DeMott, W.R. and D.C Müller-Navarra. 1997. The importance of highly unsaturated fatty acids in zooplankton nutrition: evidence from experiments with Daphnia, a cyanobacterium and lipid emulsions. Freshwater Biology 38:649-64.

DeMott, W.R. and B.J. Pape. 2005. Stoichiometry in an ecological content: testing for links between Daphnia response to seston phosphorus enrichment. Ecology 82:898-903.

Dorn, N. J., J. C. Trexler, and E. E. Gaiser. 2006. Exploring the role of large predators in marsh food webs: evidence for a behaviorally-mediated trophic cascade. Hydrobiologia 569:375-38. 
Eaton A.D., Clesceri L.S., A.E. Greenberg eds. 1995. Standard methods for the examination of water and waste water; American Public Health Association (APHA), Washington, USA.

Gaiser, E.E., D.L. Childers, R.D. Jones, J.H. Richards, L.J. Scinto, J.C. Trexler. 2006. Periphyton responses to eutrophication in the Florida Everglades: cross-system patterns of structural and compositional change. Limnology and Oceanography 51:617-630.

Gaiser, E.E., P.V. McCormick, S.E. Hagerthey, and A.D. Gottlieb. 2011. Landscape patterns of periphyton in the Florida Everglades. Critical Reviews in Environmental Science and Technology 41(S1):92-120.

Gaiser, E.E., L.J. Scinto, J.H. Richards, K. Jayachandran, D.L. Childers, J.C. Trexler, R.D. Jones. 2004. Phosphorus in periphyton mats provides the best metric for detecting low-level P enrichment in an oligotrophic wetland. Water Research 28:507-516.

Gaiser, E.E., J.C. Trexler, J.H. Richards, D.L. Childers, D. Lee, A.L. Edwards, L.J. Scinto, K. Jayachandran, G.B. Noe, and R.D. Jones. 2005. Cascading ecological effects of low-level phosphorus enrichment in the Florida Everglades. Journal of Environmental Quality 34:717-723.

Geddes, P., and J. C. Trexler. 2003. Uncoupling of omnivore-mediated positive and negative effects on periphyton mats. Oecologia 136:585-595.

Gnaiger, E. \& Bitterlich, G. 1984. Proximate biochemical composition and caloric content calculated from elemental CHN analysis: a stoichiometric concept. Oecologia 62:289-298.

Gottlieb, A., J.H. Richards, and E.E Gaiser. 2005. The effects of desiccation resistance and rewetting on the community structure of Everglades periphyton. Aquatic Botany 82:99-112.

Green, D. P. J. 2007. Community structure and physiological stresses of oligohaline zone fishes in South Florida. M.S. Thesis, Florida International University, 73.

Gulati, R.D. and W.R. DeMott. 1997. The role of food quality for zooplankton: remarks on the state-of-the-art, perspectives and priorities. Freshwater Biology 38:753768. 
Guschina I.A. and J.L Harwood. 2009. Algae lipids and effect of the environment on their biochemistry. In: Lipids in Aquatic Ecosystems (eds. M. Arts, M.T. Brett and M. Kainz), pp. 1-24. Springer, New York.

Haake, P.W, and J.M. Dean. 1983. Age and growth of four Everglades fishes using otolith techniques. South Florida Research Center Report SFRC 83(03):1-68.

Hagerthey S.E., B.J. Bellinger, K. Wheeler, M. Gantar and E. Gaiser. 2001. Everglades periphyton: a biogeochemical perspective. Critical Reviews in Environmental Science and Technology 41(S1):309-343.

Hagerthey, S.E., M.I. Cook, R.M. Kobza, S. Newman and B.J. Bellinger. 2014. Aquatic faunal response to an induced regime shift in phosphorus-impacted Everglades. Freshwater Biology 59:1389-1405.

Hairston, N.G. Jr., and N.G. Hairston Sr. 1993. Cause-effect relationships in energy flow, trophic structure, and interspecific interactions. American Naturalist 142:379-411.

Hendrixson, H.A., R.W. Sterner, and A.D. Kay. 2007. Elemental stoichiometry of freshwater fished in relation to phylogeny, allometry, and ecology. Journal of Fish Biology 70:121-140.

Hill, W. R., J. Rinchard, and S. Czesny. 2011. Light, nutrients and the fatty acid composition of stream periphyton. Freshwater Biology 56:1825-1836.

Iverson, S. J., C. Field, W. D. Bowen, and W. Blanchard. 2004. Quantitative fatty acid signature analysis: a new method of estimating predator diets. Ecological Monographs 74:211-235.

Iwaniec, D.M., D.L. Childers, D. Rondeau, C.J. Madden and C.J. Saunders. 2006. Effects of hydrologic and water quality drivers on periphyton dynamics in the southern Everglades. Hydrobiologia 569: 223-235.

Jardine, T.D., R. Woods, J. Marshall, J. Fawcett, J. Lobegeiger, D. Valdez, and M.J. Kainz. 2015. Reconciling the role of organic matter pathways in aquatic food webs by measuring multiple traces in individuals. Ecology 96(12):3257-3269.

Jenkins, J. A., H. L. Bart Jr., J. D. Bowker, P. R. Bowser, J. R. MacMillan, J. G. Nickum, J. W. Rachlin, J. D. Rose, P. W. Sorensen, B. E. Warkentine, and G. W. Whitledge. 2014. Guidelines for Use of Fishes in Research—Revised and Expanded. Fisheries 39:415-416. 
Kirsch, P.E., S.J. Iverson, W.D. Bowen, S.R. Kerr, R.G. Ackman. 1998. Dietary effects on the fatty acid signature of whole Atlantic cod (Gadus morhua). Canadian Journal of Fisheries and Aquatic Sciences 55(6): 1378-1386.

Lemons, D.E., and L.I. Crawshaw. 1985. Behavioral and metabolic adjustments to low temperature in the largemouth bass (Micropterus salmoides). Physiological Zoology 58:175-180.

Liston, S.E., S. Newman, J.C. Trexler. 2008. Macroinvertebrate community response to eutrophication in an oligotrophic wetland; an in situ mesocosm experiment. Wetlands. 28:686-694.

McCormick, P, and E. Gaiser. 2011. Periphyton-Water Quality Relationships. Scientific and Technical Knowledge Gained in Everglades Restoration. 3:101-106.

McCormick, P.V., S. Newman, S.L. Miao, K.R. Reddy, D.E. Gawlik, and T.D. Fontaine III, and D.J. Marley. 2002. Effects of anthropogenic phosphorus inputs on the Everglades. Pages 83-126 in the Everglades, Florida Bay, and Coral Reefs of the Florida Keys: An Ecosystem Sourcebook (J.W. Porter and K.G. Porter, eds.). CRC/Lewis Publishers, Boca Raton, Florida.

McCormick, P.V. and M.B. O'Dell. 1996. Quantifying periphyton responses to phosphorus in the Florida Everglades: A synoptic-experimental approach. Journal of North American Benthological Society 15(4):450-468.

McCormick P.V., P.S Rawlik, K. Lurding, E.P Smith, F.H Sklar. 1996. Periphyton-water quality relationships along a nutrient gradient in the Northern Florida Everglades. Journal of the North American Benthological Society 15:433-449.

McCormick, P.V., B.E. Shuford III, J.G. Backus, and W.C. Kennedy. 1998. Spatial and season patterns of periphyton biomass and productivity in the northern Everglades, Florida, U.S.A. Hydrobiologia 362:185-208.

Moerland, T.S. and B.D. Sidell. 1981. Characterization of metabolic carbon flow in hepatocytes isolated from thermally acclimated killifish Fundulus heteroclitus. Physiological Zoology 54:379-389.

Müller-Navarra, D.C. 1995. Biochemical versus mineral limitation in Daphnia. Limnology and Oceanography. 40:1209-1214. 
Müller-Navarra, D.C., M.T. Brett, A.M. Liston and C.R. Goldman. 2000. A highly unsaturated fatty acid predicts carbon transfer between primary producers and consumers. Nature 403: $74-77$.

Noe, G.B., D.L Childers, and R.D. Jones. 2001. Phosphorus biogeochemistry and the impact of phosphorus enrichment: Why is the Everglades so unique? Ecosystems 4:603-624.

Pan, Y., R.J. Stevenson, P. Vaithiyanathan, J. Slate, C.J. Richardson. 2000. Changes in algal assemblages along observed and experimental phosphorus gradients in a subtropical wetland, USA. Freshwater Biology 44:339-353.

Persson, J., M.T. Brett, T. Vrede and J.L. Ravet. 2007. Food quantity and quality regulation of trophic transfer between primary producers and a keystone grazer (Daphnia) in pelagic freshwater food webs. Oikos 116:1152-1163.

Plath, K. and M. Boersma. 2001. Mineral limitation of zooplankton: stoichiometric constraints and optimal foraging. Ecology 82:1260-1269.

Prentice, J. A. 1989. Low-temperature tolerance of southern flounder in Texas. Transactions of the American Fisheries Society 118:30-35.

R Core Team. 2013. R: A language and environment for statistical computing. R Foundation for Statistical Computing, Vienna, Austria. URL http://www.Rproject.org/.

Rader, R.B. and C.J. Richardson. 1994. Response of macroinvertebrates and small fish to nutrient enrichment in the Northern Everglades. Wetlands 14(2):134-146.

Rasband, W.S. 1997-2015. ImageJ, U. S. National Institutes of Health, Bethesda, Maryland, USA. http://imagej.nih.gov/ij/.

Robin, J.H., C. Regost, J. Arzel, and S.J. Kaushik. 2003. Fatty acid profile of fish following a change in dietary source model of fatty acid composition with dilution hypothesis. Aquaculture 225:283-293. 
Sargent, B.L., E.E. Gaiser, and J.C. Trexler. 2011. Indirect and direct controls of macroinvertebrates and small fish by abiotic factors and trophic interactions in the Florida Everglades. Freshwater Biology 56(11):2334-2346.

Sklar, F., S. Hagerthey, V. Engel, J. Harvey, L. Larson, K. Legault, S. Newman, G. Noe, J. Redwine, C. Saunders, J. Trexler. 2010. DECOMP Physical Model Science Plan, http://www.evergladesplan.org/pm/projects/project_docs/pdp_12_decomp/ 060410_decomp_ea_final/april_2010_decomp_ea_app_e_bk.pdf.

Skonberg, D.I., B.A Rasco, and F.M. Dong. 1994. Fatty acid composition of salmonid muscle changes in response to high oleic acid diet. The Journal of Nutrition. 124: 1628-1638.

Sterner, R.W. and J.J. Elser. 2002. Ecological Stoichiometry: the Biology of Elements from Molecules to the Biosphere. Princeton University Press, Princeton, USA.

Thomas, S., E.E Gaiser, M. Gantar, and L.J. Scinto. 2006. Quantifying the responses of calcareous periphyton crusts to rehydration: A microcosm study (Florida Everglades). Aquatic Botany 84:317-323.

Tidwell, J.H. and H.R. Robinette. 1990. Changes in proximate and fatty acid composition of fillet from catfish during a two-year growth period. Transactions of the American Fisheries Society 119:31-40.

Trexler, J. C. 1997. Resource availability and offspring provisioning: Plasticity in embryo nourishment in sailfin mollies. Ecology 78:1370-1381.

Trexler, J. C., E. E. Gaiser, J. S. Kominoski, and J. Sanchez. 2015. The role of periphyton mats in consumer community structure and function in calcareous wetlands: Lessons from the Everglades, pp 155-179. In: J. A. Entry, A. D. Gottlieb, K. Jayachandrahan and A. Ogram, eds. Microbiology of the Everglades Ecosystem, Science Publishers, CRC Press.

Trexler, J.C, J. Travis and M. Trexler. 1990. Phenotypic plasticity in the Sailfin Molly, Poecilia latipinna (Pisces: Poeciliidae). II. Laboratory Experiment. Evolution 44(1):157-167.

Turner, A.M., J.C. Trexler, F. Jordan, S.J. Slack, P. Geddes, and W. Loftus. 1999. Targeting ecosystem features for conservation: standing crops in the Florida Everglades. Conservation Biology 13:898-911. 
Twining, C.W., J.T. Brenna, N.G. Hairston, and A.S Flecker. 2015. Highly unsaturated fatty acids in nature: what we know and what we need to learn. Oikos 000:1-12.

USACE. 2014. Central Everglades Planning Project, Facts and Information. US Army Corp of Engineers, http://www.evergladesplan.org/docs/fs_cepp_jan_2014.pdf.

Vondracek, B., W.A. Wurtsbaugh, and J.J. Check Jr. 1988. Growth and reproduction of the mosquitofish, Gambusia affinis, in relation to temperature and ration level: consequences for life history. Environmental Biology of Fishes 21(1):45-57.

Vrede, T., D.R. Dobberfuhl, S.A.L.M. Kooijman, and J.J Elser. 2004. Fundamental connections among organism C:N:P stoichiometry, macromolecular composition, and growth. Ecology 85(5):1219-1229.

Williams, C. J., R. Jaffé, W. T. Anderson, and F. J. Jochem. 2009. Importance of seagrass as a carbon source for heterotrophic bacteria in a subtropical estuary (Florida Bay). Estuarine, Coastal and Shelf Science 85:507-514. 


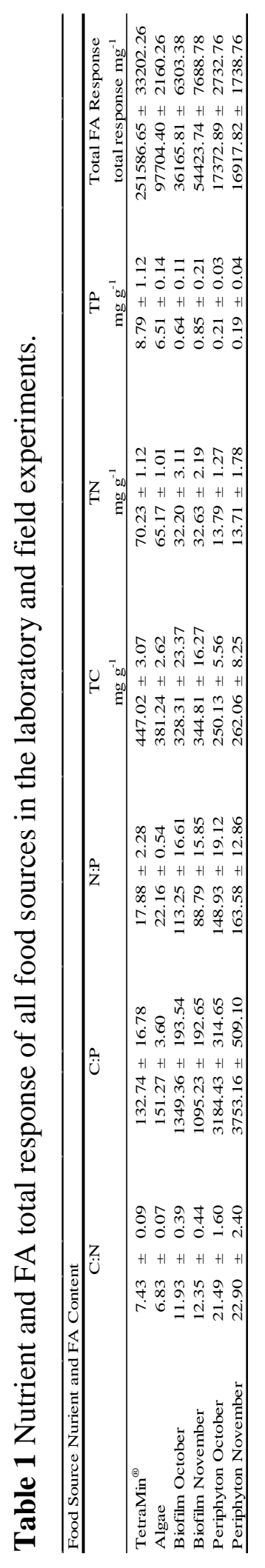


TABLE 2. Field conditions during October and November field experiments.

\begin{tabular}{|c|c|c|c|c|c|c|}
\hline \multicolumn{7}{|l|}{ Field Conditions } \\
\hline & \multicolumn{3}{|c|}{ October } & \multicolumn{3}{|c|}{ November } \\
\hline & $\max$ & mean & $\min$ & $\max$ & mean & $\min$ \\
\hline Air Temperature $\left({ }^{\circ} \mathrm{C}\right)$ & 31.0 & 29.5 & 22.6 & 27.2 & 26.4 & 18.0 \\
\hline Water Tempe rature $\left({ }^{\circ} \mathrm{C}\right)$ & 25.9 & 22.3 & 33.7 & 22.1 & 18.2 & 27.5 \\
\hline Photope riod (hours) & 11.5 & 11.8 & 11.3 & 10.8 & 11.0 & 10.6 \\
\hline \multirow[t]{2}{*}{ Wate r Depth (cm) } & 57 & 67 & 49 & 68 & 77 & 53 \\
\hline & mean & uncertainty & & mean & uncertainty & \\
\hline Flow $\left(\mathrm{cm} \mathrm{sec}^{-1}\right)$ & $<1$ & & & $>3$ & & \\
\hline Water Column $\mathrm{TPO}_{4}$ & 0.003 & 0.002 & & 0.005 & 0.002 & \\
\hline
\end{tabular}


Table $\mathbf{3}$ Sources of fatty acids reported in literature referenced from Belicka et al. 2012.

Carbon Source (Grouped fatty acids used in this study)

\section{Bacteria}

15:0i, 15:0a, 15:0n, 17:0i, 17:0a, 17:0n, 18:1w7, 19:1

Vascular Plants

22:0n, 24:0n, 26:0n, 28:0n

Algae

16:3, 18:3w3, 18:4, 18:3w6, 20:4w6, 20:5w3, 20:4, 22:4w6, 22:5w3, 22:5w6, 22:6w3 
Table 4. Within month similarity and between month dissimilarity of algal species relative abundances for biofilm samples.

Within Month Similarity

\begin{tabular}{llccc}
\hline October & \multicolumn{4}{c}{ Average similarity: 68.68 } \\
Species & Type & Av.Abund & Contrib\% & Cum.\% \\
Encyonema evergladianum & Diatom & 4.07 & 15.76 & 15.76 \\
Lyngbya sp. & Cyanobacteria & 4.28 & 14.54 & 30.3 \\
Brachysira aponina & Diatom & 3.62 & 12.89 & 43.19 \\
Mastogloia smithii & Diatom & 2.55 & 9.86 & 53.05 \\
Cymbella sp. & Diatom & 2.7 & 9.51 & 62.56 \\
Fragilaria synegrotesca & Diatom & 2.24 & 8.28 & 70.84
\end{tabular}

November

Average similarity: 78.26

Species

Mougeotia sp.

Green

Av.Abund

Contrib\%

Cum.\%

Mastogloia smithii

Diatom

9.37

51.78

51.78

Fragilaria synegrotesca

Diatom

1.55

7.4

59.17

Encyonema evergladianum

Diatom

1.23

5.84

65.02

1.16

5.6

70.61

Between Month Dissimilarity

October v. November

Species

Mougeotia sp.

Lyngbya sp.

Encyonema evergladianum

Brachysira aponina

Cymbella Sp.

Gomphonema vibrioides

Schizothrix sp.

Mastogloia smithii

Fragilaria synegrotesca

Navicula radiosa

Peridinium sp.
Average dissimilarity $=62.54$

\section{October November}

Av.Abund Av.Abund Contrib\% Cum.\%

Green

1.87

9.37

21.02

21.02

Cyanobacteria

0.72

10.28

31.31

Diatom

4.07

1.16

8.2

39.51

Diatom

3.62

0.73

8.09

47.6

2.7

0.67

5.74

53.34

Diatom

2.2

0.93

3.85

57.2

Cyanobacteria

0.53

3.68

60.87

Diatom

2.55

1.55

2.96

63.83

Diatom

2.24

1.23

2.92

66.75

Diatom

0.96

0.52

2.4

69.15

Cryptophyte

0.73

0.29

2.19

71.35 
Table 5. Within month similarity and between month dissimilarity of algal species relative abundances for periphyton samples.

Within Month Similarity

\begin{tabular}{llccc}
\hline October & \multicolumn{4}{c}{ Average similarity: 74.57 } \\
Species & Type & Av.Abund & Contrib\% & Cum.\% \\
Lyngbya sp. & Cyanobacteria & 5.22 & 17.87 & 17.87 \\
Encyonema evergladianum & Diatom & 3.45 & 12.07 & 29.94 \\
Mastogloia smithii & Diatom & 3.13 & 10.37 & 40.31 \\
Fragilaria synegrotesca & Diatom & 2.84 & 9.51 & 49.82 \\
Brachysira aponina & Diatom & 2.49 & 8.62 & 58.44 \\
Cymbella Sp. & Diatom & 2.58 & 8.08 & 66.52 \\
Schizothrix $s p$. & Cyanobacteria & 2.51 & 7.07 & 73.59
\end{tabular}

November

Average similarity: 75.99

Species

Mougeotia sp.

Lyngbya sp.

Encyonema evergladianum

Fragilaria synegrotesca

Mastogloia smithii

Brachysira aponina
Av.Abund

Green

Cyanobacteria

Diatom

Diatom

Diatom

Diatom
7.79

2.79

2.34

1.97

2.07

1.5

$\begin{array}{cc}\text { Contrib\% } & \text { Cum.\% } \\ 32.39 & 32.39 \\ 10.51 & 42.9 \\ 8.88 & 51.78 \\ 7.7 & 59.48 \\ 7.57 & 67.05 \\ 6.06 & 73.11\end{array}$

Between Month Dissimilarity

October v. November

Average dissimilarity $=42.97$

Species

Mougeotia sp.

Lyngbya sp.

Cymbella $S p$.

Schizothrix sp.

Encyonema evergladianum

Mastogloia smithii

Brachysira aponina

Gomphonema vibrioides

Fragilaria synegrotesca

Scytonema sp.

Navicula radiosa

Nitzschia scalaris

Fragilaria ulna
October November

Av.Abund Av.Abund

Green

1.17

7.79

2.79

1.2

1.62

2.34

2.07

1.5

0.75

1.97

0

0.75

0.49

0.82

Diatom

0

\begin{tabular}{cc} 
Contrib\% & Cum.\% \\
23.55 & 23.55 \\
8.66 & 32.21 \\
5.03 & 37.24 \\
4.94 & 42.18 \\
4.12 & 46.29 \\
4.05 & 50.34 \\
3.51 & 53.85 \\
3.46 & 57.31 \\
3.25 & 60.56 \\
2.99 & 63.55 \\
2.79 & 66.34 \\
2.44 & 68.78 \\
1.99 & 70.77 \\
\hline
\end{tabular}




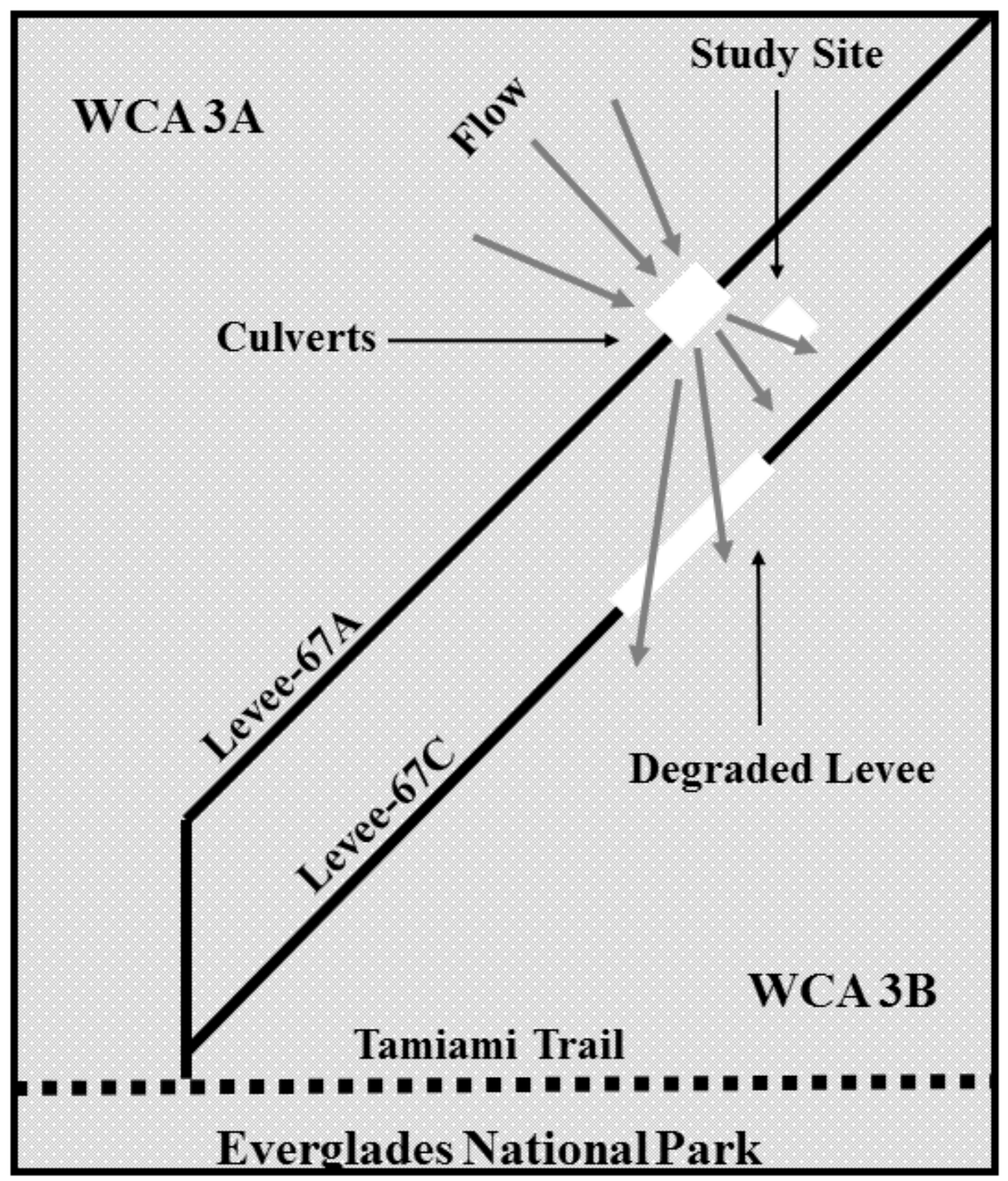

Figure 1. Map of study area. 


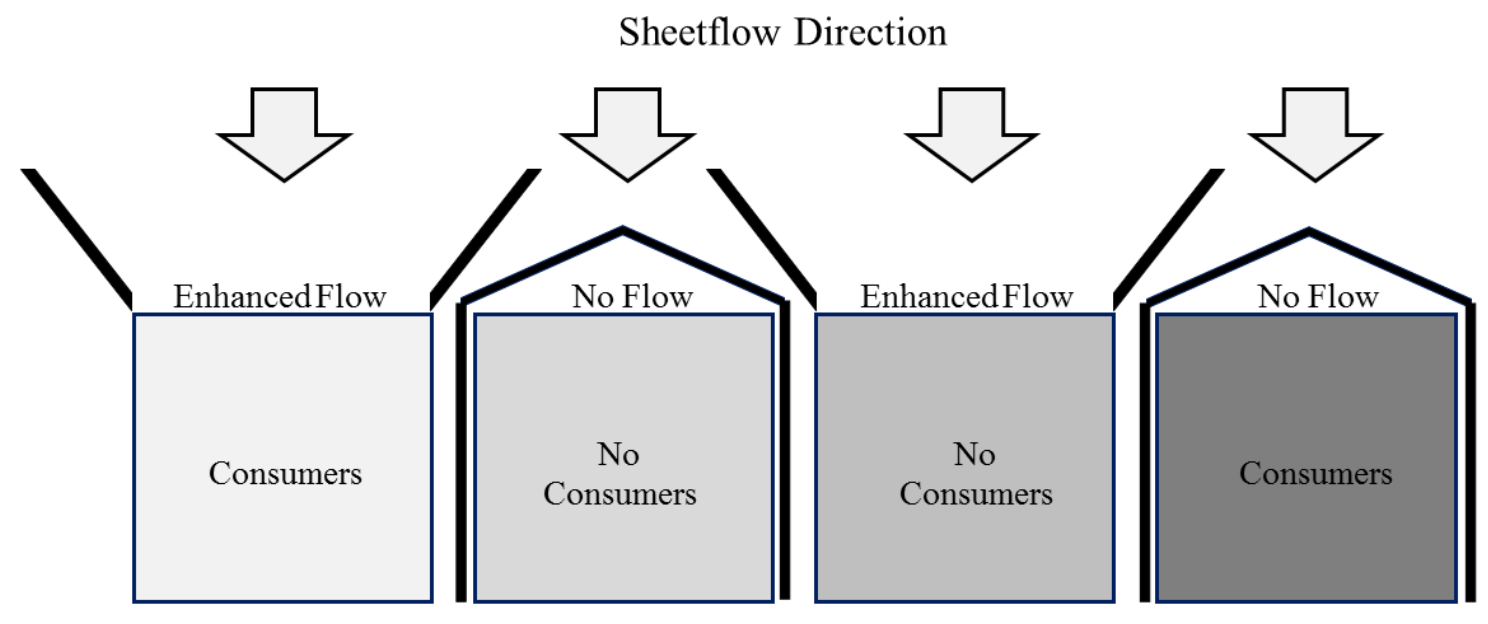

Figure 2. Diagram of a single block with four treatment cages in the field experiment and its orientation within the path of flow. 

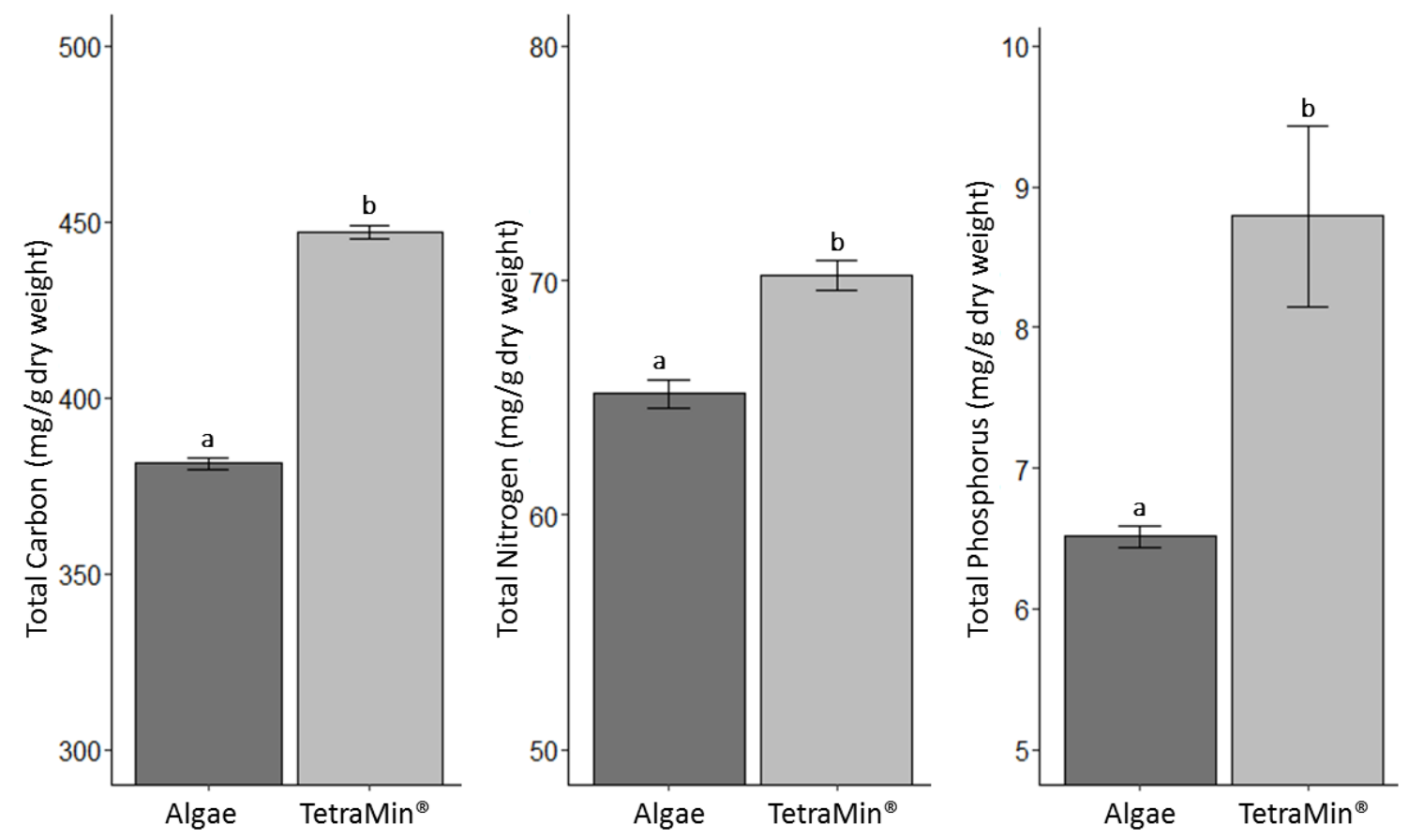

Figure 3. Total nutrient stoichiometry from laboratory experiment diets. Bars represent means of at least 3 samples; error bars represent one SE. Bars with the same letter indicate no significant differences at $\mathrm{p}<0.05$ for Tukey's test. 


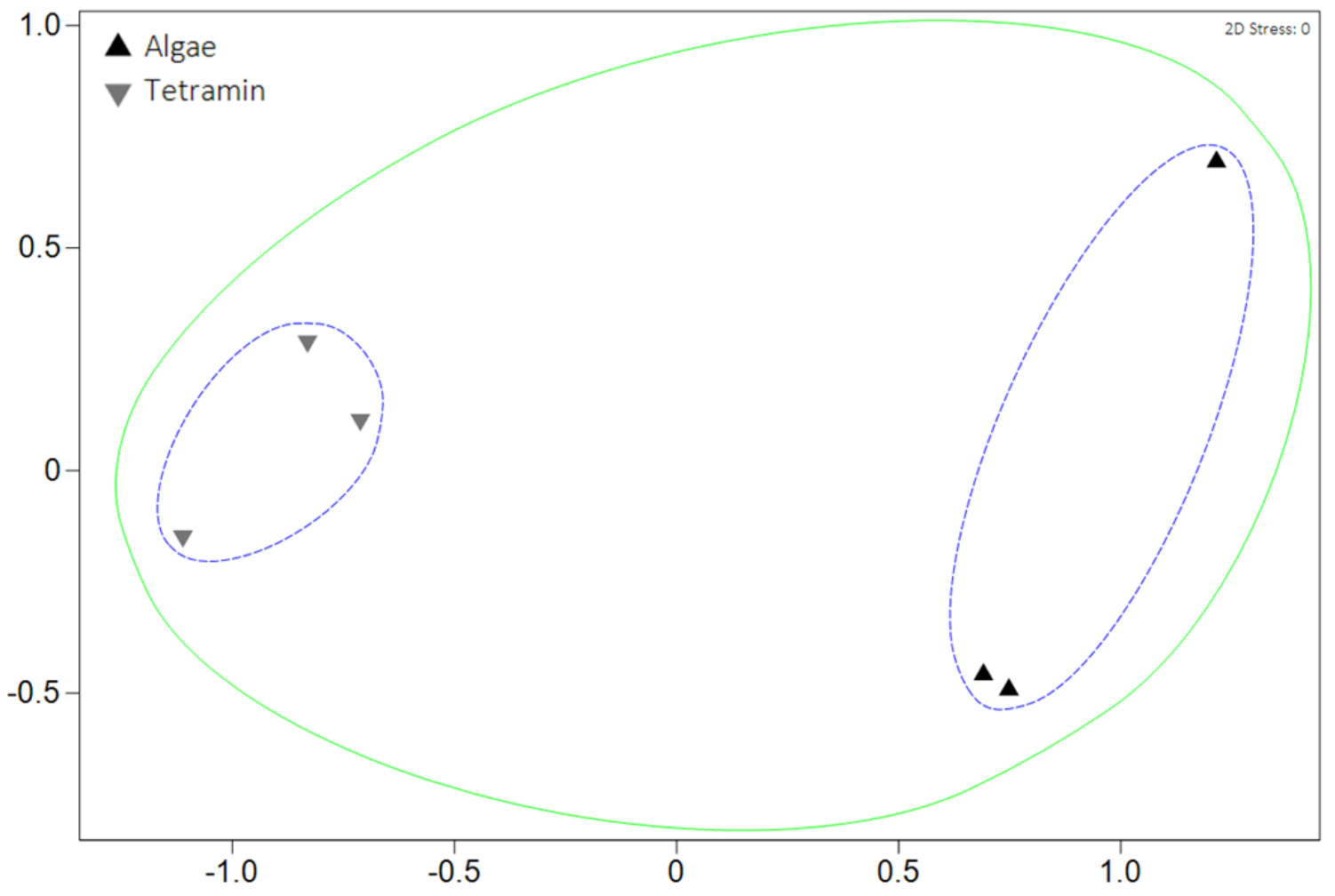

FIGURE 4. Two dimensional non-metric multidimensional scaling ordination plot based on square root transformed FA relative abundances from experimental diets. Solid line indicates $40 \%$ similarity and dashed line indicated $80 \%$ similarity. Each symbol represents one sample with a total of 3 from each diet (Algae; TetraMin ${ }^{\circledR}$ ). 


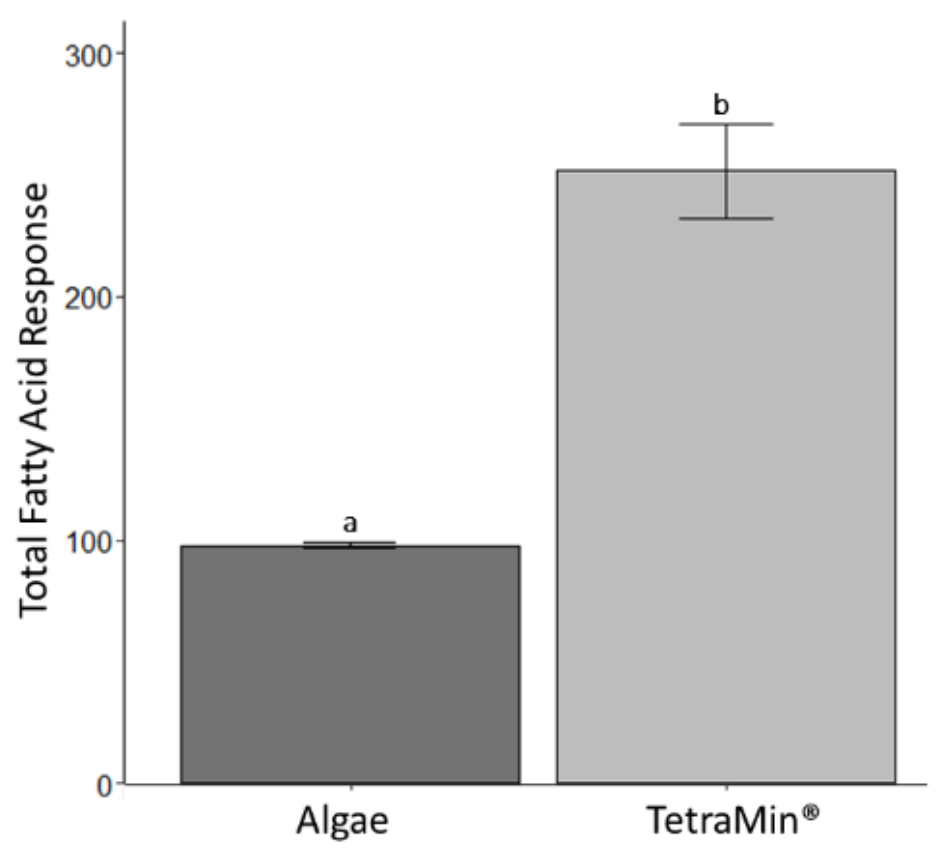

Figure 5. Total FA response of experiment diets (Algae and TetraMin ${ }^{\circledR}$ ). Bars represent means of at least 3 samples; error bars represent one SE. Bars with the same letter indicate no significant differences at $\mathrm{p}<0.05$ for Tukey's test. 


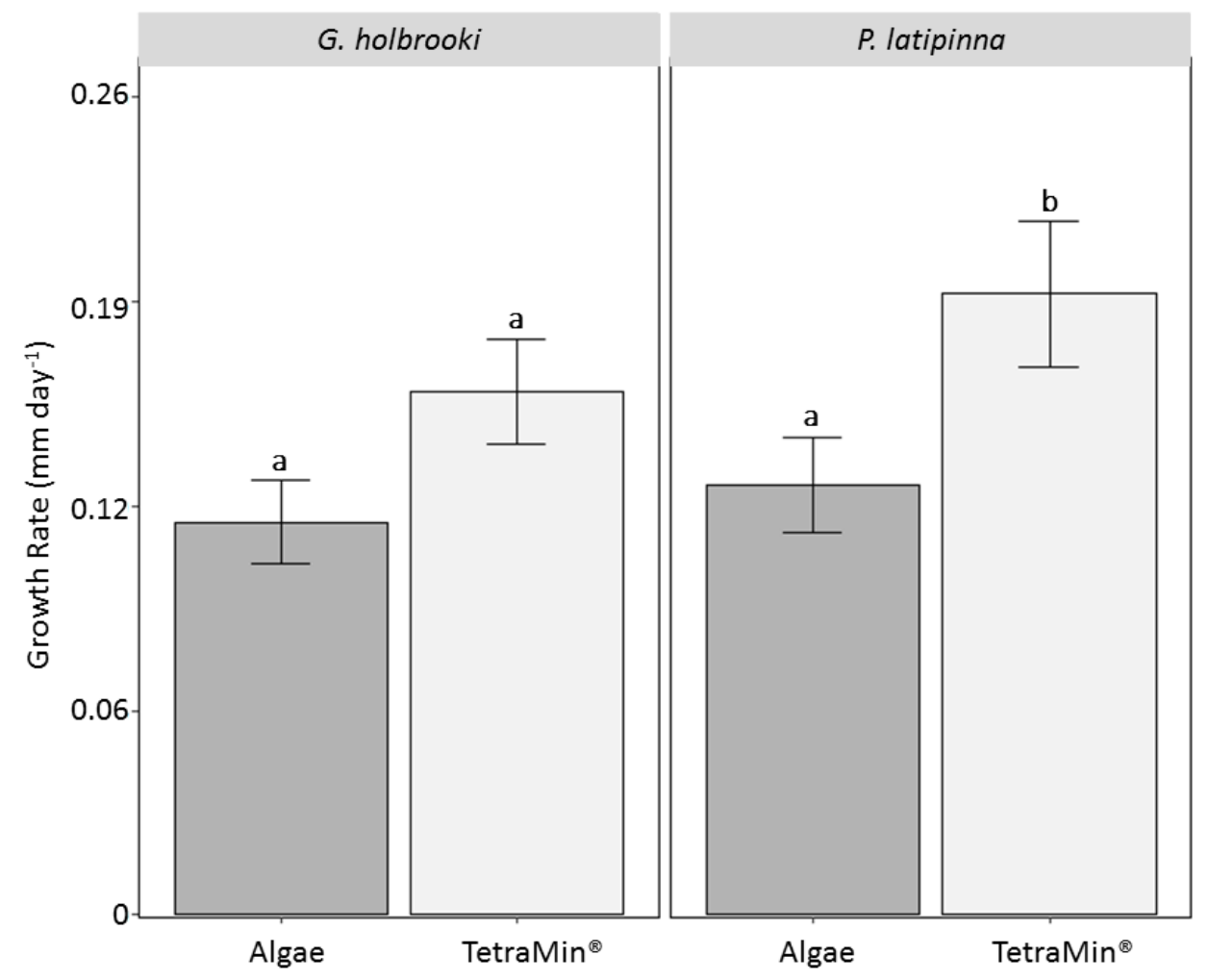

Figure 6. Growth rate of consumers (G. holbrooki; P. latipinna) at 3 weeks from laboratory experiments on full-Algae and full-TetraMin ${ }^{\circledR}$ experimental diets. Bars represent means of 3 samples; error bars represent one SE. Bars with the same letter indicate no significant differences at $\mathrm{p}<0.05$ for Tukey's test. 


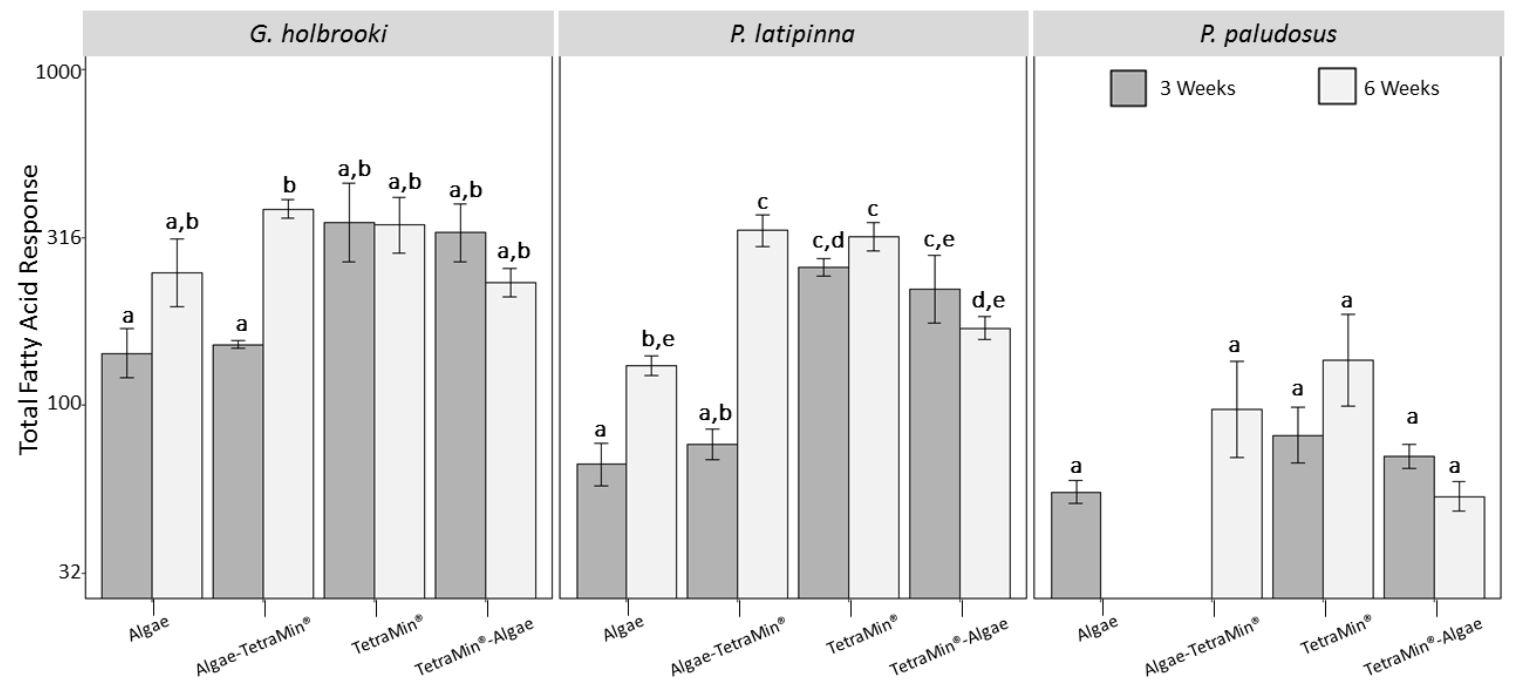

Figure 7. Total FA response of consumers (G. holbrooki; P. latipinna; P. paludosus) from laboratory experiments including those on each diet (full-Algae; full-TetraMin®; Algae to TetraMin $®$; TetraMin $®$ to Algae) and sampling period (3 weeks and 6 weeks). Bars represent means of 3 samples; error bars represent one SE. Bars with the same letter indicate no significant differences at $\mathrm{p}<0.05$ for Tukey's test. 

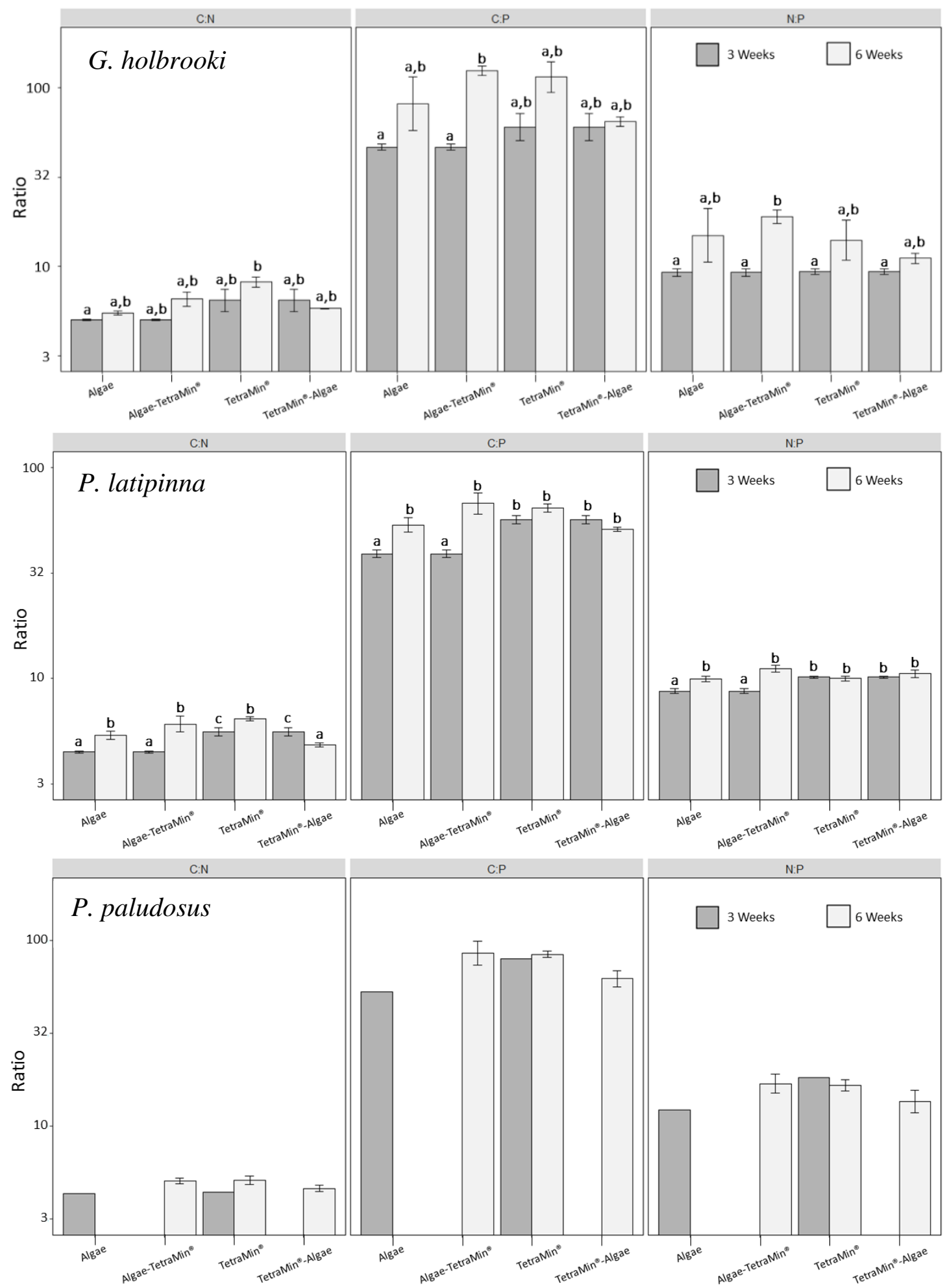

Figure 8. Consumer stoichiometric nutrient ratios from laboratory experiment. Bars represent means of at least 3 samples; error bars represent one SE. 


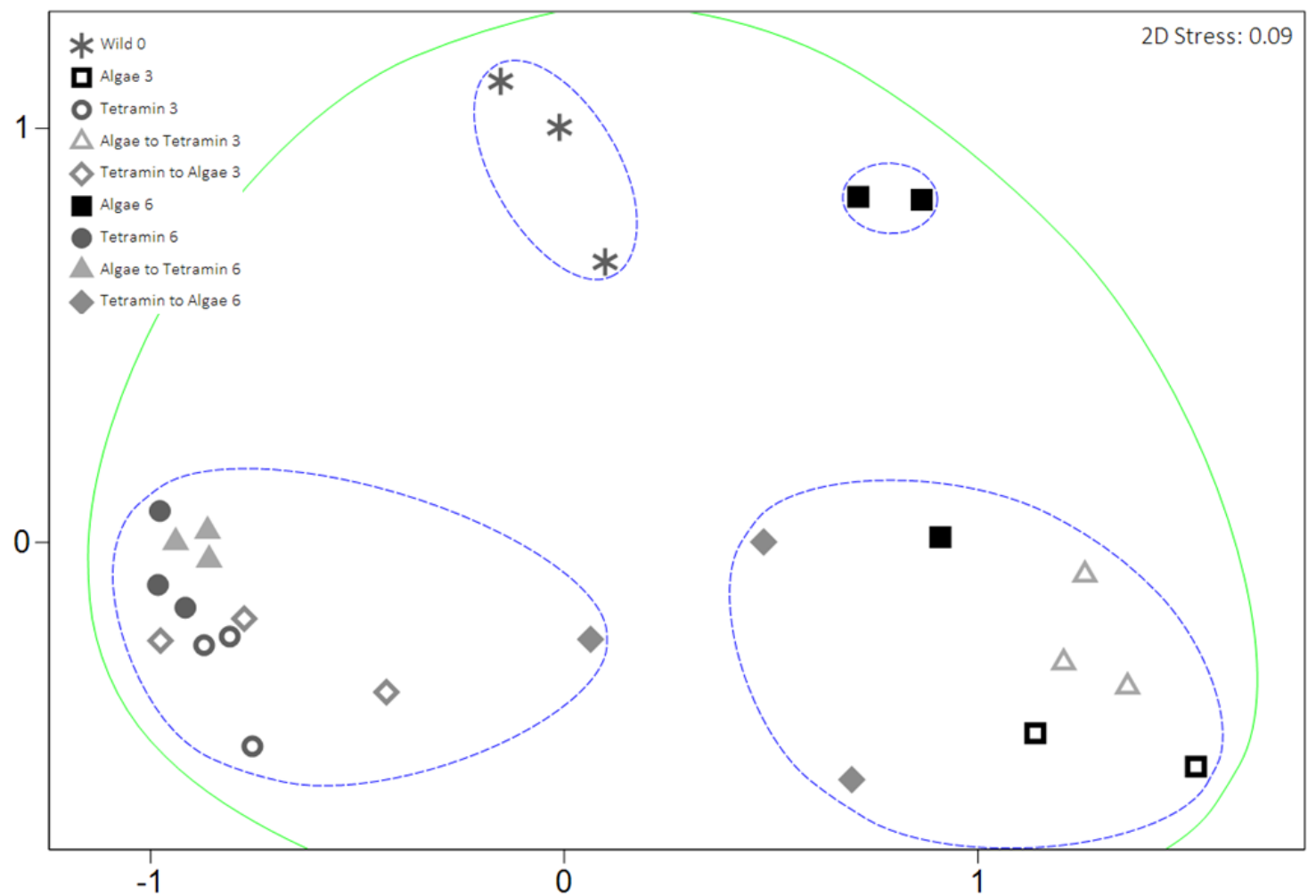

Figure 9. Two dimensional non-metric multidimensional scaling ordination plot based on square root transformed $P$. latipinna FA relative abundances from the laboratory experiment. Solid line indicates $60 \%$ similarity and dashed line indicated $80 \%$ similarity. Each symbol represents one fish with a total of 3 from each diet (full-Algae; fullTetraMin ${ }^{\circledR}$; Algae to TetraMin ${ }^{\circledR}$; TetraMin ${ }^{\circledR}$ to Algae) and sampling period (wild, 3 weeks and 6 weeks). 


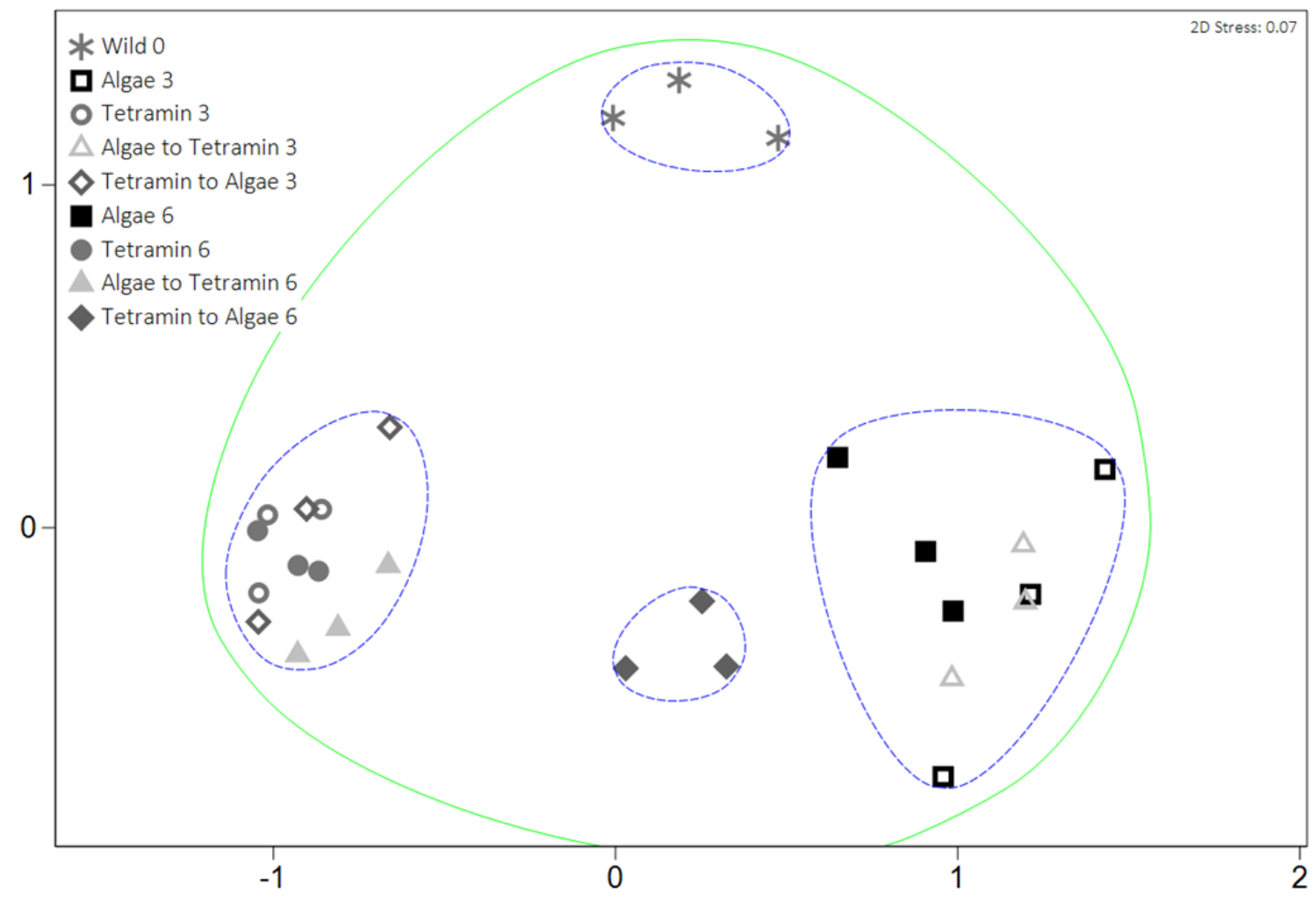

Figure 10. Two dimensional non-metric multidimensional scaling ordination plot based on square root transformed, G. holbrooki FA relative abundances from the laboratory experiment. Solid line indicates $60 \%$ similarity and dashed line indicated $84 \%$ similarity. Each symbol represents one fish with a total of 3 from each diet (full-Algae; fullTetraMin $^{\circledR}$; Algae to TetraMin ${ }^{\circledR}$; TetraMin ${ }^{\circledR}$ to Algae) and sampling period (wild, 3 weeks and 6 weeks). 


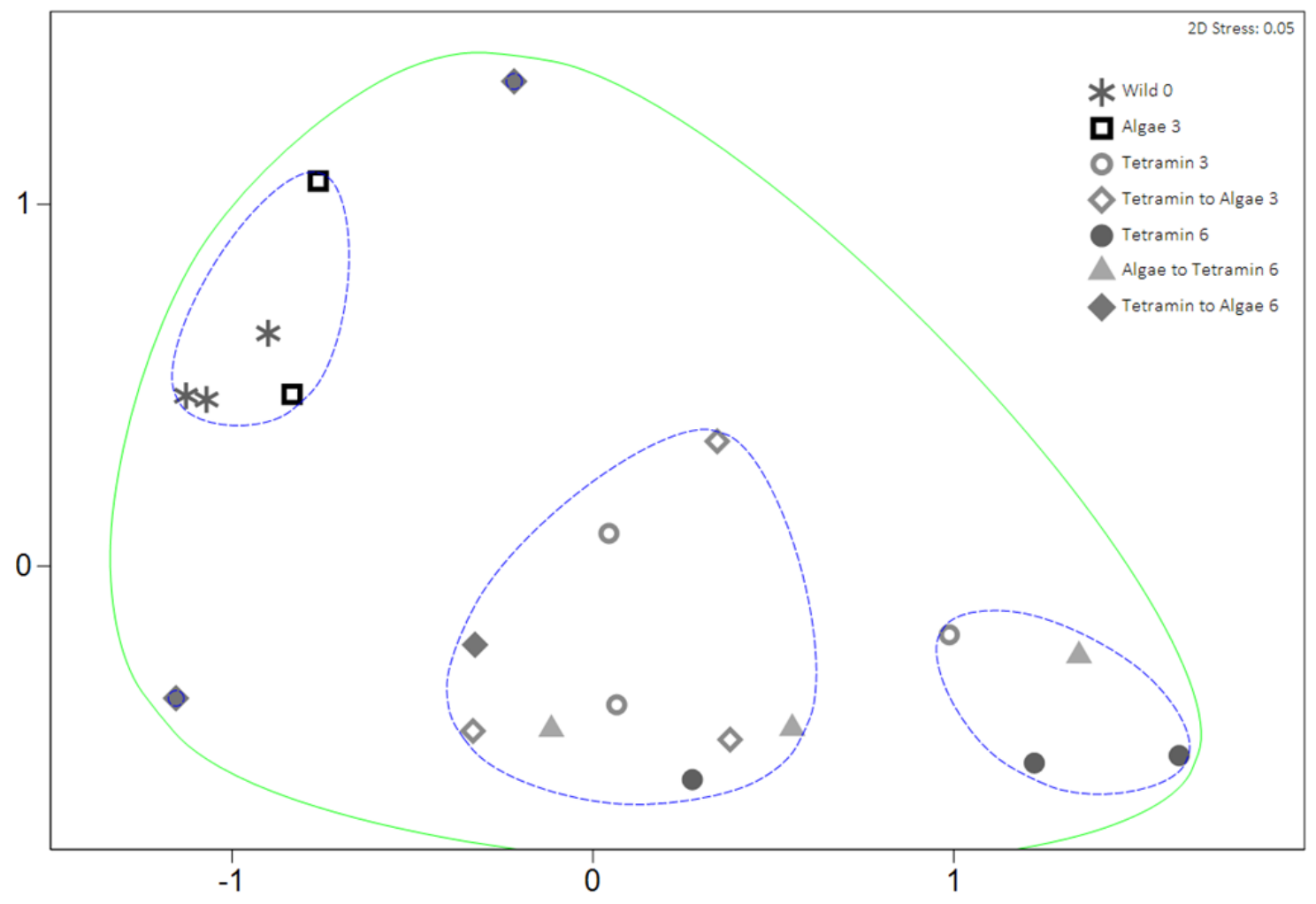

Figure 11. Two dimensional non-metric multidimensional scaling ordination plot based on square root transformed, $P$. paludosus FA relative abundance from the laboratory experiment. Solid line indicates $80 \%$ similarity and dashed line indicated $90 \%$ similarity. Each symbol represents one grass shrimp with a total of 3 from each diet (full-Algae; full-TetraMin ${ }^{\circledR}$; Algae to TetraMin ${ }^{\circledR}$; TetraMin ${ }^{\circledR}$ to Algae) and sampling period (wild, 3 weeks and 6 weeks). 

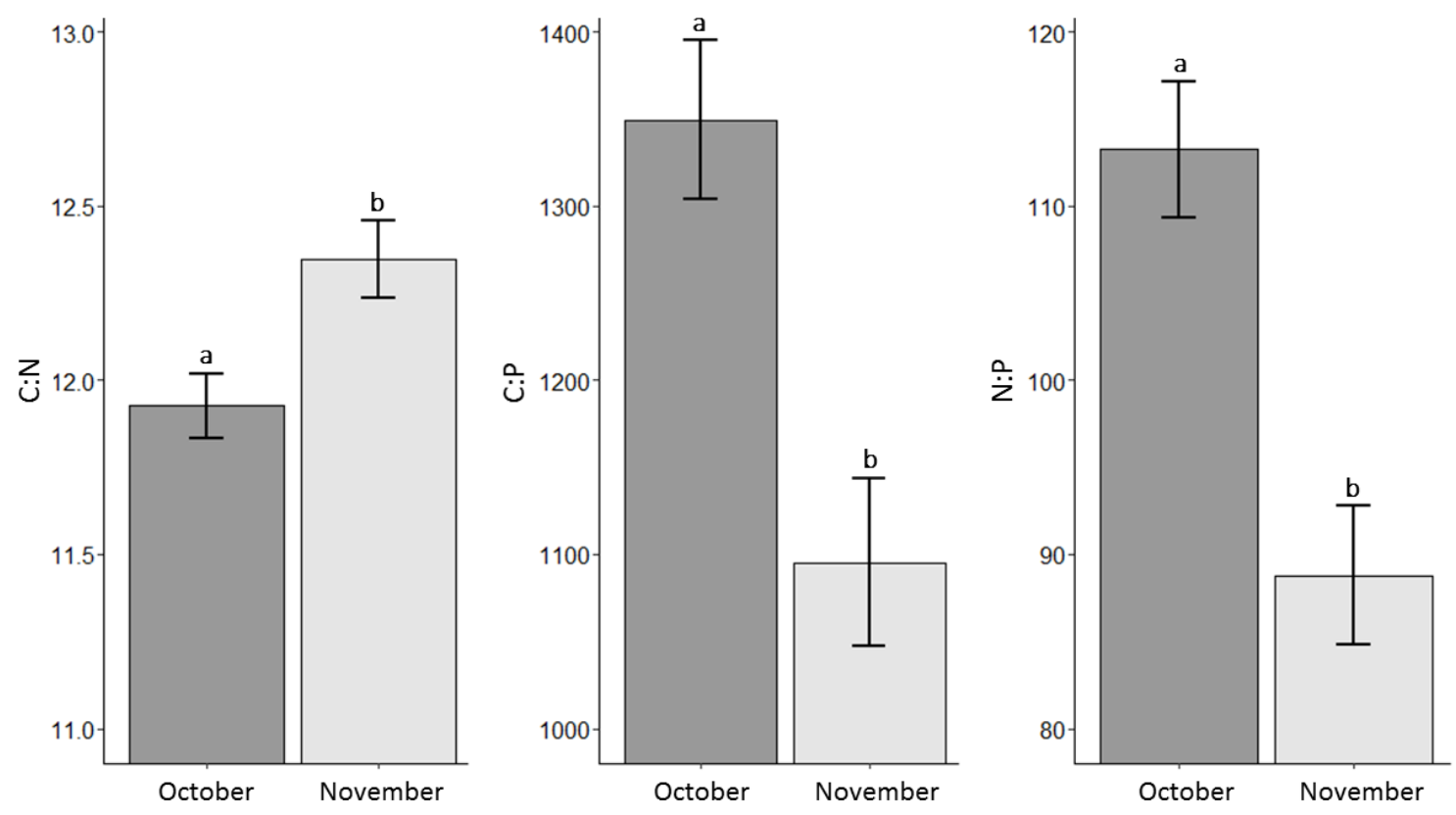

Figure 12. Biofilm stoichiometry from October and November field experiments. Bars represent means of 20 samples; error bars represent one SE of the logged ratios. Bars with the same letter indicate no significant differences at $p<0.05$ for Tukey's test. 

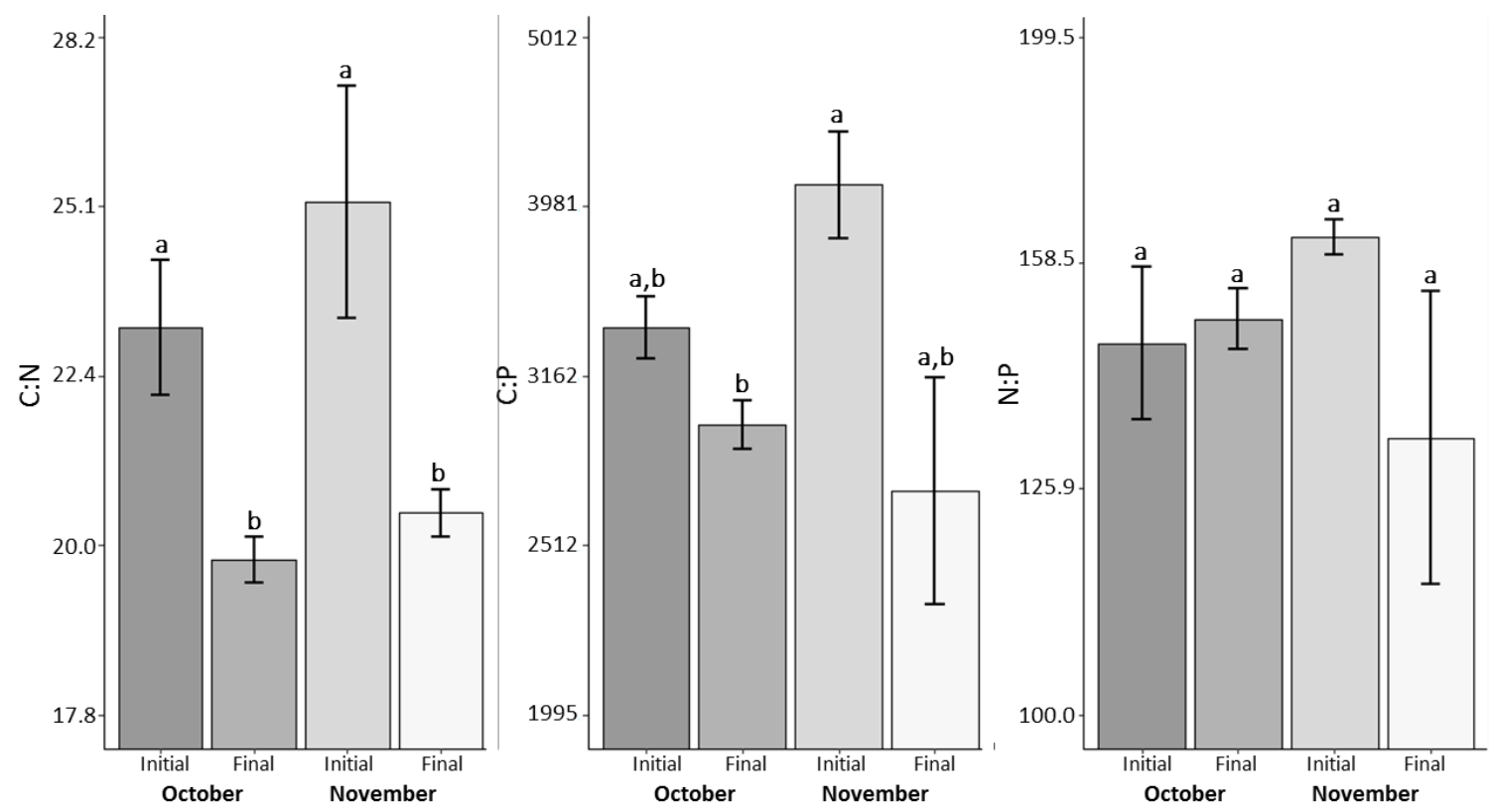

Figure 13. Periphyton stoichiometry from October and November field experiments including initial and final samples. Bars from initial samples represent means of 3 samples; bars from final samples represent means of 20 samples; error bars represent one $\mathrm{SE}$ of the logged ratios. Bars with the same letter indicate no significant differences at $\mathrm{p}<0.05$ for Tukey's test. 

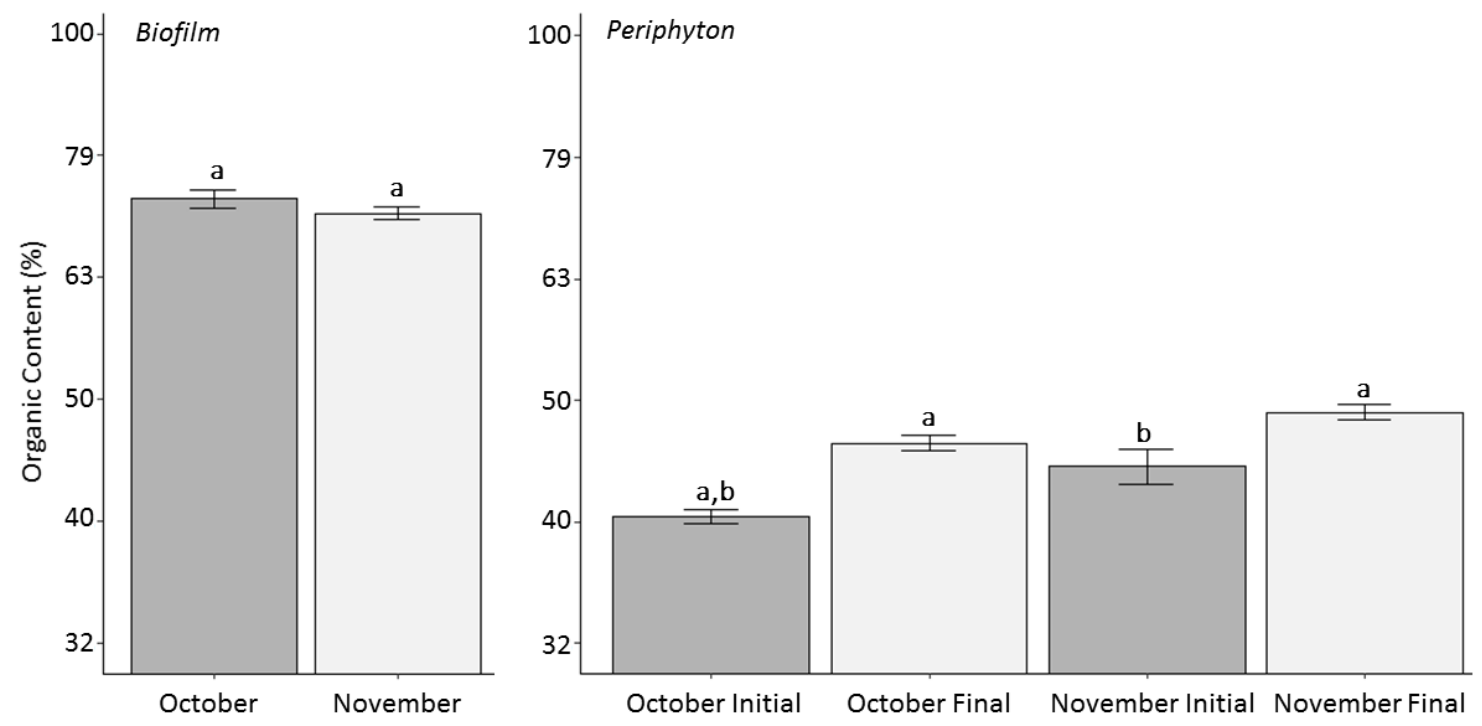

Figure 14. Percent organic content for basal resource (biofilm; periphyton) samples from October and November samples. Initial bars represent means of 3 samples; final bars represent means of 20 samples; error bars represent one SE of means. Bars with the same letter indicate no significant differences at $\mathrm{p}<0.05$ for Tukey's test. 

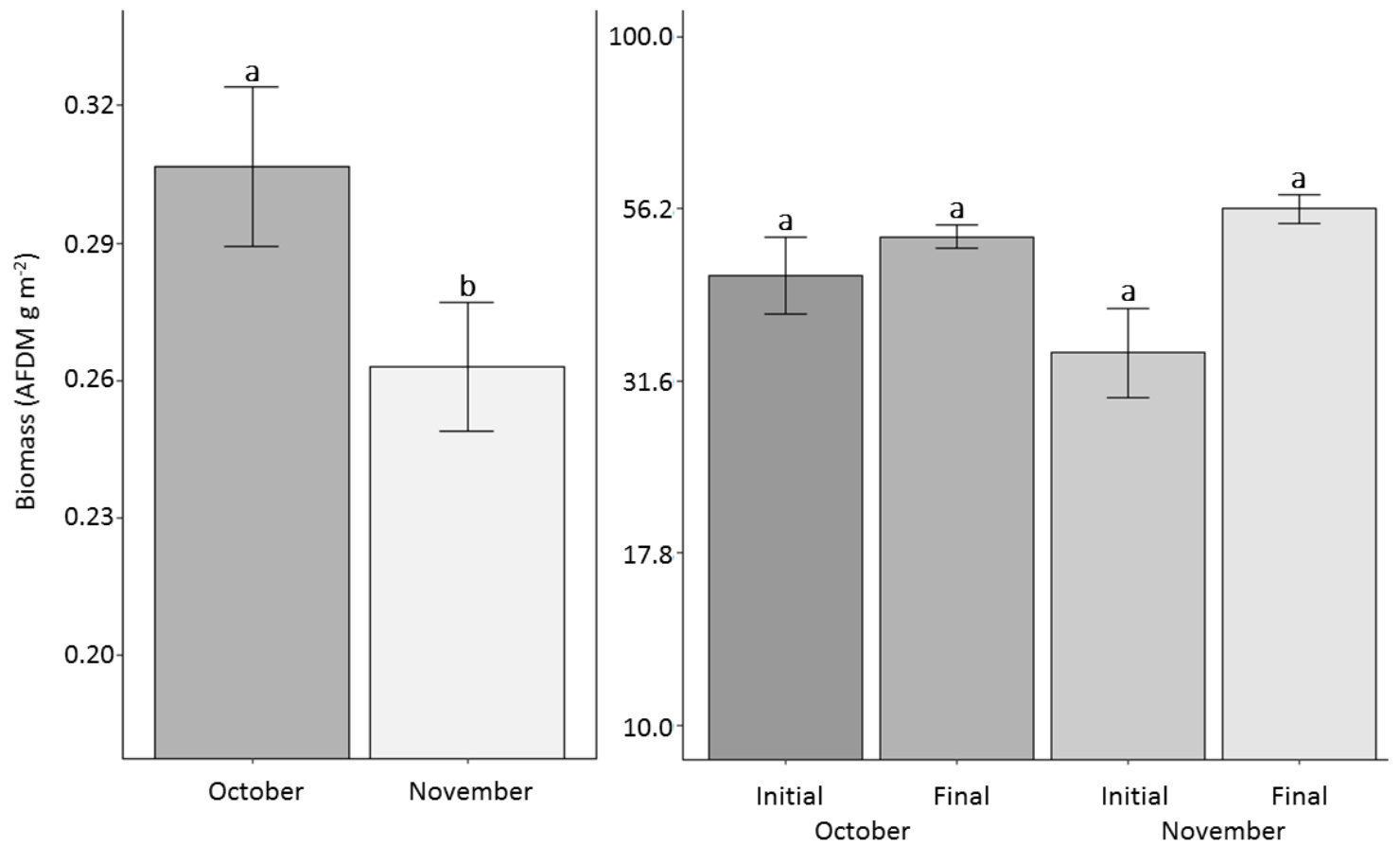

Figure 15. Biomass of basal resource (biofilm; periphyton) samples from October and November samples. Initial bars represent means of 3 samples; final bars represent means of 20 samples; error bars represent one SE of means. Bars with the same letter indicate no significant differences at $\mathrm{p}<0.05$ for Tukey's test. 


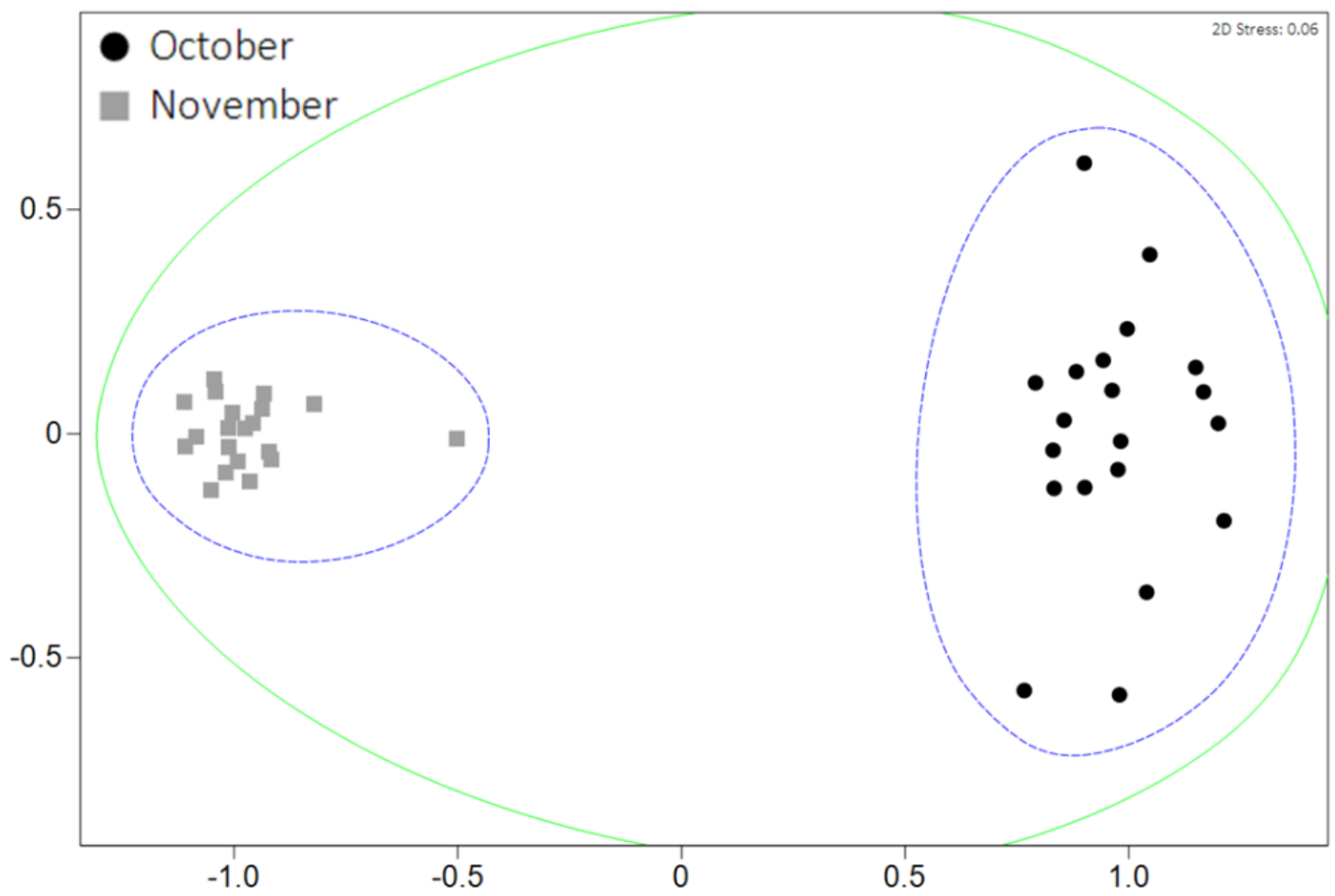

Figure 16. Two dimensional non-metric multidimensional scaling ordination plot based on biofilm algae species relative abundances from October and November field experiment, standardized by total and square root transformed. Solid line indicates $20 \%$ similarity and dashed line indicated $60 \%$ similarity. Each symbol represents one sample with a total of 20 from each time period. 


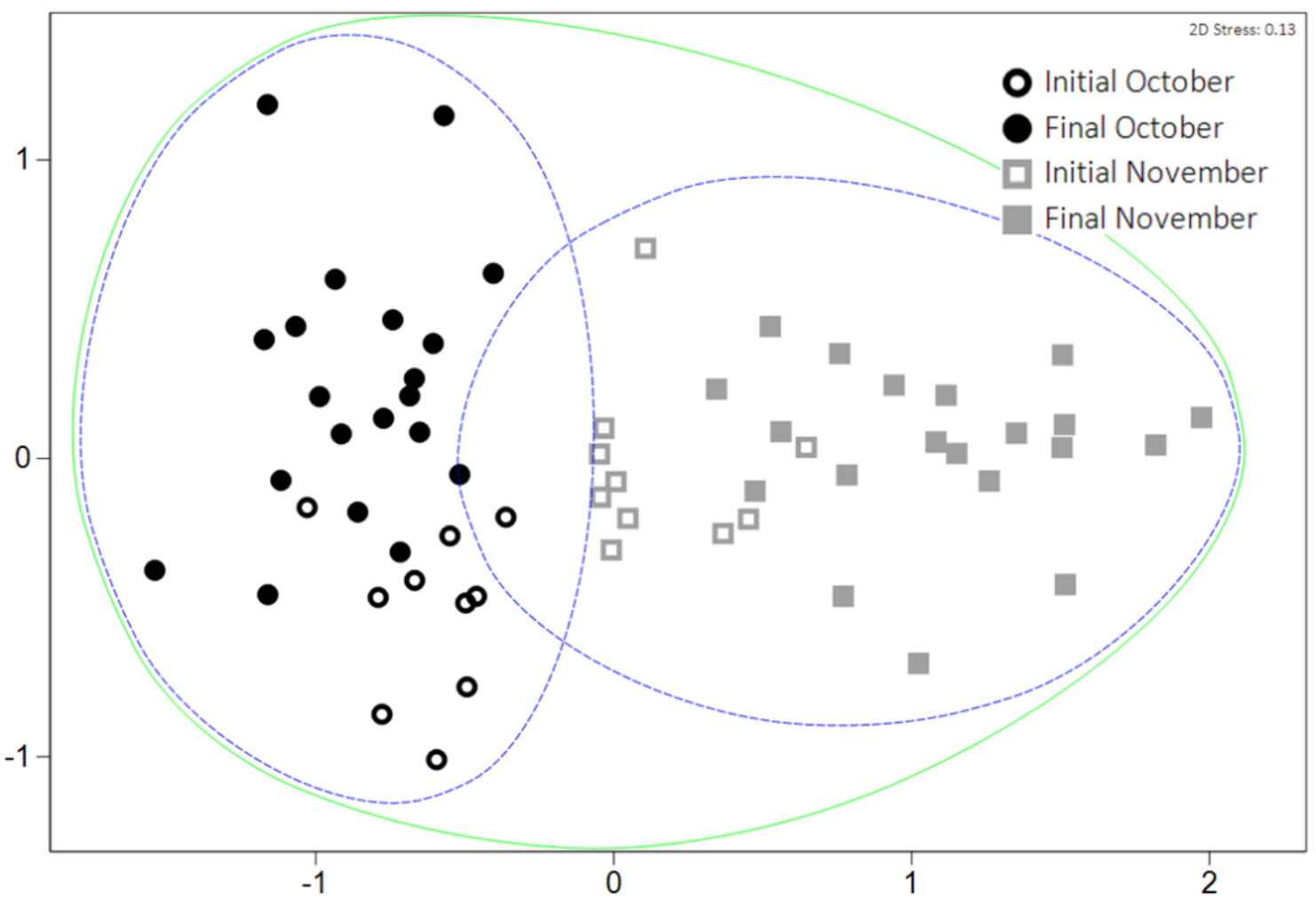

Figure 17. Two dimensional non-metric multidimensional scaling ordination plot based on periphyton algal species relative abundances from October and November field experiment, standardized by total and square root transformed, including initial and final samples. Solid line indicates $60 \%$ similarity and dashed line indicated $65 \%$ similarity.

Each symbol represents one sample with a total of 3 samples from initial sampling and 20 from each final sampling. 


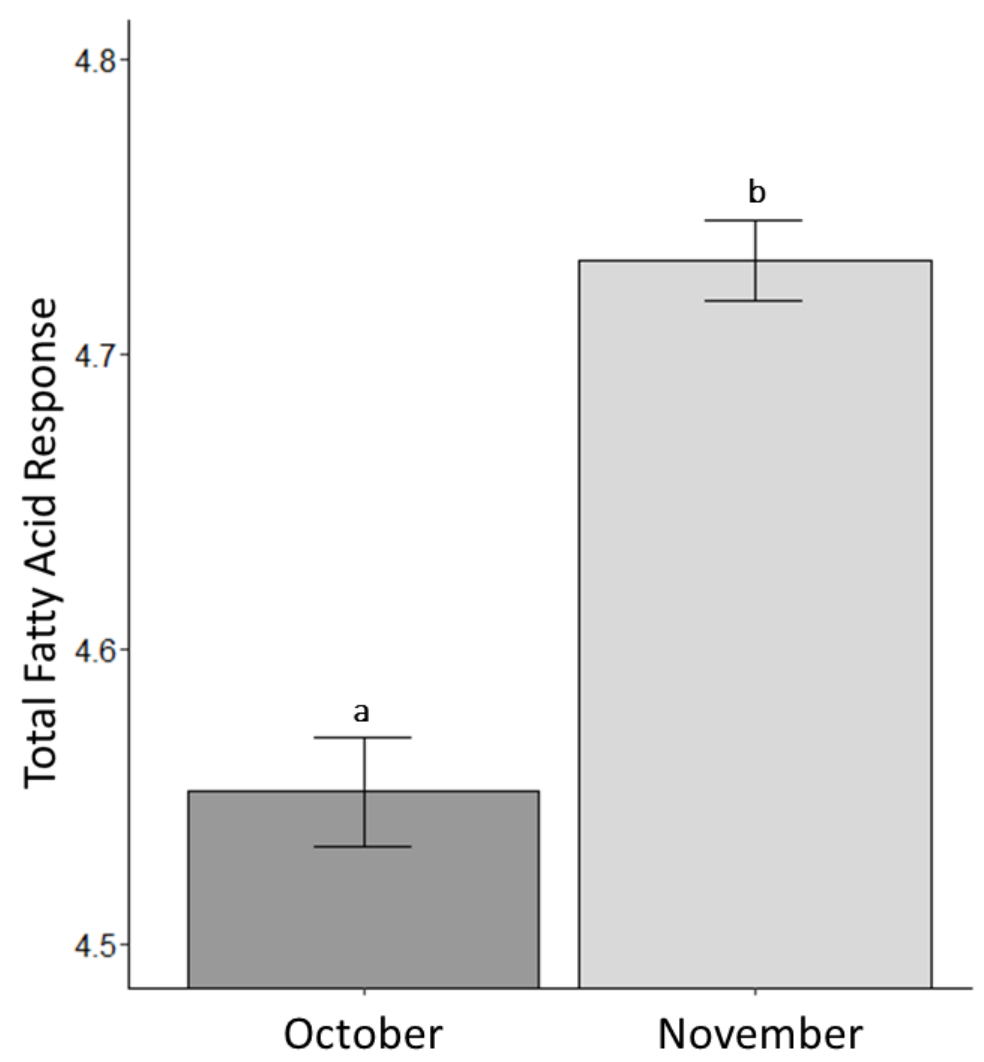

Figure 18. Total FA response of biofilm during October and November field experiments. Bars from initial samples represent means of 20 samples; error bars represent one SE of means. Bars with the same letter indicate no significant differences at $\mathrm{p}<0.05$ for Tukey's test. 


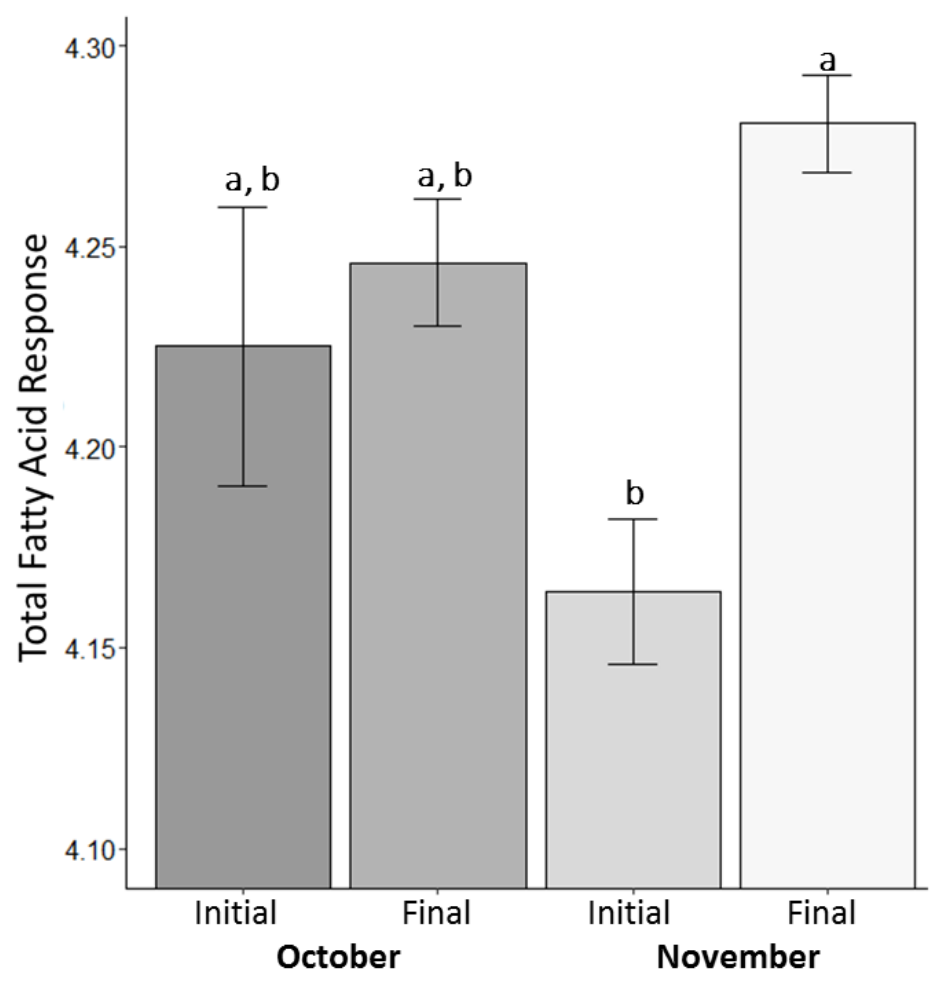

Figure 19. Total FA response for periphyton during October and November field experiments, including initial and final samples. Bars from initial samples represent means of 3 samples; bars from final samples represent means of 20 samples; error bars represent one SE of means. Bars with the same letter indicate no significant differences at $\mathrm{p}<0.05$ for Tukey's test. 


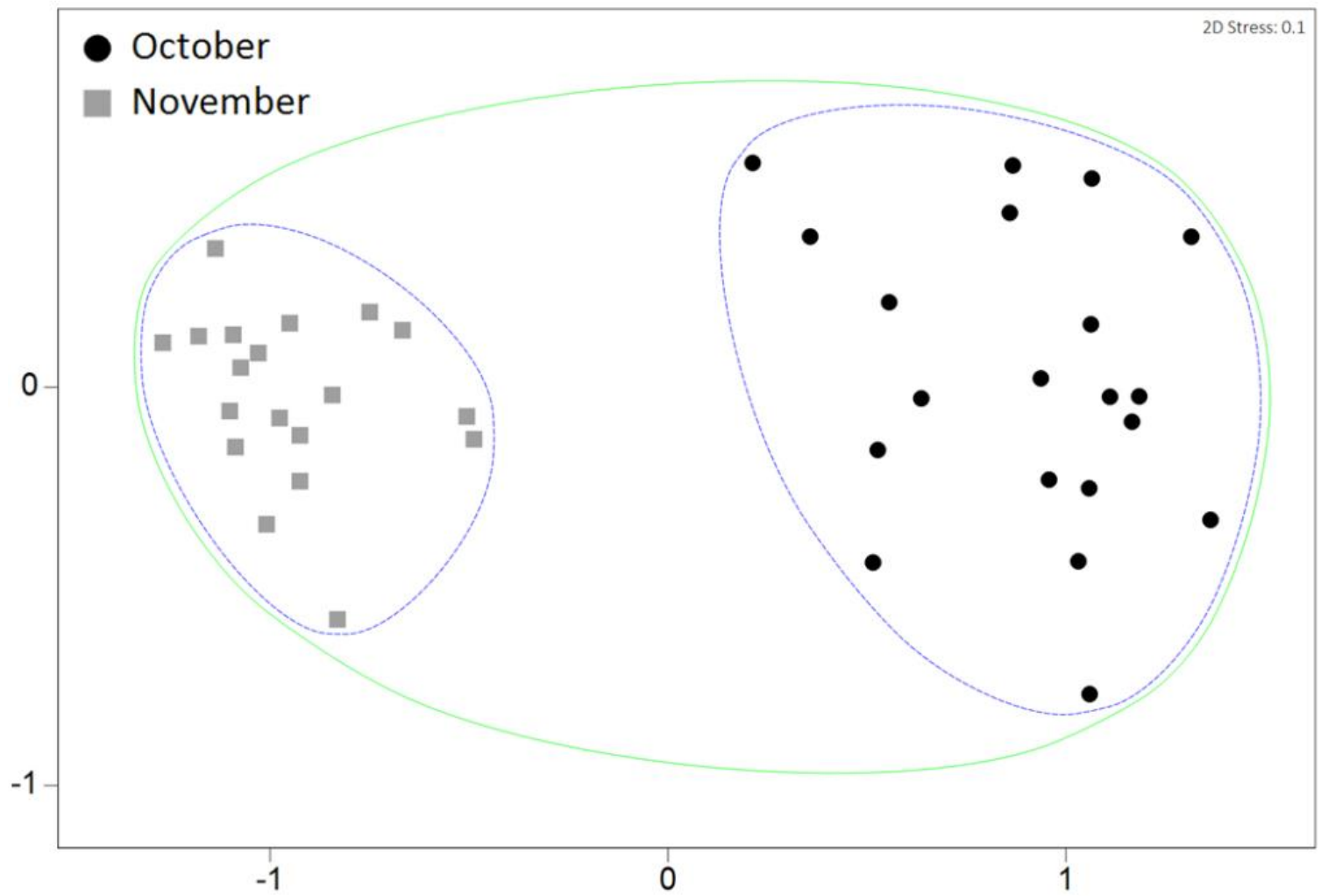

Figure 20. Two dimensional non-metric multidimensional scaling ordination plot based on square root transformed biofilm FA relative abundances from October and November field experiment. Solid line indicates $80 \%$ similarity and dashed line indicated $85 \%$ similarity. Each symbol represents one sample with a total of 20 from each time period. 


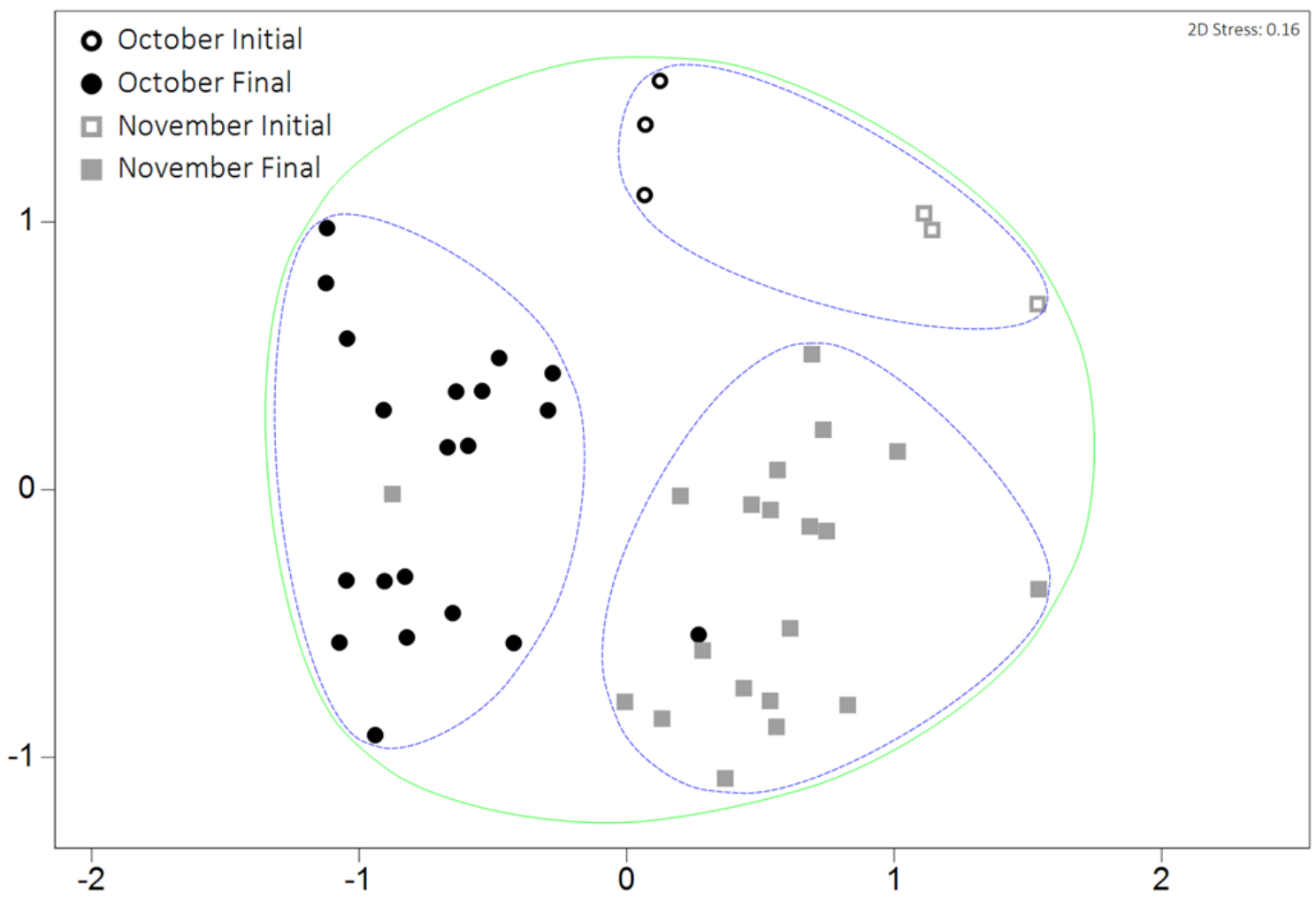

Figure 21. Two dimensional non-metric multidimensional scaling ordination plot based on periphyton square root transformed FA relative abundances from October and November field experiments including initial and final samples. Solid line indicates $80 \%$ similarity and dashed line indicated $85 \%$ similarity. Each symbol represents one sample with a total of 3 samples from initial sampling and 20 from each final sampling. 


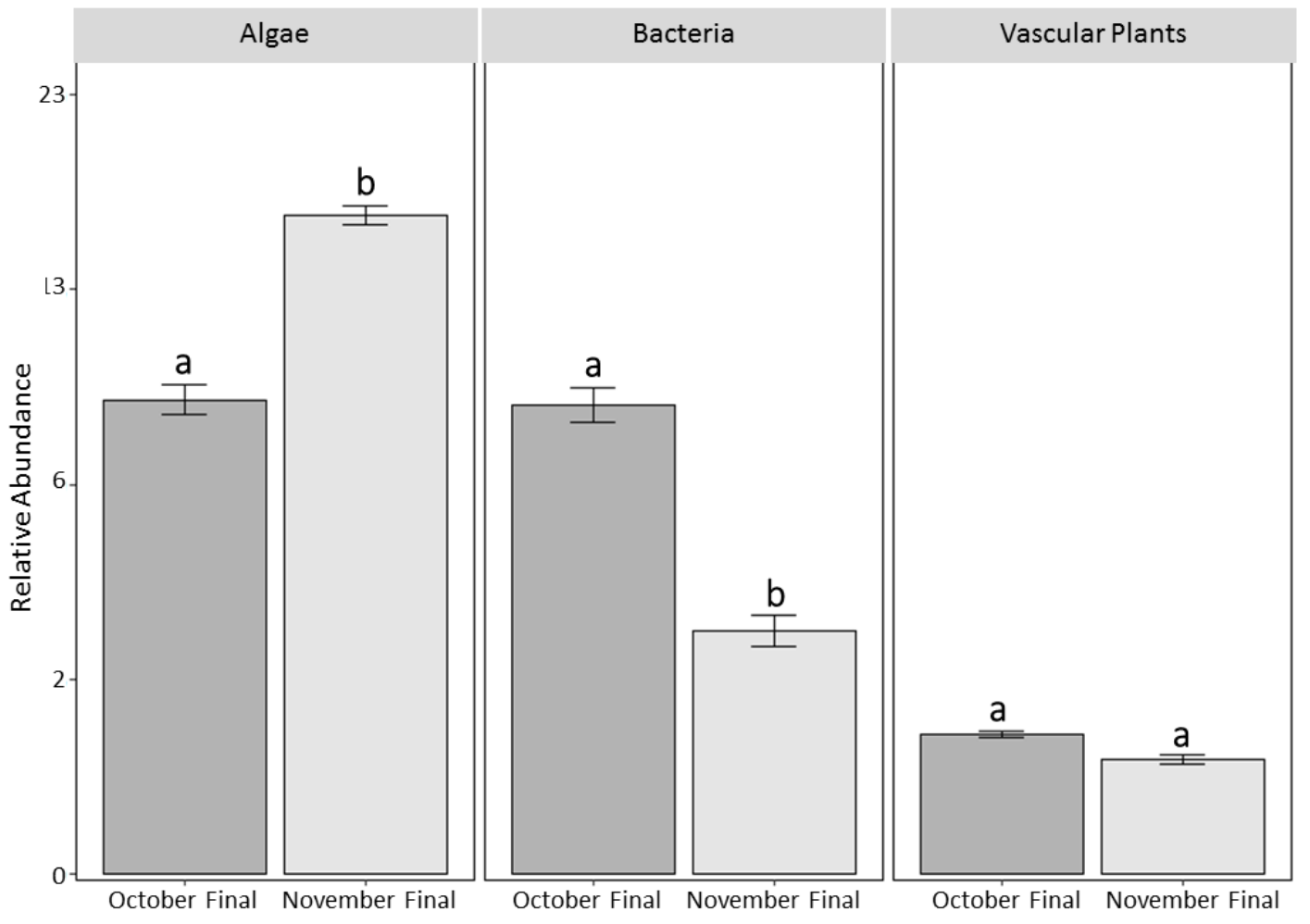

Figure 22. Relative abundance of dietary tracer FA groups (algae; bacteria; vascular plant) in biofilm samples from October and November samples. Bars represent means of 20 samples; error bars represent one SE of means. Bars with the same letter indicate no significant differences at $\mathrm{p}<0.05$ for Tukey's test. 

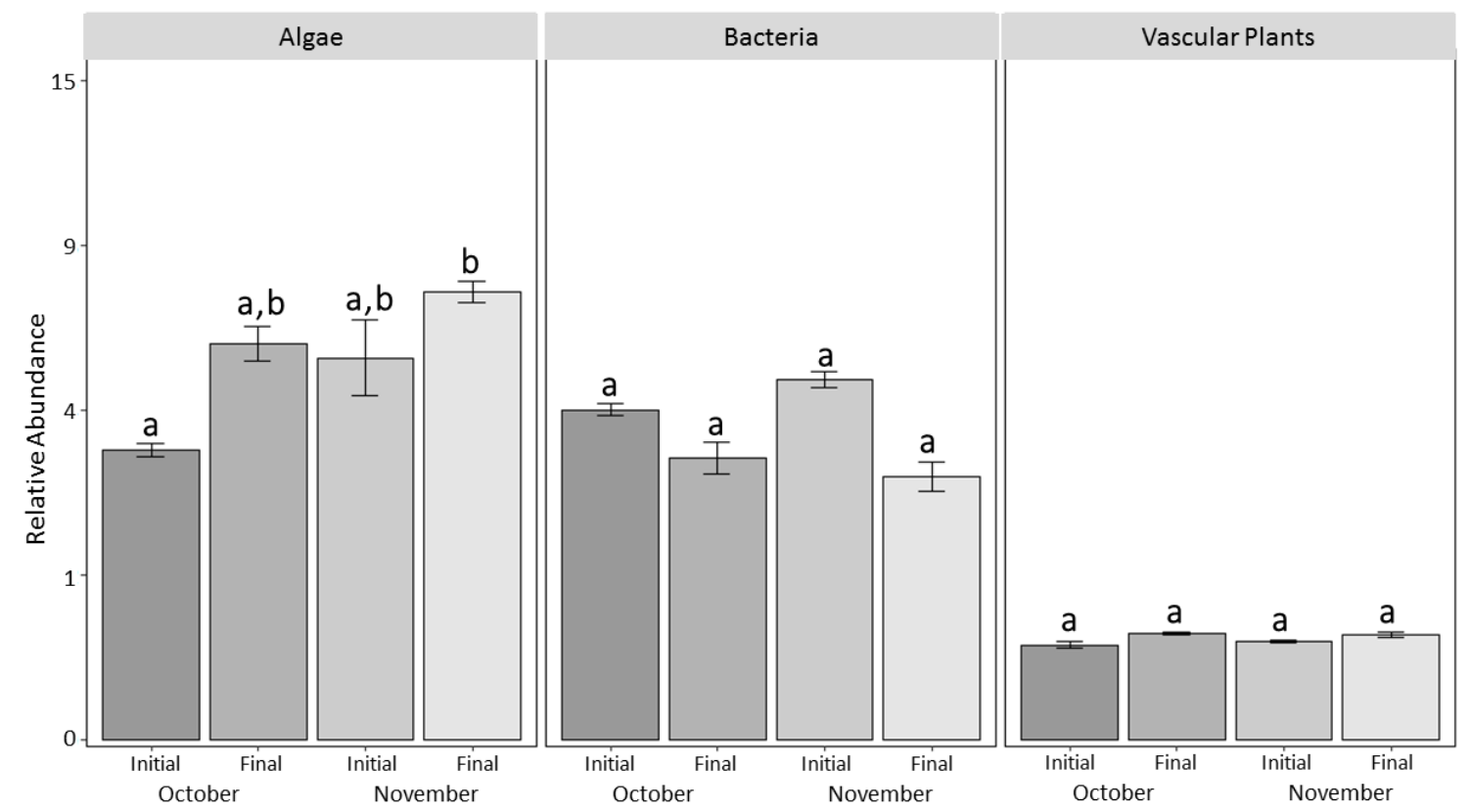

Figure 23. Relative abundance of dietary tracer FA groups (algae; bacteria; vascular plant) in periphyton samples from October and November samples, including initial and final samples. Bars represent means of 20 samples; error bars represent one SE of means. Bars with the same letter indicate no significant differences at $p<0.05$ for Tukey's test. 


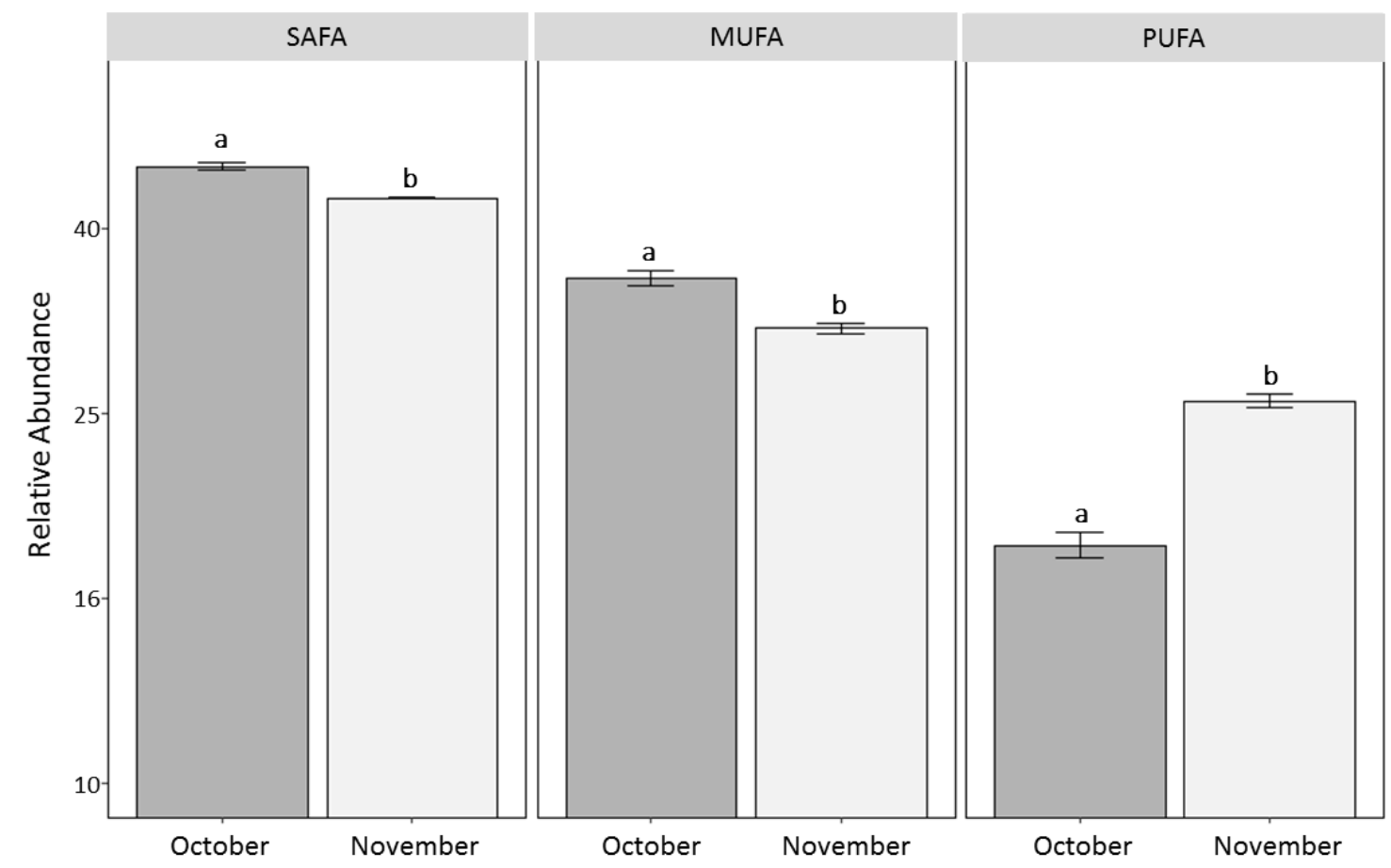

Figure 24. Relative abundance of FAs by saturation type (SAFA; MUFA; PUFA) from biofilm samples. SAFA, saturated fatty acids; MUFA, mono-unsaturated fatty acids; PUFA, poly-unsaturated fatty acids. Bars represent means of 20 samples; error bars represent one SE of means. Bars with the same letter indicate no significant differences at $\mathrm{p}<0.05$ for Tukey's test. 

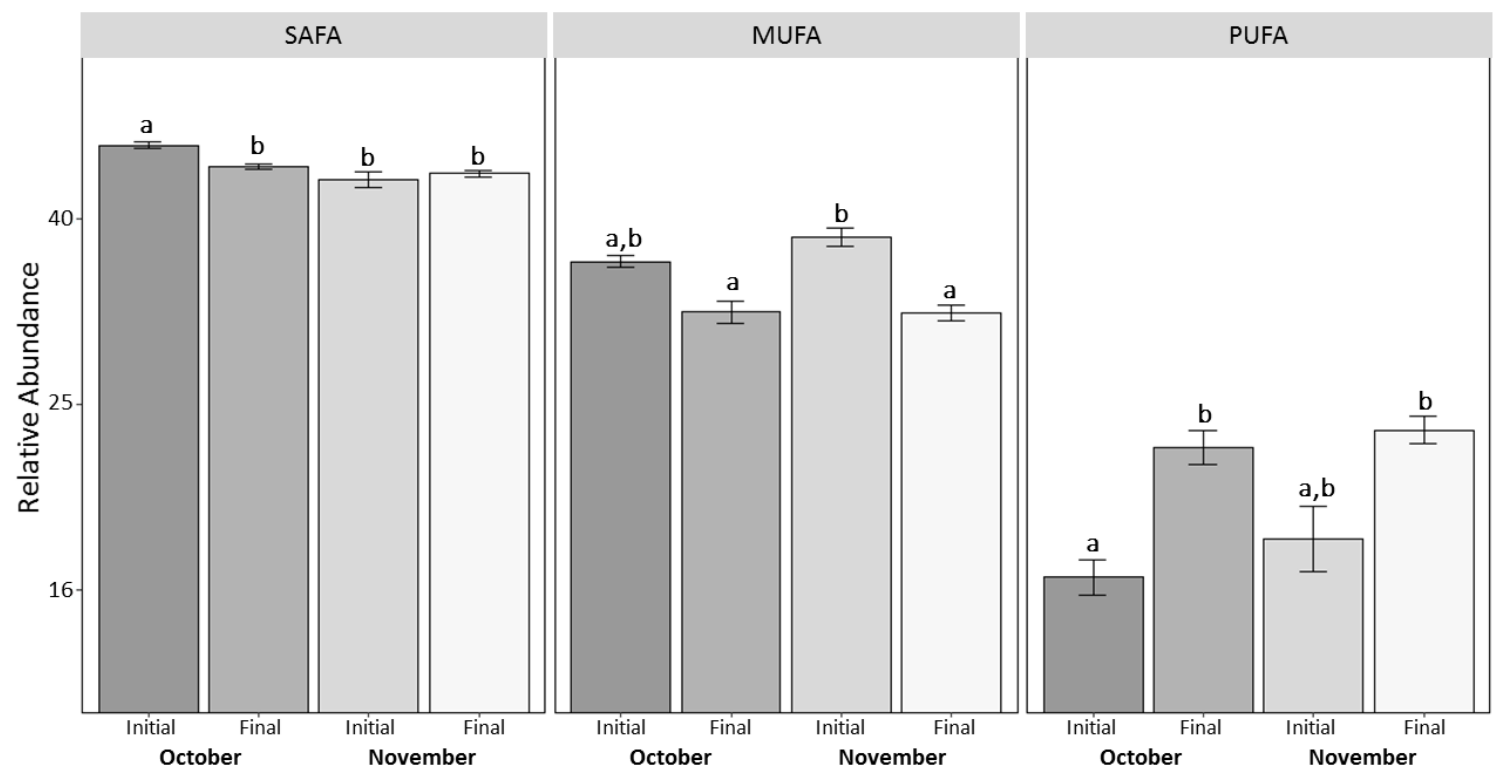

Figure 25. Relative abundance of FAs by saturation type (SAFA; MUFA; PUFA) from periphyton final and initial samples. SAFA, saturated fatty acids; MUFA, monounsaturated fatty acids; PUFA, poly-unsaturated fatty acids. Initial bars represent means of 3 samples; final bars represent means of 20 samples; error bars represent one SE of means. Bars with the same letter indicate no significant differences at $\mathrm{p}<0.05$ for Tukey's test. 


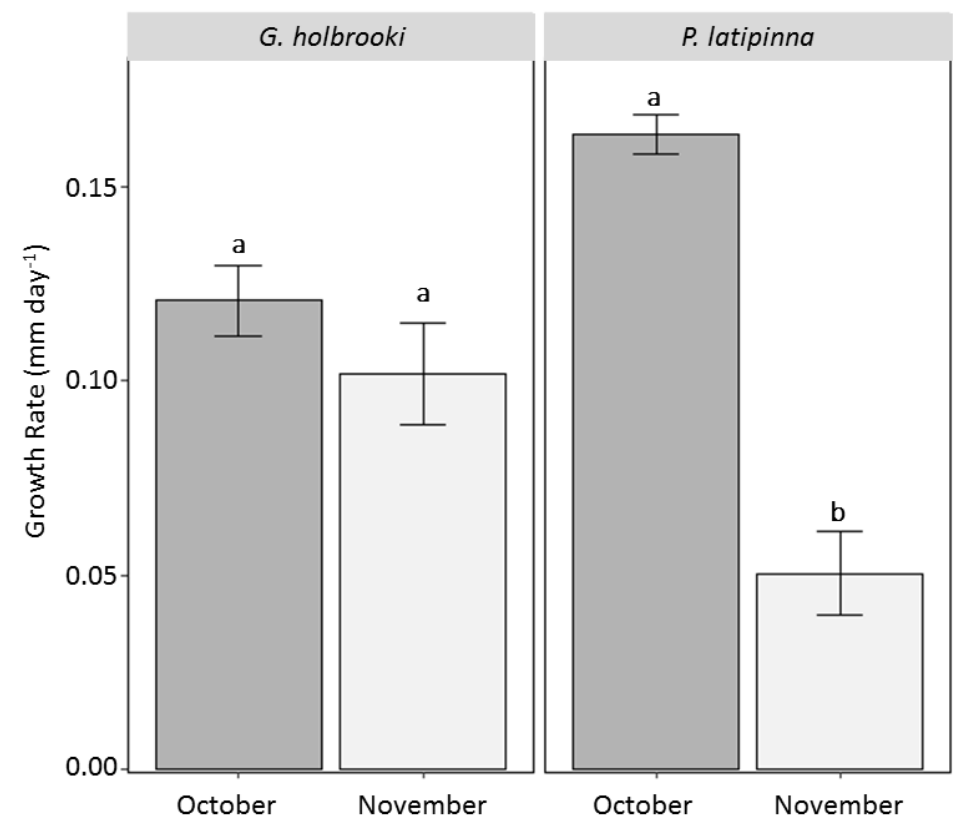

Figure 26. Growth rate of consumers ( $G$. holbrooki; P. latipinna) from field experiments (October and November). Bars represent means of at least 25 fish; error bars represent one SE. Bars with the same letter indicate no significant differences at $p<0.05$ for Tukey's test. 

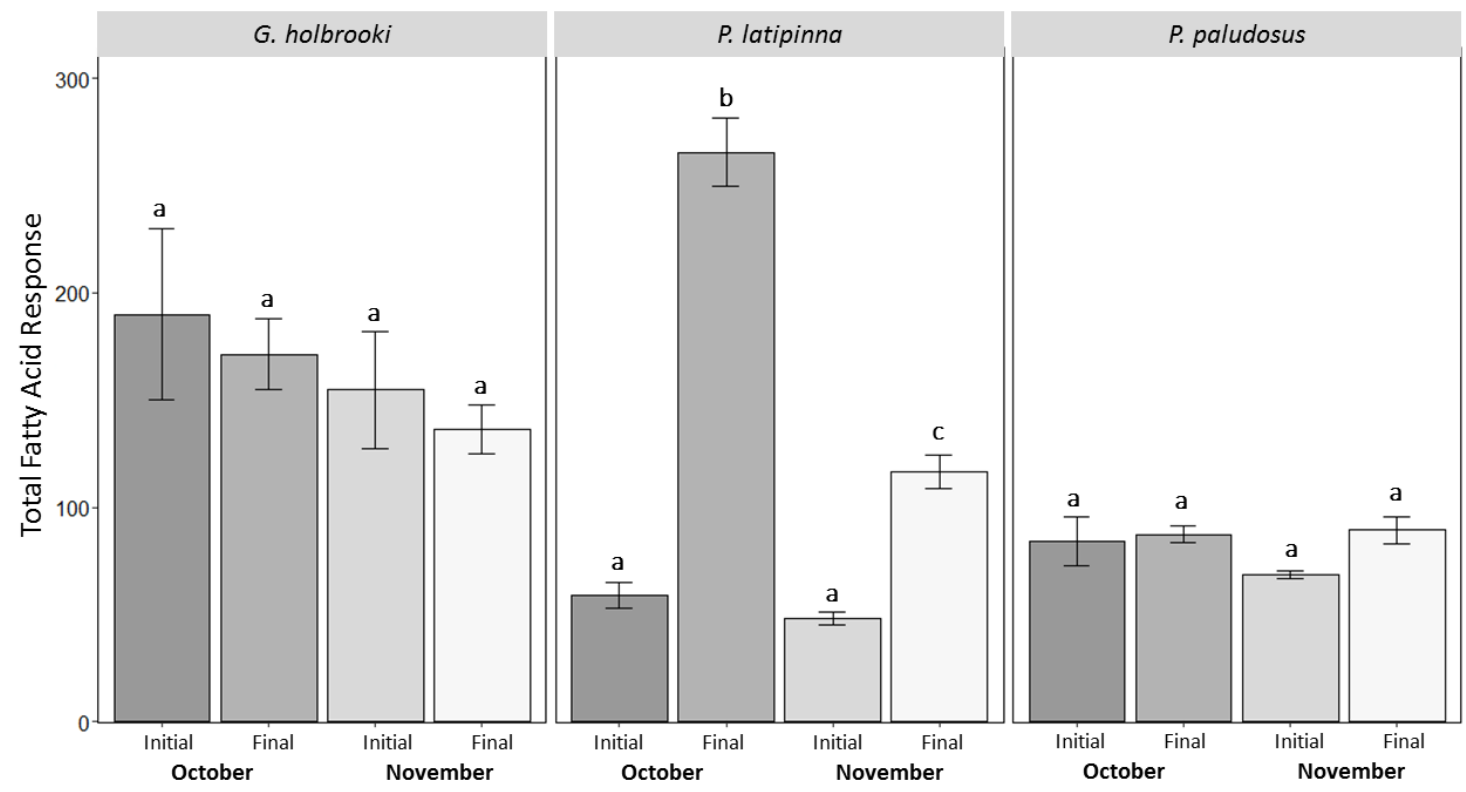

Figure 27. Total FA response of consumers (G. holbrooki; P. latipinna; P. paludosus) during October and November field experiments including initial and final specimens. Bars from initial samples represent means of 3 samples; bars from final samples represent means of 10 samples; error bars represent one SE. Bars with the same letter indicate no significant differences at $\mathrm{p}<0.05$ for Tukey's test. 

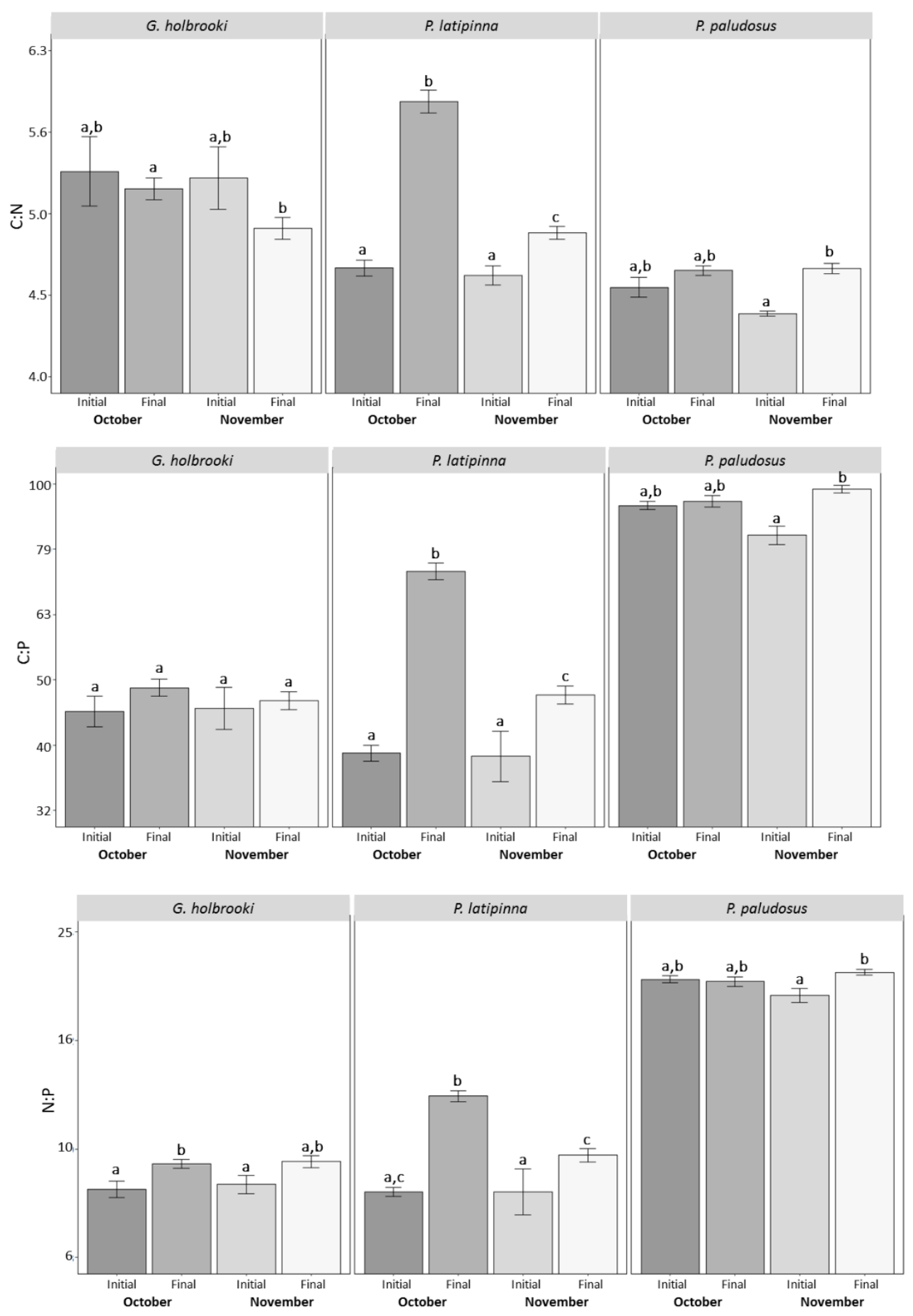

Figure 28. Consumer stoichiometry (G. holbrooki; P. latipinna; P. paludosus) from October and November field experiments including initial and final specimens. Bars represent means of at least 3 samples; error bars represent one SE of the logged ratios. Bars with the same letter indicate no significant differences at $p<0.05$ for Tukey's test. 


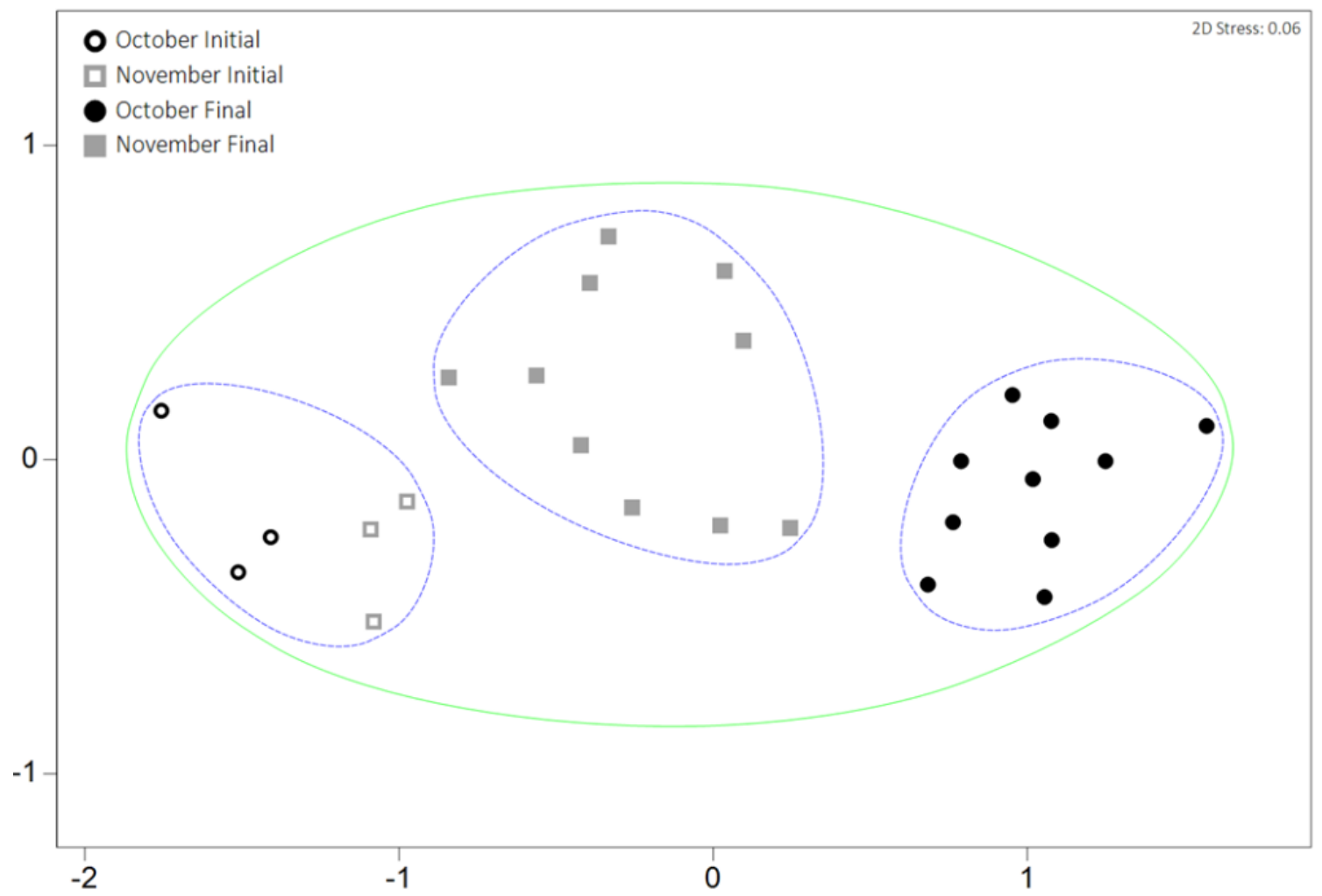

Figure 29. Two dimensional non-metric multidimensional scaling ordination plot based on square root transformed $P$. latipinna FA relative abundances from October and November field experiment, including final and initial specimens. Solid line indicates $75 \%$ similarity and dashed line indicated $85 \%$ similarity. Each symbol represents one sample with a total of 3 samples from initial sampling and 20 from each final sampling. 

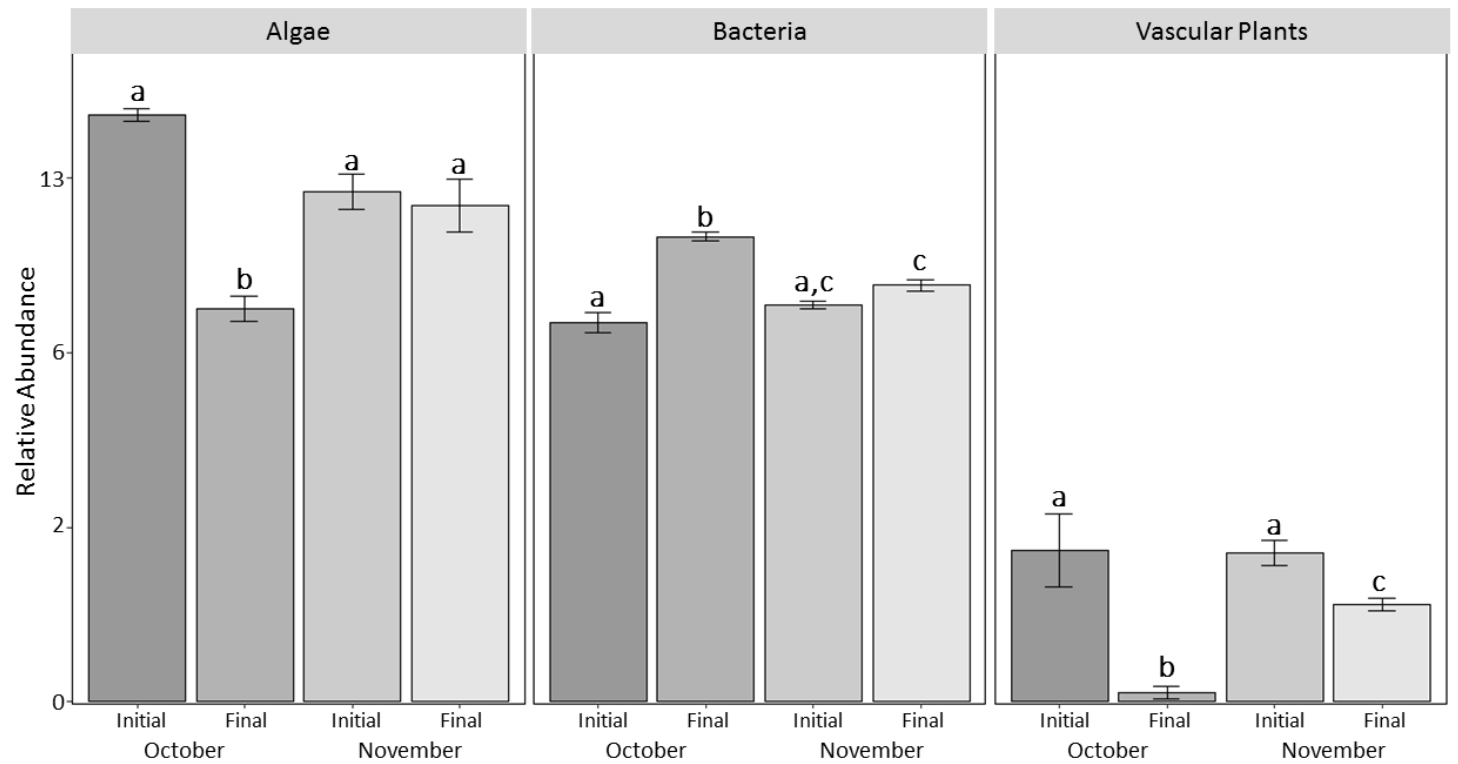

Figure 30. Relative abundance of dietary tracer FA groups (algae; bacteria; vascular plant) in $P$. latipinna from October and November. Initial bars represent means of 3 samples; final bars represent means of 10 samples; each sample is a combination of 3 individual fish; error bars represent one SE of means. Bars with the same letter indicate no significant differences at $\mathrm{p}<0.05$ for Tukey's test. 


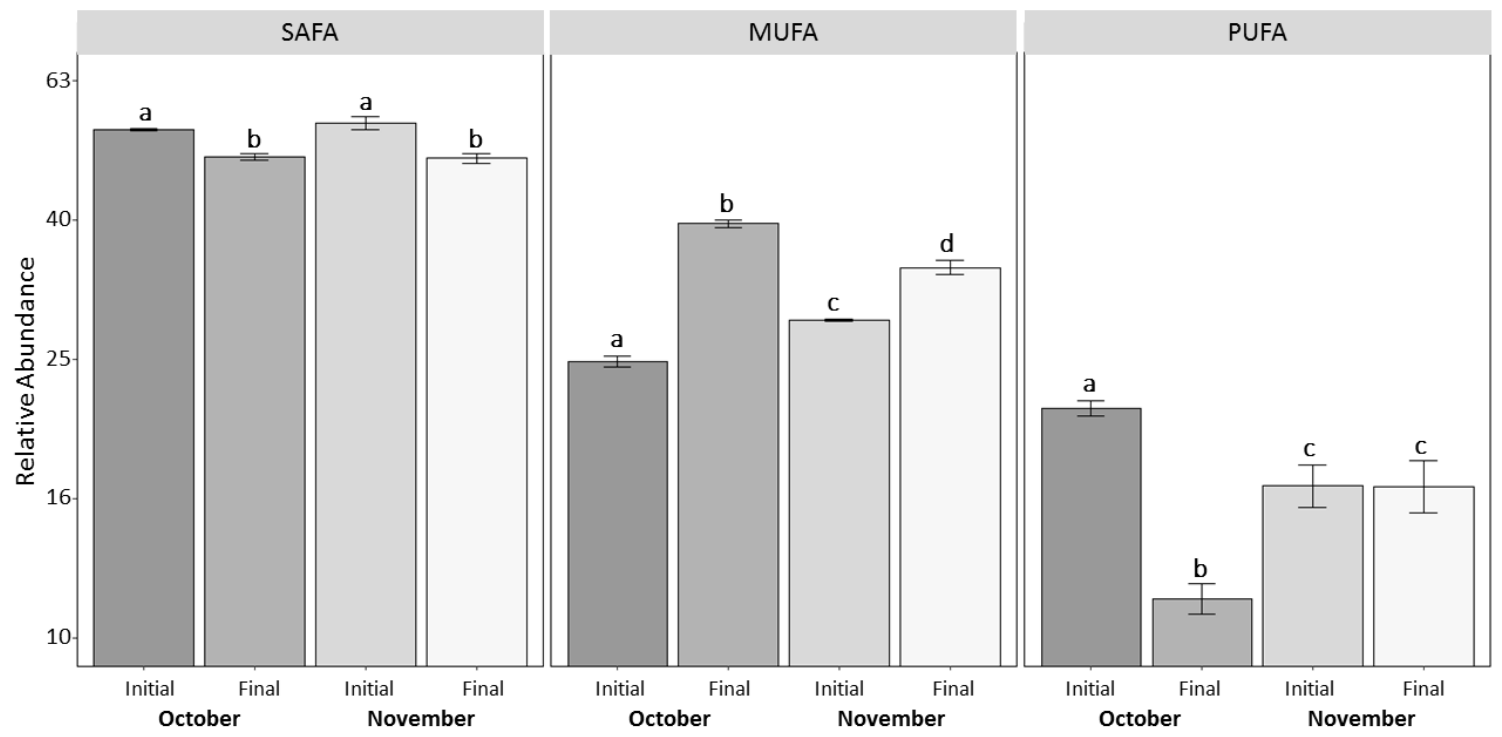

Figure 31. Relative abundance of FAs by saturation type (SAFA; MUFA; PUFA) from $P$. latipinna final and initial samples. SAFA, saturated fatty acids; MUFA, monounsaturated fatty acids; PUFA, poly-unsaturated fatty acids. Initial bars represent means of 3 samples; final bars represent means of 10 samples error bars represent one SE of means. Bars with the same letter indicate no significant differences at $\mathrm{p}<0.05$ for Tukey's test. 


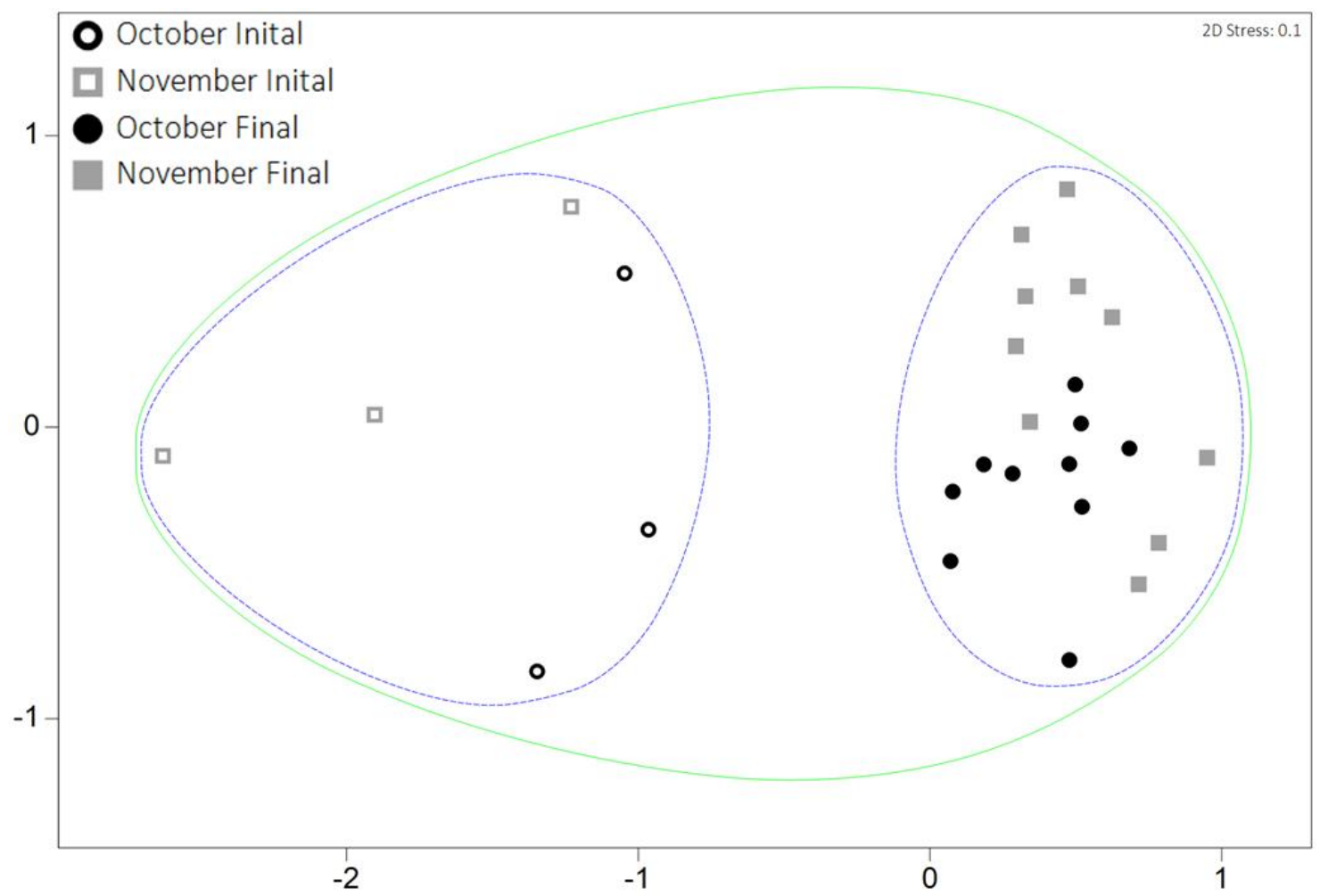

Figure 32. Two dimensional non-metric multidimensional scaling ordination plot based on square root transformed $G$. holbrooki FA relative abundances from October and November field experiment, including initial and final specimens. Solid line indicates $70 \%$ similarity and dashed line indicated $76 \%$ similarity. Each symbol represents one sample with a total of 3 samples from initial sampling and 20 from each final sampling. 


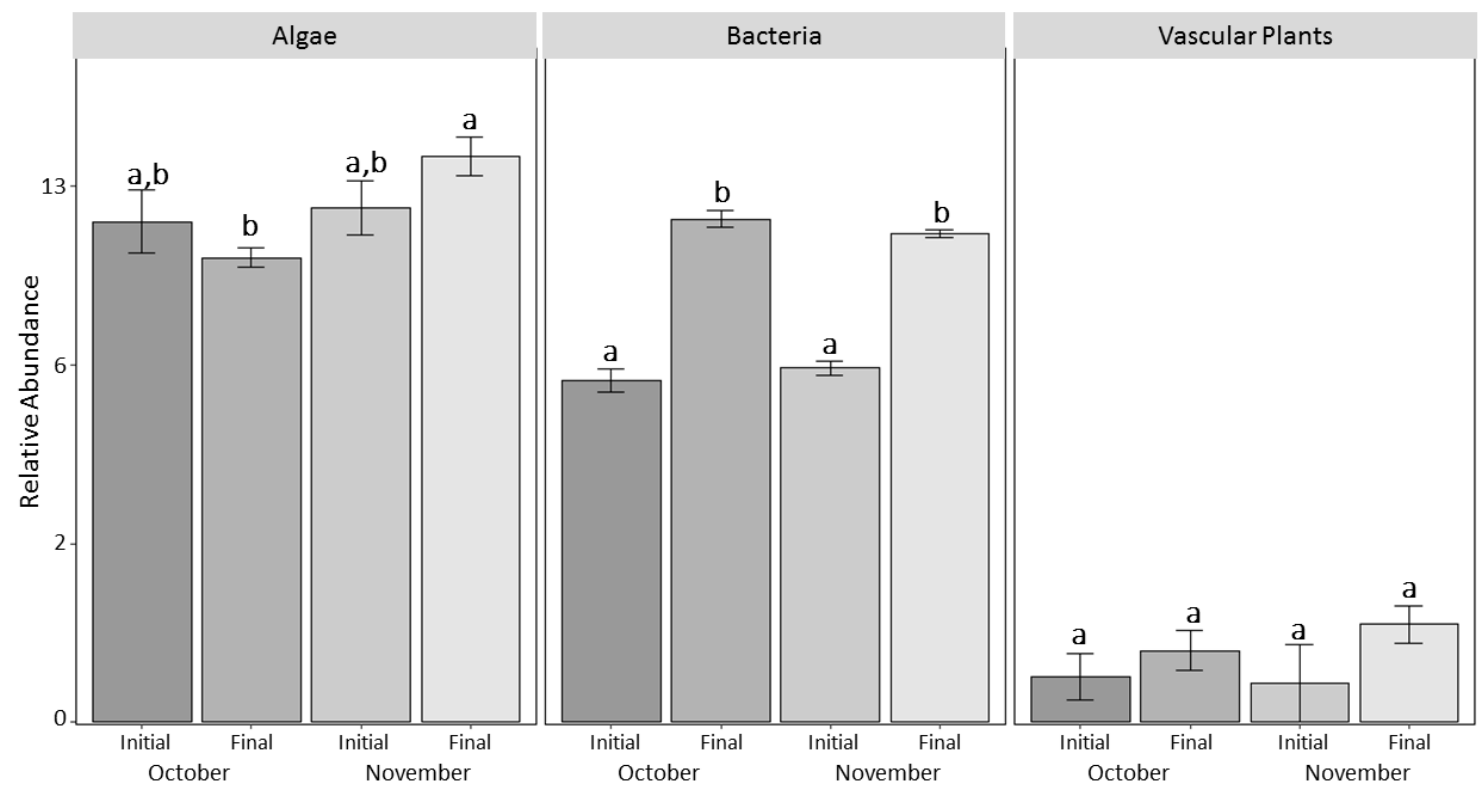

Figure 33. Relative abundance of dietary tracer FA groups (algae; bacteria; vascular plant) in $G$. holbrooki from October and November. Initial bars represent means of 3 samples; final bars represent means of 10 samples; each sample initial is a combination of at least 4 individual fish; each sample final is a combination of at least 5 individual fish; error bars represent one SE of means. Bars with the same letter indicate no significant differences at $\mathrm{p}<0.05$ for Tukey's test. 


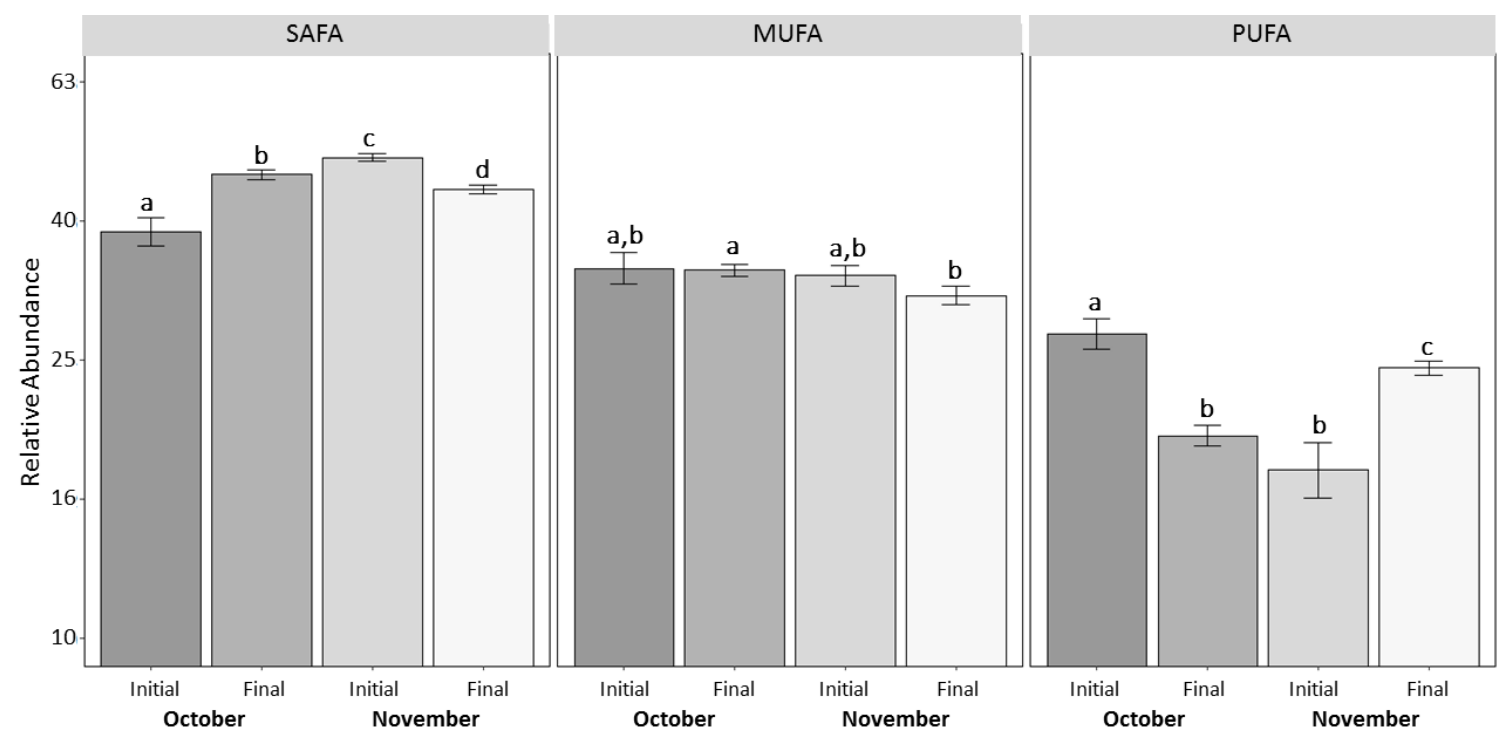

Figure 34. Relative abundance of FAs by saturation type in G. holbrooki final and initial samples. SAFA, saturated fatty acids; MUFA, mono-unsaturated fatty acids; PUFA, polyunsaturated fatty acids. Initial bars represent means of 3 samples; final bars represent means of 10 samples error bars represent one SE of means. Bars with the same letter indicate no significant differences at $\mathrm{p}<0.05$ for Tukey's test. 


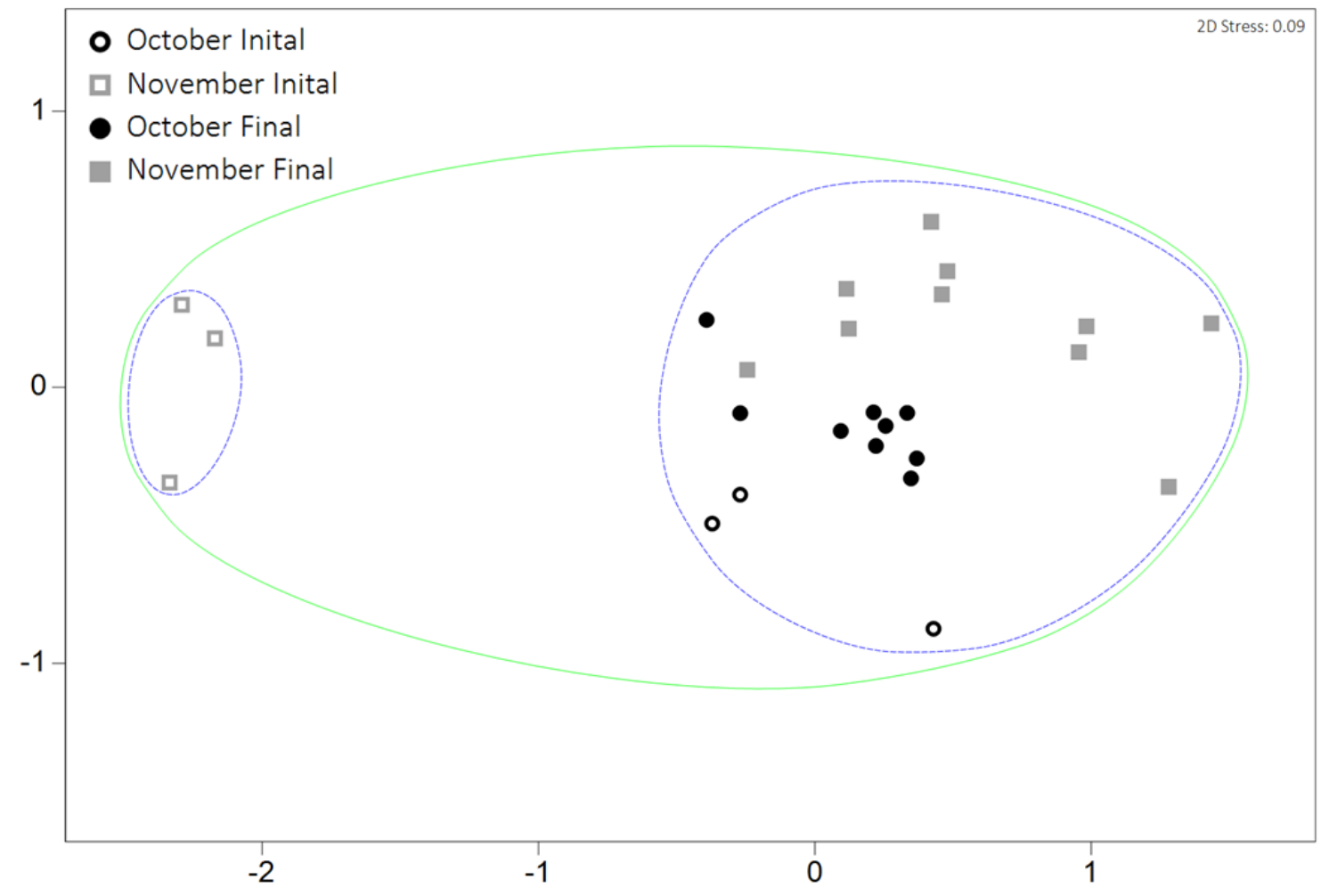

Figure 35. Two dimensional non-metric multidimensional scaling ordination plot based on square root transformed $P$. paludosus FA relative abundances from October and November field experiment, including initial and final specimens. Solid line indicates $80 \%$ similarity and dashed line indicated $85 \%$ similarity. Each symbol represents one sample with a total of 3 samples from initial sampling and 20 from each final sampling. 


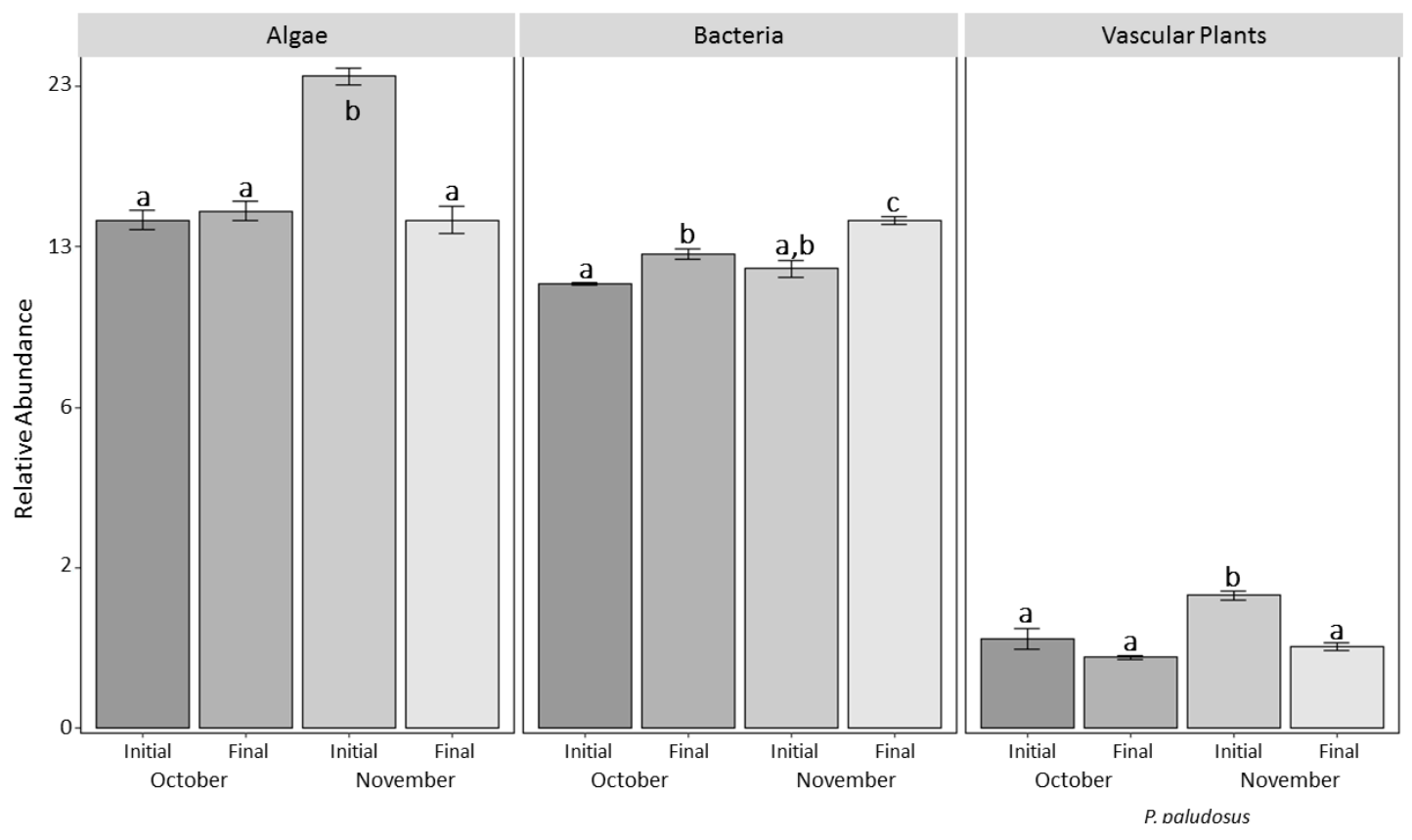

Figure 36. Relative abundance of dietary tracer FA groups (algae; bacteria; vascular plant) in P. paludosus from October and November field experiments. Initial bars represent means of 3 samples; final bars represent means of 10 samples; each sample initial is a combination of at least 4 individual shrimp; each sample final is a combination of at least 3 individual shrimp; error bars represent one SE of means. Bars with the same letter indicate no significant differences at $\mathrm{p}<0.05$ for Tukey's test. 


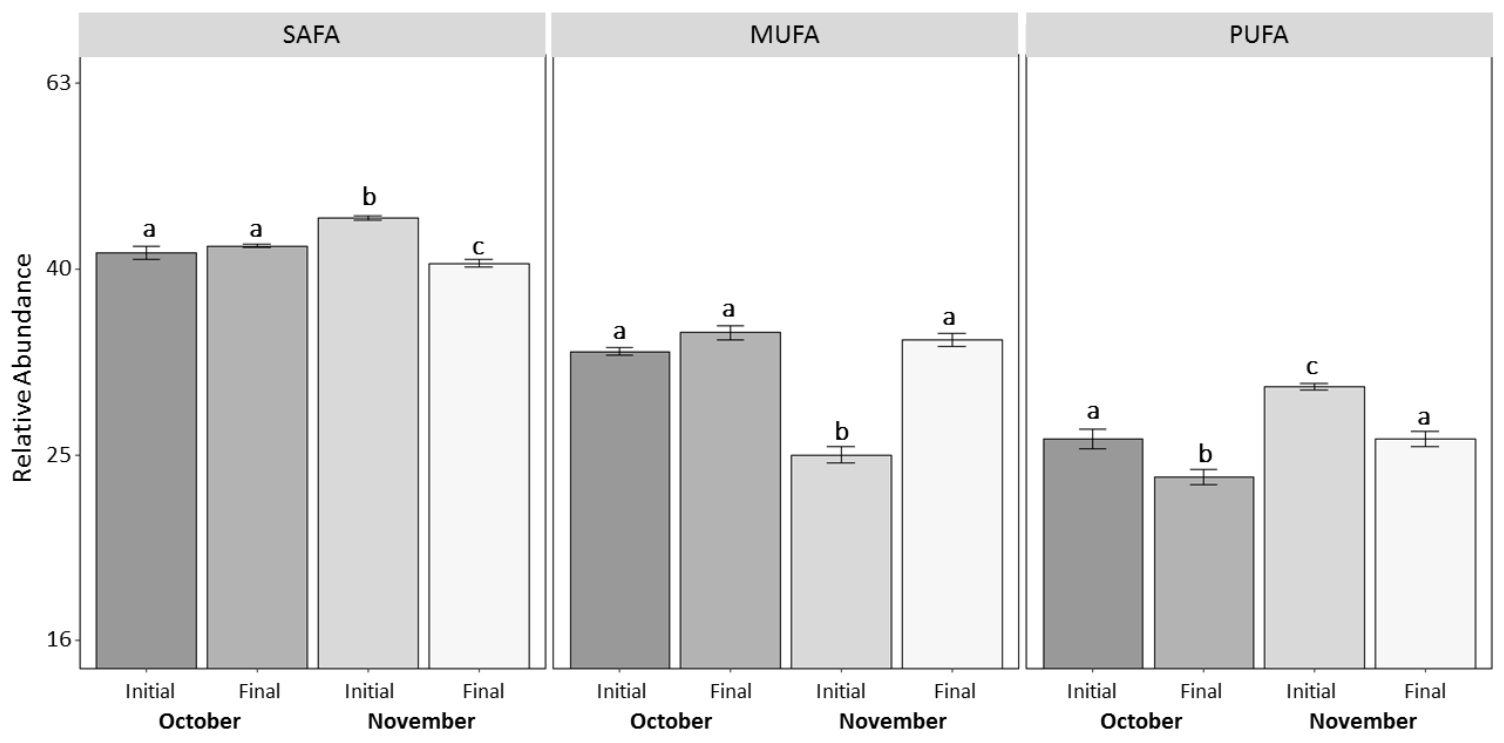

Figure 37. Relative abundance of FAs by saturation type (SAFA; MUFA; PUFA) in $P$. paludosus final and initial samples. SAFA, saturated fatty acids; MUFA, monounsaturated fatty acids; PUFA, poly-unsaturated fatty acids. Initial bars represent means of 3 samples; final bars represent means of 10 samples error bars represent one SE of means. Bars with the same letter indicate no significant differences at $p<0.05$ for Tukey's test. 


\section{APPENDIX A}

\section{Power Analysis}

To evaluate our experimental design's ability to detect the hypothesized changes, power analyses were completed on variables of interest using effect sizes from previous research. Effect sizes were chosen for use in the analysis because of their similarity to results hypothesized for an experimental variable, study location, or nutrient enrichment status. Calculations were made with R “pwr” package (Champely 2009) using a significance level of 0.05 and power of 0.80 .

Periphyton nutrient content and taxa composition have been documented to predictably change with increases in the limiting nutrient phosphorus (McCormick and Gaiser, 2011). These changes will be indicators used to monitoring increases in nutrient loading during this experiment. Using periphyton TP content has been shown to be a better metric than water column $\mathrm{P}$ for early detection of nutrient enrichment because it rapidly sequesters $\mathrm{P}$, yielding a response time in days following initial exposure (Gaiser et al. 2004). Belicka et al. (2012) used a sample size of three periphyton cores from both a nutrient-enriched near-canal site and an unenriched marsh site and found that the marsh site had an average TP content less than the near-canal site. However, this difference was not statistically significant because of a high variance among the within-site samples. An experimental dosing study using 12 mesocosm enclosures at two locations in Taylor Slough, in Everglades National Park, showed that periphyton TP increased with increasing levels of dosing until the periphyton biomass began to break down (Liston et al. 2008). Another experimental dosing study, designed to deliver $\mathrm{P}$ at rates similar to natural loading, also found significant treatment effects on periphyton $\mathrm{P}$ concentrations 
over time (Gaiser et al. 2004). Using mean values of periphyton TP from a periphyton survey in 5 Everglades marshes (Gaiser et al. 2006), we calculated that a sample size of 6.3 was required to detect a 1.7 times increase in periphyton TP as significant at the 0.05 critical level. TP values used to calculate this sample size were from enriched and unenriched locations within WCA-3A, with realistic values that may result from increased flow.

To detect changes in periphyton biomass, we will determine periphyton ash-free dry mass (AFDM) at the beginning and end of each field experiment. Periphyton biomass along known enrichment gradients were shown to be negatively correlated with TP. (Sargent et al. 2011; Gaiser et al. 2011). With a periphyton sample size of 20, we will be able to detect a $25 \%$ reduction in AFDM from mean values characteristic for the Everglades based on data from Sargent et al. (2011).

With increasing absorption of $\mathrm{P}$, the productivity of the most competitive algae species increase, leading to changes in species assemblages (Gaiser et al. 2011). To detect these changes in algal composition, cells will be identified to lowest distinguishable taxonomic unit and enumerated from both periphyton mats and epiphytic growth on "periphytometers." The replacement of the characteristic Everglades calcareous periphyton mats by non-mat forming algal assemblages has been documented throughout nutrient enriched areas (Pan et al. 2000; Gaiser et al. 2005). A study that compared algal composition at 32 sloughs along natural $\mathrm{P}$ gradients to changes within phosphorus dosed mesocosms found that algal species composition was more sensitive to $\mathrm{P}$ concentration than algal biomass was (Pan et al. 2000). Cluster analysis showed that diatom species grouped into three main assemblages corresponding to differing levels of eutrophication. 
Gaiser et al. (2005) showed that nutrient loading through time increased levels of periphyton TP, followed by changes in diatom species composition and the eventual degradation of calcareous mats. Another study used water quality and periphyton samples along a nutrient enrichment gradient in the northern Everglades and found that interior marsh sites contained on average $27-70 \%$ cyanobacteria and $11-49 \%$ diatoms of total biovolume (McCormick and O'Dell 1996). At locations with slightly elevated total phosphorus, this assemblage was replaced by $80-99 \%$ filamentous green algae species and less than $6 \%$ diatoms of total biovolume. An additional survey of 28 periphyton samples found a correlation was found between increasing nutrient levels, decreasing relative abundances of bluegreen and filamentous bluegreen algae and increasing relative abundances in green algae and diatoms (Sargent et al. 2011). We estimated an average of sample sizes of 9,12 , and 9 required to detect 0.6 -fold, 1.6 -fold, and 0.4 -fold change in diatoms, green algae, and cyanobacteria assemblages respectively (Chick et al. 2008). This was calculated using cell counts collected from a sampling region, period of time, and eutrophication statuses similar to our sampling area and hypothesized changes.

To detect impacts to consumers from hypothesized nutrient loading we will document growth rate and fatty acid composition. Growth rate is known to increase in fishes with increasing food consumption and food quality (Vondracek et al. 1988; Brett and Groves 1979). Increases in somatic and gonadal growth corresponded with increasing rations of Tubifex species in a study using Gambusia affinis (Vondracek et al. 1988). In that study, growth rate increased from $1.2 \%$ to $2.5 \%$ per day with increases in temperature and ration. With hypothesized nutrient loading, we expect the edibility of periphyton to increase, thus provided more food for consumers and in turn increasing 
their growth rates. A sample size of 9 was calculated to detect a similar change in growth rate as found in Vondracek et al. (1988).

The results of these power analyses give us confidence that a sample size of 5 experimental cages per treatment will provide a minimum, but sufficient, sample size to detect biologically important changes in our experimental variables as statistically significant. We conducted the study as carefully as possible to minimize within treatment variability, which could make the preceding discussion conservative. 